Cochrane Database of Systematic Reviews

\title{
Citicoline for treating people with acute ischemic stroke (Review)
}

Martí-Carvajal AJ, Valli C, Martí-Amarista CE, Solà I, Martí-Fàbregas J, Bonfill Cosp X

Martí-Carvajal AJ, Valli C, Martí-Amarista CE, Solà I, Martí-Fàbregas J, Bonfill Cosp X.

Citicoline for treating people with acute ischemic stroke.

Cochrane Database of Systematic Reviews 2020, Issue 8. Art. No.: CD013066.

DOI: 10.1002/14651858.CD013066.pub2.

www.cochranelibrary.com 
TABLE OF CONTENTS

HEADER

ABSTRACT

PLAIN LANGUAGE SUMMARY

SUMMARY OF FINDINGS

BACKGROUND

OBJECTIVES

METHODS

RESULTS

Figure 1.

Figure 2.

Figure 3.

Figure 4.

Figure 5.

DISCUSSION

AUTHORS' CONCLUSIONS

ACKNOWLEDGEMENTS

REFERENCES

CHARACTERISTICS OF STUDIES

DATA AND ANALYSES

Analysis 1.1. Comparison 1: Citicoline versus placebo or not intervention, Outcome 1: All-cause mortality

Analysis 1.2. Comparison 1: Citicoline versus placebo or not intervention, Outcome 2: All-cause mortality: subgroup analysis .. Analysis 1.3. Comparison 1: Citicoline versus placebo or not intervention, Outcome 3: All-cause mortality: subgroup analysis .. Analysis 1.4. Comparison 1: Citicoline versus placebo or not intervention, Outcome 4: All-cause mortality: sensitivity analysis: impact of missing outcome data

Analysis 1.5. Comparison 1: Citicoline versus placebo or not intervention, Outcome 5: All-cause mortality: sensitivity analysis: best-case scenario

Analysis 1.6. Comparison 1: Citicoline versus placebo or not intervention, Outcome 6: All-cause mortality: sensitivity analysis: worst-case scenario

Analysis 1.7. Comparison 1: Citicoline versus placebo or not intervention, Outcome 7: All-cause mortality: sensitivity analysis: the Gamble-Hollis analysis

Analysis 1.8. Comparison 1: Citicoline versus placebo or not intervention, Outcome 8: Patients with moderate or lower degree of disability or dependence (according to $<3$ scores in the modified Rankin scale)

Analysis 1.9. Comparison 1: Citicoline versus placebo or not intervention, Outcome 9: Patients with moderate or lower degree of disability or dependence (according to < 3 scores in the modified Rankin scale): subgroup analysis

Analysis 1.10. Comparison 1: Citicoline versus placebo or not intervention, Outcome 10: Patients with moderate or lower degree of disability or dependence (according to $<3$ scores in the modified Rankin scale): sensitivity analysis: impact of missing outcome data

Analysis 1.11. Comparison 1: Citicoline versus placebo or not intervention, Outcome 11: Patients with moderate or lower degree of disability or dependence (according to $<3$ scores in the modified Rankin scale): sensitivity analysis: best-case scenario ..... Analysis 1.12. Comparison 1: Citicoline versus placebo or not intervention, Outcome 12: Patients with moderate or lower degree of disability or dependence (according to $<3$ scores in the modified Rankin scale): sensitivity analysis: worst-case scenario .... Analysis 1.13. Comparison 1: Citicoline versus placebo or not intervention, Outcome 13: Patients with moderate or lower degree of disability or dependence (according to $<3$ scores in the modified Rankin scale): sensitivity analysis: the Gamble-Hollis analysis

Analysis 1.14. Comparison 1: Citicoline versus placebo or not intervention, Outcome 14: Severe adverse events ..................... Analysis 1.15. Comparison 1: Citicoline versus placebo or not intervention, Outcome 15: Non-severe adverse events .............. Analysis 1.16. Comparison 1: Citicoline versus placebo or not intervention, Outcome 16: Functional recovery: assessed with the Barthel Index

Analysis 1.17. Comparison 1: Citicoline versus placebo or not intervention, Outcome 17: Patients with minor impairment (according to $\leq 1$ scores in the National Institutes of Health Stroke Scale) 
[Intervention Review]

\section{Citicoline for treating people with acute ischemic stroke}

Arturo J Martí-Carvajal1,2, Claudia Valli3 ${ }^{3}$, Cristina Elena Martí-Amarista ${ }^{4}$, Ivan Solà5, Joan Martí-Fàbregas ${ }^{6}$, Xavier Bonfill Cosp ${ }^{7}$

1Facultad de Ciencias de la Salud Eugenio Espejo, Universidad UTE (Cochrane Ecuador), Quito, Ecuador. ${ }^{2}$ School of Medicine, Universidad Francisco de Vitoria (Cochrane Madrid), Madrid, Spain. ${ }^{3}$ Iberoamerican Cochrane Centre, Biomedical Research Institute Sant Pau (IIB Sant Pau), Barcelona, Spain. ${ }^{4}$ Department of Family Medicine, Northwell Health Southside Hospital, Bay Shore, New York, USA. 5 Iberoamerican Cochrane Centre, Biomedical Research Institute Sant Pau (IIB Sant Pau), CIBER Epidemiología y Salud Pública (CIBERESP), Barcelona, Spain. 6Unitat de Malalties Vasculars Cerebrals - Stroke Unit, Servei De Neurologia - Department of Neurology, Hospital de la Santa Creu i Sant Pau, Barcelona, Spain. 7Iberoamerican Cochrane Centre, Biomedical Research Institute Sant Pau (IIB Sant Pau), Universitat Autònoma de Barcelona, CIBER Epidemiología y Salud Pública (CIBERESP), Barcelona, Spain

Contact address: Arturo J Martí-Carvajal, arturo.marti.carvajal@gmail.com.

Editorial group: Cochrane Stroke Group.

Publication status and date: Edited (no change to conclusions), published in Issue 12, 2020.

Citation: Martí-Carvajal AJ, Valli C, Martí-Amarista CE, Solà I, Martí-Fàbregas J, Bonfill Cosp X. Citicoline for treating people with acute ischemic stroke. Cochrane Database of Systematic Reviews 2020, Issue 8. Art. No.: CD013066. DOI: 10.1002/14651858.CD013066.pub2.

Copyright @ 2020 The Cochrane Collaboration. Published by John Wiley \& Sons, Ltd.

\section{A B S T R A C T}

\section{Background}

Stroke is one of the leading causes of long-lasting disability and mortality and its global burden has increased in the past two decades. Several therapies have been proposed for the recovery from, and treatment of, ischemic stroke. One of them is citicoline. This review assessed the benefits and harms of citicoline for treating patients with acute ischemic stroke.

\section{Objectives}

To assess the clinical benefits and harms of citicoline compared with placebo or any other control for treating people with acute ischemic stroke.

\section{Search methods}

We searched in the Cochrane Stroke Group Trials Register, CENTRAL, MEDLINE Ovid, Embase Ovid, LILACS until 29 January 2020. We searched the World Health Organization Clinical Trials Search Portal and ClinicalTrials.gov. Additionally, we also reviewed reference lists of the retrieved publications and review articles, and searched the websites of the US Food and Drug Administration (FDA) and European Medicines Agency (EMA).

\section{Selection criteria}

We included randomized controlled trials (RCTs) in any setting including participants with acute ischemic stroke. Trials were eligible for inclusion if they compared citicoline versus placebo or no intervention.

\section{Data collection and analysis}

We selected RCTs, assessed the risk of bias in seven domains, and extracted data by duplicate. Our primary outcomes of interest were allcause mortality and the degree of disability or dependence in daily activities at 90 days. We estimated risk ratios (RRs) for dichotomous outcomes. We measured statistical heterogeneity using the $\mathrm{I}^{2}$ statistic. We conducted our analyses using the fixed-effect and randomeffects model meta-analyses. We assessed the overall quality of evidence for six pre-specified outcomes using the GRADE approach. 


\section{Main results}

We identified 10 RCTs including 4281 participants. In all these trials, citicoline was given either orally, intravenously, or a combination of both compared with placebo or standard care therapy. Citicoline doses ranged between $500 \mathrm{mg}$ and $2000 \mathrm{mg}$ per day. We assessed all the included trials as having high risk of bias. Drug companies sponsored six trials.

A pooled analysis of eight trials indicates there may be little or no difference in all-cause mortality comparing citicoline with placebo (17.3\% versus $18.5 \%$; RR $0.94,95 \% \mathrm{Cl} 0.83$ to $1.07 ; \mathrm{I}^{2}=0 \%$; low-quality evidence due to risk of bias). Four trials showed that citicoline may not increase the proportion of patients with a moderate or lower degree of disability or dependence compared with placebo, according to the Rankin Scale (21.72\% versus 19.23\%; RR 1.11, 95\% Cl 0.97 to $1.26 ; \mathrm{I}^{2}=1 \%$; low-quality evidence due to risk of bias).

Meta-analysis of three trials indicates there may be little or no difference in serious cardiovascular adverse events comparing citicoline with placebo (8.83\% versus $7.77 \%$; RR $1.04,95 \% \mathrm{Cl} 0.84$ to $1.29 ; \mathrm{I}^{2}=0 \%$; low-quality evidence due to risk of bias). Overall, either serious or non-serious adverse events - central nervous system, gastrointestinal, musculoskeletal, etc. - were poorly reported and harms may have been underestimated.

Four trials suggested that citicoline results in no difference in functional recovery, according to the Barthel Index, compared with placebo ( $32.78 \%$ versus $30.70 \%$; RR $1.03,95 \% \mathrm{Cl} 0.94$ to $1.13 ; \mathrm{I}^{2}=24 \%$; low-quality evidence due to risk of bias). Citicoline may not increase the proportion of patients with a minor impairment (according to $\leq 1$ scores in the National Institutes of Health Stroke Scale) (5 trials, $24.31 \%$ versus $22.44 \%$; RR $1.08,95 \% \mathrm{Cl} 0.96$ to $1.21 ; \mathrm{I}^{2}=27 \%$, low-quality evidence due to risk of bias). None of the included trials reported data on quality of life.

A pre-planned Trial Sequential Analysis suggested that no more trials may be needed for the primary outcomes.

\section{Authors' conclusions}

This review assessed the clinical benefits and harms of citicoline compared with placebo or any other standard treatment for people with acute ischemic stroke. The findings of the review suggest there may be little to no difference between citicoline and its controls regarding all-cause mortality, disability or dependence in daily activities, functional recovery, neurological function and severe adverse events, based on low-certainty evidence. None of the included trials assessed quality of life and the safety profile of citicoline remains unknown. The available evidence is of low quality due to either limitations in the design or execution of the trials.

\section{PLAIN LANGUAGE SUMMARY}

\section{Citicoline for treating people with acute ischemic stroke}

\section{Review question}

What is the clinical benefit and harm of citicoline compared with placebo or other standard treatment for treating people with acute ischemic stroke?

\section{Background}

Acute ischemic stroke is defined as a sudden episode of disturbance of brain function caused by a blockage in the blood vessels of the brain. It is the leading cause of long-lasting disability and the second major cause of death. Citicoline is a substance that may prevent the death of brain cells located close to the area of brain damage.

\section{Search date}

Searching was completed on 29 January 2020

\section{Study characteristics}

We included randomized controlled trials, both published and unpublished. We did not apply any limitation by language, country, or study design. We included people (adults or children) with acute ischemic stroke irrespective of the underlying cause. Stroke was based on the clinical diagnosis confirmed with brain scans. We included trials that compared citicoline with placebo, usual care, or other usual treatment.

\section{Key results}

We identified 10 relevant trials that included 4281 participants; six trials were carried out in multiple centers and two were international. We considered most trials to be at high risk of bias and they included small numbers of participants. This raises the risk of over-estimating benefits and under-estimating harms. Trials tested citicoline given either by mouth or by injection. Citicoline did not seem to influence death or disability in daily activities, severe side-effects, functional recovery, or neurological recovery.

\section{Quality of the evidence}

Risks of bias, imprecision, and outcome reporting bias all make the quality of evidence low. None of the included trials reported data on quality of life. Researchers poorly reported harms caused by citicoline, so the profile of harms remains unclear. 
SUMMARY OF FINDINGS

Summary of findings 1. Citicoline compared with placebo or standard treatment for treating people with acute ischemic stroke

Citicoline compared with placebo or no intervention for treating people with acute ischemic stroke

Patient or population: people with acute ischemic stroke

Settings: either inpatients or outpatients

Intervention: citicoline

Comparison: placebo or standard treatment

\begin{tabular}{|c|c|c|c|c|c|c|}
\hline \multirow[t]{3}{*}{ Outcomes } & \multicolumn{2}{|c|}{$\begin{array}{l}\text { Illustrative comparative risks }{ }^{\star} \\
(95 \% \mathrm{Cl})\end{array}$} & \multirow[t]{3}{*}{$\begin{array}{l}\text { Relative effect } \\
(95 \% \mathrm{Cl})\end{array}$} & \multirow{3}{*}{$\begin{array}{l}\text { No of Partici- } \\
\text { pants } \\
\text { (studies) }\end{array}$} & \multirow{3}{*}{$\begin{array}{l}\text { Quality of the } \\
\text { evidence } \\
\text { (GRADE) }\end{array}$} & \multirow[t]{3}{*}{ Comments } \\
\hline & Assumed risk & $\begin{array}{l}\text { Corresponding } \\
\text { risk }\end{array}$ & & & & \\
\hline & $\begin{array}{l}\text { Placebo or no } \\
\text { intervention }\end{array}$ & Citicoline & & & & \\
\hline $\begin{array}{l}\text { Disability or dependence in daily activities } \\
\text { Patients with moderate or lower degree of } \\
\text { disability or dependence (according to }<3 \\
\text { scores in the modified Rankin scale) } \\
\text { lower scores indicate better outcome } \\
\text { Follow-up: } 6 \text { weeks }\end{array}$ & 226 per $1000 a$ & $\begin{array}{l}\mathbf{2 5 1} \text { per } \mathbf{1 0 0 0} \\
\text { (219 to } 284)\end{array}$ & $\begin{array}{l}\text { RR } 1.11 \\
\text { (0.97 to } 1.26)\end{array}$ & $\begin{array}{l}3668 \\
\text { (4 studies) }\end{array}$ & $\begin{array}{l}\oplus \oplus \ominus \ominus \\
\text { low } c\end{array}$ & \\
\hline $\begin{array}{l}\text { Severe adverse events } \\
\text { Follow-up: } 6 \text { weeks }\end{array}$ & 159 per $1000 a$ & $\begin{array}{l}\mathbf{1 6 6} \text { per } 1000 \\
\text { (134 to } 205)\end{array}$ & $\begin{array}{l}\text { RR } 1.12 \\
(1.00 \text { to } 1.26)\end{array}$ & $\begin{array}{l}3591 \\
\text { (3 studies) }\end{array}$ & $\begin{array}{l}\oplus \oplus \Theta \odot \\
\text { low } d\end{array}$ & $\begin{array}{l}\text { This information corre- } \\
\text { sponds to pooled analy- } \\
\text { sis for the risk of severe } \\
\text { cardiovascular adverse } \\
\text { events. Trials reported } \\
\text { number of adverse events } \\
\text { instead of number of par- } \\
\text { ticipants with adverse } \\
\text { events. See Analysis } 1.14 \text {. }\end{array}$ \\
\hline Functional recovery & 336 per $1000 a$ & $\begin{array}{l}\mathbf{3 4 7} \text { per } \mathbf{1 0 0 0} \\
\text { (316 to } 380)\end{array}$ & $\begin{array}{l}\text { RR } 1.03 \\
\text { (0.94 to } 1.13)\end{array}$ & $\begin{array}{l}3850 \\
\text { (4 studies) }\end{array}$ & $\begin{array}{l}\oplus \oplus \ominus \ominus \\
\text { low e }\end{array}$ & $\begin{array}{l}\text { Alviarez } 2007 \text { reported this } \\
\text { outcome using } 50 \text { points }\end{array}$ \\
\hline
\end{tabular}


Neurological function

Patients with minor impairment (according to

$\leq 1$ scores in the National Institutes of Health

226 per $1000 a \quad 244$ per 1000

\section{RR 1.08}

3950

to 100 )

Stroke Scale)

Follow-up: 6 weeks

Quality of life (at the time of follow-up)

See comment See comment

(217 to 274 )

(0.96 to 1.21$)$

(5 studies)

$\oplus \oplus \odot \ominus$

low ${ }^{f}$

Not estimable

See comment

No trials assessed this out-

${ }^{*}$ The basis for the assumed risk (e.g. the median control group risk across studies) is provided in footnotes. The corresponding risk (and its $95 \% \mathrm{Cl}$ ) is based on the as-

sumed risk in the comparison group and the relative effect of the intervention (and its $95 \% \mathrm{Cl}$ ).

Cl: Confidence interval; RR: Risk ratio;

GRADE Working Group grades of evidence

High quality: Further research is very unlikely to change our confidence in the estimate of effect.

Moderate quality: Further research is likely to have an important impact on our confidence in the estimate of effect and may change the estimate.

Low quality: Further research is very likely to have an important impact on our confidence in the estimate of effect and is likely to change the estimate.

Very low quality: We are very uncertain about the estimate.

aAssumed risk is based on median control group risks in the meta-analysis.

bDowngraded 2 levels for limitations in design and execution: 88\% (7/8) of the trials assessing this outcome had high risk for allocation, and $38 \%$ (3/8) showed high risk for attrition bias for this outcome.

cDowngraded 2 levels for limitations in design and execution: 75\% (3/4) of the trials assessing this outcome had high risk for allocation, and 50\% (2/4) showed high risk for attrition bias, and $75 \%$ (3/4) had high risk for detection bias for this outcome.

dDowgraded 2 levels due to high risk of bias and imprecision (small number of events).

eDowngraded 2 levels for limitations in design and execution: 75\% (3/4) of the trials assessing this outcome had high risk for allocation, and $75 \%$ (3/4) showed high risk for detection bias for this outcome.

fDowngraded 2 levels for limitations in design and execution: 80\% (4/5) of the trials assessing this outcome had high risk for allocation, and $40 \%(2 / 5)$ showed high risk for attrition bias, and $75 \%(3 / 4)$ had high risk for detection bias for this outcome. 


\section{B A C K G R O U N D}

\section{Description of the condition}

Stroke is one of the leading causes of long-lasting disability and mortality (Martynov 2015; Yan 2017). The global burden of stroke has increased in the past two decades (Hankey 2017). In 2015, ischemic heart disease and stroke were the two leading causes of premature mortality worldwide, and the leading causes of years of life lost (YLLS) in 119 countries and territories (Wang 2016). Finding a safe, inexpensive therapy to prevent and treat stroke is becoming an area of interest in international public health.

Stroke is defined as an acute (sudden) episode characterized by clinical signs of focal or global disturbance of cerebral (brain) function caused by infarction (blockage in blood flow) or spontaneous hemorrhage (bleeding) in the relevant part of the brain, retina, or spinal cord, lasting more than 24 hours, or of any duration if imaging (computed tomography [CT]; or magnetic resonance imaging $[\mathrm{MRI}]$ ) or autopsy show focal infarction or hemorrhage relevant to the symptoms. By comparison, a transient ischemic attack (TIA) is defined as a focal dysfunction of less than 24 hours' duration and with no imaging evidence of infarction (Hankey 2017; Portegies 2016). Stroke is classified into ischemic stroke (obstruction of cerebral blood), intracerebral hemorrhage (a focal collection of blood within the brain parenchyma or ventricular system that is not caused by trauma), and subarachnoid hemorrhage (bleeding into the subarachnoid space). Ischemic stroke is the most prevalent type and accounts for $75 \%$ to $85 \%$ of all strokes (Cassella 2017; Martynov 2015). This Cochrane Review focused on acute ischemic stroke.

Different strategies have been proposed for the recovery from, and treatment of, ischemic stroke. During the first few hours of onset of an ischemic stroke, blood flow can be restored through mechanical thrombus extraction (thrombectomy) or by intravenous thrombolysis with the administration of recombinant tissue plasminogen activators (rt-PA) that break down blood clots. However, only $5 \%$ to $20 \%$ of people with acute ischemic stroke are treated with thrombolysis or thrombus extraction, or both (Martynov 2015; Wardlaw 2014).

Three parenchymal vascular states are seen in people with acute ischemic stroke, namely: the ischemic core; the zone of penumbra adjacent to it; and the region of benign oligemia adjacent to that (Manning 2014). The ischemic penumbra region is defined as the "zone of nonfunctioning but still viable tissue that may recover its function if blood flow can be restored for example, by therapeutic intervention" (Astrup 1981; Astrup 1982). The penumbra region represents that portion of the ischemic territory that is still potentially salvageable, and so it is the target of all acute therapies (Hillis 2015; Manning 2014; Martynov 2015). Therefore, the zone of penumbra must be protected; this protection is called neuroprotection. In this scenario, neuroprotection has been defined as "administering therapy as rapidly as possible following the onset of symptoms in an effort to minimize cerebral infarction while the ischemic brain is awaiting reperfusion" (Patel 2017). There are pharmacological and non-pharmacological forms of neuroprotection (Patel 2017; Wang 2017), and this Cochrane Review focused on one type of pharmacological neuroprotector: citicoline.
Several studies have suggested that citicoline is effective for treating central nervous system disorders (CNS), including acute and chronic cerebral ischemia, intracerebral hemorrhage, global cerebral hypoxia, and neurodegenerative diseases (Martynov 2015). These studies claim that citicoline treatment reduces size of infarct (region of dead tissue), decreases free fatty acid concentration, decreases neurologic deficits, restores animal learning performance, reduces glutamate-mediated injury, preserves phosphatidylcholine levels, and improves neuronal survival (Clark 2009).

\section{Description of the intervention}

Citicoline is the generic name for cytidine 5'-diphosphocholine (CDP-choline). Citicoline is the combination of two molecules: cytidine and choline. These molecules cross the blood-brain barrier separately; after reaching the brain cells they combine to generate CDP-choline (Martynov 2015). Thus, it is a natural endogenous compound and a precursor for the synthesis of phosphatidylcholine, one of the components of cell membranes. During cerebral ischemia, phosphatidylcholine is broken down into free fatty acids and free radicals that increase the likelihood of ischemic injury (Clark 2009).

Citicoline is synthesized in oral and enteral formulations for clinical practice. Citicoline is a water-soluble compound, and pharmacokinetic studies on healthy adults have shown an optimal absorption of both oral and intravenous doses. Once absorbed, citicoline is converted to choline and cytidine, which circulate in the body, enter systemic circulation and cross the blood-brain barrier for resynthesis into citicoline in the brain (Clark 2009). Citicoline has been administered intravenously at doses ranging between 500 $\mathrm{mg}$ and $2000 \mathrm{mg}$ respectively in randomized controlled trials (RCTs) (Avarez-Sabín 2013; Clark 1997).

\section{How the intervention might work}

The cytidine-5'-diphosphocholine (CDP-choline or citicoline) pathway begins with the uptake of exogenous choline into the cell, followed by different enzymatic reactions that lead to the synthesis of phosphatidylcholine. The hypothesized mechanism of action assumes that citicoline undergoes hydrolysis and dephosphorylation to yield cytidine and choline products. These breakdown products then enter the brain separately and act as substrates for the resynthesis of CDP-choline. This mechanism is believed to slow down phospholipid breakdown and accelerate phospholipid resynthesis, which are necessary for membrane repair (Grieb 2014). Citicoline is a free radical scavenger that reduces the availability of free radicals after acute ischemic episodes (Rajah 2017), and so may slow the damage. It may facilitate recovery by activating neurogenesis, synaptogenesis, and angiogenesis (creation of brain cells, gaps between them, and blood supply), and enhances neurotransmitter metabolism. In an animal model, administration of citicoline showed an upregulation of synaptophysin in the penumbra region that could indicate an increase of synaptic (brain) activity (Martynov 2015).

The administration of citicoline increases brain choline, and accelerates the synthesis of phosphatidylcholine, decreases levels of free fatty acids, and reduces the generation of free radicals. Overall, the administration of citicoline may protect cell membranes by reducing phosphatidylcholine breakdown (Martynov 2015). Recent research suggests that citicoline may 
enhance endogenous brain plasticity and repair even when it is administered several hours after the ischemic event (Clark 2009; Overgaard 2014). An animal study reported significantly improved motor and functional recovery in the citicoline-treated group at the end of a 28-day intervention period, when citicoline was given 24 hours after middle cerebral artery stroke, and taken for 28 days (Clark 2009).

\section{Why it is important to do this review}

This Cochrane Review is important because controversy exists regarding the clinical effectiveness of citicoline for treating people with acute stroke. Some randomized placebo, or head-to-head, controlled clinical trials and meta-analyses suggest limited or no clinical benefits (Clark 1999; Clark 2001; ECCS- AIS 2012; ICTUS 2012; Secades 2016; Shi 2016), while other randomized, placebocontrolled clinical trials report beneficial effects (Alviarez 2007; Clark 1997; Tazaki 1988). Furthermore, Dávalos 2002, Secades 2016, and Shi 2016 have several methodological limitations such as lack of reporting summary of finding tables, use of odds ratio instead of risk ratio, and use of cumulative meta-analysis (Sterne 2001), instead of Trial Sequential Analysis (TSA) (Wetterslev 2017). Regarding odds ratio, there are several publications opposed to the use of odds ratio in conducting systematic reviews (Altman 1998; Barnes 1998; Bland 2000; Davies 1998; Higgins 2019; Sackett 1996). In addition, drug companies have funded many trials (Alviarez 2007; Clark 1997; Clark 1999; Clark 2001; ICTUS 2012), and it is necessary to assess the effectiveness of the drug independently (Lundh 2017). Argentina, Austria, Chile, Indonesia, Mexico, Portugal, Thailand, and Venezuela prescribe citicoline (Chen 2016). Since 17 April 2009, citicoline has been banned in the USA and Canada (Chen 2016; FDA 2019). Conducting a systematic review according to Cochrane methodology is fundamental to identify the clinical benefits and harms of citicoline compared with placebo or any other control for treating people with acute ischemic stroke.

\section{O B JE C T IVES}

To assess the clinical benefits and harms of citicoline compared with placebo, any other drug or usual care for treating people with acute ischemic stroke.

\section{METHODS}

\section{Criteria for considering studies for this review Types of studies}

We included randomized controlled trials (RCTs) irrespective of publication status. We did not apply any limitation by language, country, or duration of follow-up. We only included parallel-design trials.

\section{Types of participants}

People (children or adults) with acute ischemic stroke, irrespective of etiology. We used clinical diagnosis with imaging as an eligibility criterion.

\section{Types of interventions}

We included trials that compared citicoline with placebo, usual care, or other interventions.
Citicoline administered at any dose, by any route, and for any duration of treatment, versus no intervention, placebo, or other interventions. Since acute ischemic stroke requires a variety of medical treatments (that is, primary interventions), we considered citicoline as a supplementary intervention. Thus, for the purpose of this review, eligible RCTs were those that compared the same primary interventions with and without citicoline supplementation.

\section{Types of outcome measures}

\section{Primary outcomes}

- All-cause mortality (at 90 days).

- Degree of disability or dependence in daily activities according to the modified Rankin scale (at 90 days) (Harrison 2013; McArthur 2014; van Swieten 1988). See Appendix 1.

\section{Secondary outcomes}

- Adverse events during the first 30 days, assessed according to recommendations from Lineberry 2016.

- Functional recovery: assessed with the Barthel Index (at 90 days) (Harrison 2013; Mahoney 1965). See Appendix 2 for details.

- Neurological function assessed with the National Institutes of Health Stroke Scale (NIHSS) (Harrison 2013). We assessed this at the first 24 hours (acute phase), at 72 hours, and at discharge. See Appendix 3 for details.

- Quality of life (at 90 days): assessed using the 36-item Short Form Survey (SF-36), EuroQol, the Stroke Specific Quality of Life scale (SS-QoL) (Harrison 2013).

The timing of outcome measures indicates the approximate target for the review. It is based on the conventional timing used in the assessment of these outcomes.

\section{Search methods for identification of studies}

See the methods for the Cochrane Stroke Group Specialised register. We searched for trials in all languages and arranged for translation of relevant articles where necessary.

\section{Electronic searches}

We searched in the Cochrane Stroke Group Trials Register and the following electronic databases.

- Cochrane Central Register of Controlled Trials (CENTRAL; 2020, Issue 1) in the Cochrane Library (searched 29 January 2020) (Appendix 4)

- MEDLINE Ovid (from 1948 to 29 January 2020) (Appendix 5)

- Embase Ovid (from 1974 to 29 January 2020) (Appendix 6)

- LILACS (Latin American and Caribbean Health Science Information database; 1982 to 29 January 2020) Appendix 7

With the assistance of the Cochrane Stroke Group's Information Specialist, we designed the search strategy in MEDLINE and adapted it to all other databases (Appendix 5). We combined all search strategies deployed with subject strategy adaptations of the Highly Sensitive Search Strategy designed by Cochrane for identifying randomized controlled trials and controlled clinical trials (as described in the Cochrane Handbook for Systematic Reviews of Interventions Chapter 6: Lefebvre 2011). 


\section{Searching other resources}

We also searched the following ongoing trials registries.

- US National Institutes of Health Ongoing Trials Register (www.ClinicalTrials.gov) (Appendix 8)

- World Health Organization (WHO) International Clinical Trials Registry Platform (ICTRP) (www.who.int/ictrp/en) (Appendix 9)

- Stroke Trials Registry (www.strokecenter.org/trials)

In order to identify unpublished information submitted for the marketing approval of citicoline, we also searched the following sites.

- Food and Drug Administration (www.fda.gov) (Appendix 10);

- European Medicines Agency (www.ema.europa.eu/ema) (Appendix 11).

We screened the reference lists of relevant studies and use Cited Reference Search within Web of Science to identify further studies for potential inclusion in the review, and we contacted trialists and companies for further information.

\section{Data collection and analysis}

We conducted data collection and analysis of data according to the Cochrane Handbook for Systematic Reviews of Interventions (Higgins 2011a; Higgins 2011b).

\section{Selection of studies}

Two review authors (AMC, CV) independently screened titles and abstracts of the references obtained as a result of our searching activities, and excluded obviously irrelevant reports. We retrieved the full-text articles for the remaining references and, independently, two or more review authors (AMC, CV, IS) screened the full-text articles and identified studies for inclusion. They also identified and recorded reasons for exclusion of the ineligible studies. We resolved any disagreements through discussion or, if required, we consulted a third review author (JMF). We collated multiple reports of the same study so that each study, not each reference, was the unit of interest in the review. We recorded the selection process and completed a PRISMA flow diagram.

\section{Data extraction and management}

Two review authors (AMC, CV) independently extracted data from included studies. We developed an Excel spreadsheet based on the 'Data extraction template for included studies' from the Consumers and Communication Group resources for authors. We planned to describe the details of the intervention following recommendations from Hoffmann 2014 and Hoffmann 2017.

\section{Assessment of risk of bias in included studies}

Two review authors (AMC, CV) independently assessed risk of bias for each study using the criteria outlined in the Cochrane Handbook for Systematic Reviews of Interventions (Higgins 2011c). We resolved any disagreements by discussion or by involving another review author (JMF, XB). We assessed the risk of bias according to the following domains.

- Random sequence generation

- Allocation concealment

- Blinding of participants and personnel
- Blinding of outcome assessment

- Incomplete outcome data

- Selective outcome reporting

- Other bias

We graded the risk of bias for each domain as high, low, or unclear and provide information from the study report together with a justification of our judgment in the 'Risk of bias' tables.

We included company funding, bias in the presentation of the data, design bias, measurements and confounding biases under 'Other bias'. See Porta 2014 for definitions of the examples of biases.

See Appendix 12 for details of domains.

\section{Measures of treatment effect}

For binary outcomes in this review, such as all-cause mortality and adverse events, we calculated the risk ratio (RR) with $95 \%$ confidence intervals (Cls).

For future updates we will follow this approach: for continuous outcomes, such as functional outcome, degree of disability or dependence in daily activities, and neurological, behavioral and cognitive function, we plan to calculate the mean difference (MD) with $95 \% \mathrm{Cl}$. If ordinal data are reported, we will use a proportional odds model as a measure of treatment effect with Stata statistical software (STATA) (Bath 2012: Deeks 2017; Scott 1997). If different scales are used for measuring the same outcome, for example quality of life, we plan to use the standardized mean difference (SMD) with $95 \% \mathrm{Cl}$. We will also estimate ratio of means (RoM) with 95\% Cl from mean difference (Friedrich 2011). Due to practitioners' understanding and preferring dichotomous presentations of continuous outcomes, which they perceive to be the most useful (Johnston 2016), we will estimate odds ratios (OR) with $95 \% \mathrm{Cl}$ and the number needed to treat for an additional beneficial outcome (NNTB) from SMD with Furukawa's method (Furukawa 1999; Furukawa 2011).

As recommended in section 9.2.3.2 of the Cochrane Handbook for Systematic Reviews of Interventions (Higgins 2011a), if necessary we will multiply the mean values from one set of studies by -1 to ensure that all the scales point in the same direction (Deeks 2017).

If statistical information is missing (such as standard deviations), we will try to extract them from other relevant information in the paper, such as $\mathrm{P}$ values and $\mathrm{Cls}$.

We will calculate the NNTB if the RR was significant $(P$ value $<$ 0.05). NNTB is a measure of assessment of clinical useful of the consequences of treatment (Laupacis 1988). We will estimate NNTB with GraphPad software and with the Cochrane Stroke Group NNT calculator. If ordinal data are reported, we will estimate NNTB according to Bath 2011.

\section{Unit of analysis issues}

The unit of analysis was participants. We excluded cluster RCTs.

As recommended in the Cochrane Handbook for Systematic Reviews of Interventions, we conducted the following plan to assess the outcomes with multiple observations. 
- For primary outcomes (all-cause mortality and degree of disability or dependence in daily activities according to the modified Rankin scale) and secondary outcomes (adverse events, functional recovery and quality of life), we selected a single time point and analyzed only data at this time for trials in which it will be presented.

- Neurological function assessed with the National Institutes of Health Stroke Scale (secondary outcome): we planned to define different periods of follow-up (short-term, medium-term, and long-term follow-up) (Deeks 2017), and perform separate analyses.

\section{Dealing with missing data}

We assessed the percentage of dropouts for each intervention group for each included trial, and evaluated whether an intentionto-treat (ITT) analysis was performed or could have been performed from the available published information. We contacted study authors to resolve any questions arising from this issue.

In order to undertake an ITT analysis, we sought data from the trial authors about the number of participants in treatment groups, irrespective of their compliance and whether or not they were later thought to be ineligible, otherwise excluded from treatment, or lost to follow-up. If this information was not forthcoming, we performed a 'per protocol' analysis of those who completed the study, being aware that it may be biased.

We included participants with incomplete or missing data in sensitivity analyses by imputing them according to the following scenarios (Hollis 1999).

- Extreme case analysis favoring the experimental intervention ('best-worse' case scenario): none of the drop-outs/participants lost from the experimental arm, but all of the drop-outs/ participants lost from the control arm experienced the outcome, including all randomized participants in the denominator.

- Extreme case analysis favoring the control ('worst-best' case scenario): all drop-outs/participants lost from the experimental arm, but none from the control arm experienced the outcome, including all randomized participants in the denominator.

- Gamble-Hollis analysis, which takes account of the uncertainty and generates uncertainty intervals for a trial incorporating both sampling error and the potential impact of missing data (Gamble 2005). This method increases the uncertainty of the trials using the results from the best-case and worst-case analyses (Chaimani 2014).

\section{Assessment of heterogeneity}

We quantified statistical heterogeneity using the $\mathrm{I}^{2}$ statistic, which describes the percentage of total variation across trials that is due to heterogeneity rather than sampling error (Higgins 2003). We had set an $\mathrm{I}^{2}$ threshold greater than $60 \%$ to consider the presence of statistical heterogeneity (Deeks 2017).

\section{Assessment of reporting biases}

We did not identify 10 or more RCTs to conduct the assessment of reporting biases for any outcome. For the future update, therefore, we will use the contour-enhanced funnel plot to differentiate asymmetry that is due to publication bias from that due to other factors (Peters 2008). We will assess likelihood of publication bias with Harbord's and Peters' tests (Sterne 2011). We will use Stata statistical software to produce conventional and contour funnel plots (STATA).

\section{Data synthesis}

We performed meta-analyses with $95 \% \mathrm{Cl}$ using either a fixed-effect or random-effects model. For future updates, in case of statistical heterogeneity $\left(I^{2}>60 \%\right)$, we will report data using the randomeffects model and prediction interval (Deeks 2017; IntHout 2016; Riley 2011). We conducted meta-analysis with Review Manager 5 (Review Manager 2014).

\section{Trial sequential analysis (TSA)}

We applied trial sequential analysis (TSA), as cumulative metaanalyses are at risk of producing random errors due to sparse data and repetitive testing of the accumulating data (Brok 2008; Brok 2009; Imberger 2015; Imberger 2016; Thorlund 2010; Wetterslev 2008; Wetterslev 2009; Wetterslev 2017). To minimize random errors, we calculated the required information size (i.e. the number of participants needed in a meta-analysis to detect or reject a certain plausible intervention effect) (Wetterslev 2008; Wetterslev 2017). The required information size calculation also accounted for the heterogeneity or diversity present in the meta-analysis (Wetterslev 2008; Wetterslev 2009; Wetterslev 2017). We used the event proportion in the control group; assumption of a plausible RR reduction of $20 \%$ or the RR reduction observed in the included trials with low risk of bias; a risk of type I error of $5 \%$; a risk of type II error of $10 \%$; and the empirical diversity of the meta-analysis for estimating the diversity-adjusted required information size (Wetterslev 2009; Wetterslev 2017). We added the trials according to the year of publication. On the basis of the required information size, we constructed trial sequential monitoring boundaries (Lan 1983; Thorlund 2011a; Wetterslev 2008). These boundaries determined the statistical inference one may draw regarding the cumulative meta-analysis that has not reached the required information size. If the trial sequential monitoring boundary for benefit or harm is crossed before the required information size is reached, further trials may turn out to be superfluous. On the other hand, if the boundary is not surpassed, it is probably necessary to continue conducting trials in order to detect or reject a certain intervention effect. This can be determined by assessing whether the cumulative Z-curve crosses the trial sequential boundaries for futility. If futility boundaries are crossed, then further trials may be unnecessary (CTU 2011). We conducted TSA using software from the Copenhagen Trial Unit (CTU 2011; Thorlund 2011a). We did only for the primary outcomes: allcause mortality and degree of disability or dependence in daily activities according to the modified Rankin scale.

\section{GRADE and 'Summary of findings' table}

We developed a 'Summary of findings' table with the following outcomes: all-cause mortality; degree of disability or dependence in daily activities on the modified Rankin scale; adverse events; functional recovery (Barthel Index); neurological function (National Institutes of Health Stroke Scale: NIHSS); and quality of life (Summary of findings 1 ). We assessed the quality of the evidence for each outcome according to GRADE domains (study limitations, consistency of effect, imprecision, indirectness and publication bias) (Atkins 2004). We used methods and recommendations described in Section 8.5 and Chapter 12 of the Cochrane Handbook for Systematic Reviews of Interventions (Schünemann 2011a), and GRADEpro GDT software (GRADEpro GDT 2015). We justified all 
decisions to downgrade the quality of the evidence using footnotes, and we made comments to aid the reader's understanding of the review where necessary. We calculated the assumed control group risks using the median control group risk (Schünemann 2011b).

\section{Subgroup analysis and investigation of heterogeneity}

We conducted the following subgroup analysis for primary outcomes if more than five trials were included.

- Trials supported by pharmaceutical companies versus trials without support by pharmaceutical companies.

- Trials with low risk of bias versus trials with high risk of bias.

- Trials with small sample size ( $\leq 200$ participants) versus trials with large sample size (> 200 participants).

Due to lack of data, we were not able to conduct subgroup analysis with:

- participants with diabetes mellitus versus participants without diabetes mellitus;

- participants with high blood pressure versus participants without high blood pressure.

\section{Sensitivity analysis}

We performed sensitivity analysis for primary outcomes with Stata statistical software (STATA), in order to explore the influence of particular factors on the intervention effect size: 'best-worst case' scenario versus 'worst-best case' scenario and Gamble-Hollis analysis (Gamble 2005).

\section{Bayes factors}

We estimated the threshold for clinical relevance for primary outcomes through use of Bayes factors (Jakobsen 2014). The Bayes factor is a likelihood ratio that indicates the relative strength of evidence for two theories (Dienes 2014; Dienes 2018 Goodman 1999; Goodman 2005). The Bayes factor is a comparison of how well two hypotheses (the null hypothesis - $\mathrm{H} 0$; and the alternative hypothesis - H1) predict the data (Goodman 1999). The Bayes factor provides a continuous measure of evidence for $\mathrm{H} 1$ over $\mathrm{H} 0$. When the Bayes factor is 1, evidence is insensitive, and this means that the data are equally well predicted by both models and the evidence does not favor either model over the other (1 means the data are as well predicted by $\mathrm{H} 1$ as $\mathrm{H} 0$, so it should not be interpreted as favoring $\mathrm{HO}$; rather the evidence does not point either way). As the Bayes factor increases above 1 (towards infinity) the evidence favors $\mathrm{H} 1$ over $\mathrm{HO}$. As the Bayes factor decreases below 1 (towards 0) the evidence favors H0 over H1 (Dienes 2008; Dienes 2014; Dienes 2018).

Despite the use of Bayes factors, we based the conclusions of this Cochrane Review on the Review Manager 5 analysis (Review Manager 2014).

\section{RES U L T S}

\section{Description of studies}

\section{Results of the search}

The search yielded 1410 references, of which we deemed 18 to be potentially eligible on the basis of title and abstract. Ten trials involving 4543 participants met our inclusion criteria (Alviarez 2007; Clark 1997; Clark 1999; Clark 2001; Ghosh 2015; Guillen 1995; ICTUS 2012; Seifaddini 2017; Tazaki 1988; Warach 2000). The evidence is current to 29 January 2020. See Figure 1 for details of the flow diagram with the search results and selection of studies. 
Figure 1. -Study flow diagram.

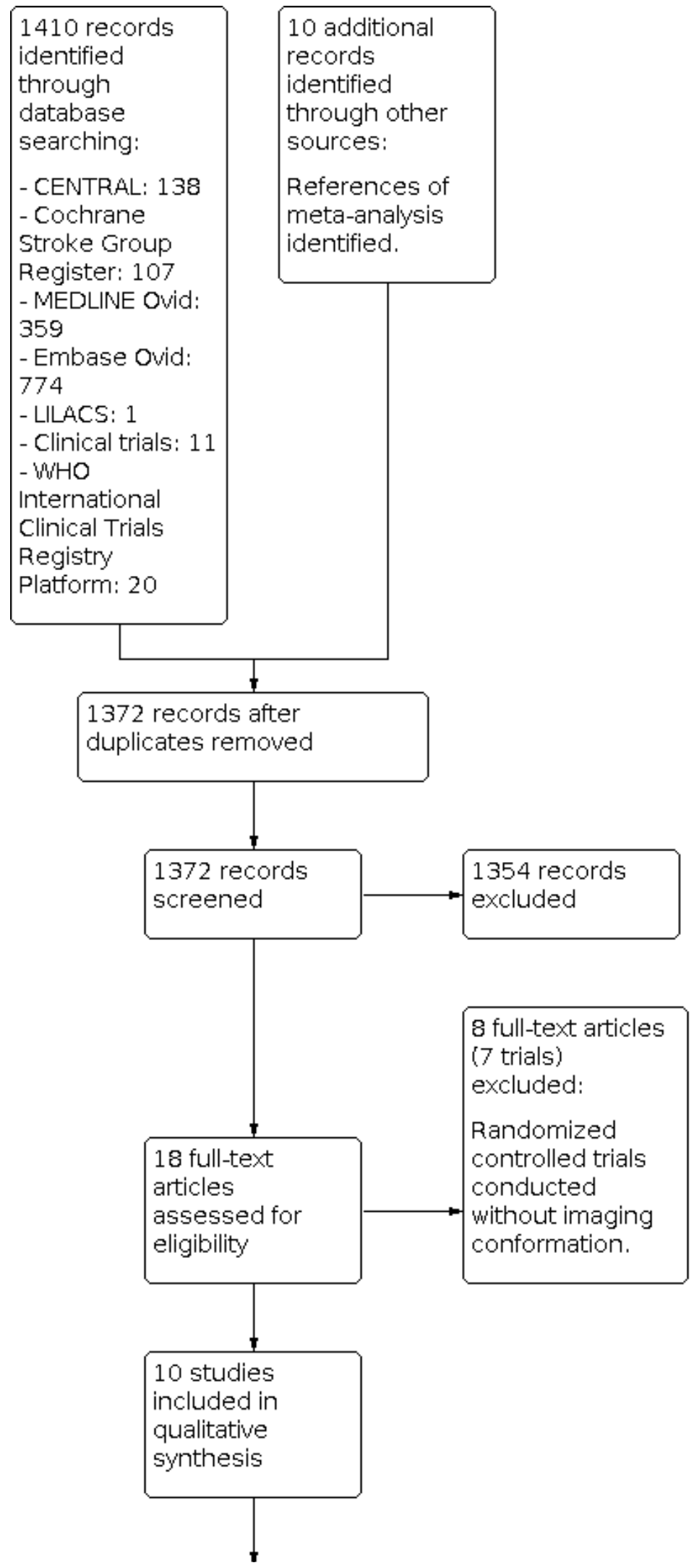


Figure 1. (Continued)

8 studies
included in
quantitative
synthesis

\section{Included studies}

The trials are described in Characteristics of included studies. Trials varied in size as well as in the characteristics of the included participants, duration of intervention, and drug dosage.

\section{Methods}

Between 1988 and 2017 (29 years), 10 trials were conducted in nine countries: Canada (Clark 2001), Germany (ICTUS 2012), India (Ghosh 2015), Iran (Seifaddini 2017), Japan (Tazaki 1988), Portugal (ICTUS 2012), Spain (ICTUS 2012; Guillen 1995), USA (Warach 2000; Clark 1997; Clark 1999; Clark 2001), and Venezuela (Alviarez 2007). There were two international trials (ICTUS 2012; Clark 2001). The number of the centers ranged between 1 and 118 . There were six multicenter trials: Warach $2000(\mathrm{~N}=16)$; ICTUS 2012 ( $\mathrm{N}=59)$, Tazak 1988 (N=63); Clark 1997 (N=21); Clark 1999 ( $N=31)$; and Clark 2001 $(\mathrm{N}=118)$. Six trials reported the duration of follow-up, which ranged between 1 and 12 weeks (Clark 1997; Clark 1999; Clark 2001; Ghosh 2015; ICTUS 2012; Warach 2000). Nine trials had two comparison groups (Alviarez 2007; Clark 1999; Clark 2001; Ghosh 2015; Guillen 1995; ICTUS 2012; Seifaddini 2017; Tazaki 1988; Warach 2000), while one trial had four arms (Clark 1997). All trials reported the duration of treatment, which ranged between 1 and 12 weeks (Alviarez 2007; Clark 1997; Clark 1999; Clark 2001; Ghosh 2015; Guillen 1995; ICTUS 2012; Seifaddini 2017; Tazaki 1988; Warach 2000). ICTUS 2012 tested for superiority, while the rest of the trials specified no type of test. ICTUS 2012 and Seifaddini 2017 stated the timing for starting citicoline treatment, which remains unknown for the other trials. ICTUS 2012 reported during the first 24 hours after the onset of symptoms. Seifaddini 2017 noted post- 24 hours after the onset of symptoms.

\section{Participants}

The trials randomized 4543 participants (mean: 450.3; median: 179; minimum: 40; maximum: 2298). Four trials reported missing data whose percentages of missing outcome data ranged between $1.8 \%$ and 19.6\% (mean: 13.45\%; median: 16.5\%) (Alviarez 2007; ICTUS 2012; Tazaki 1988; Warach 2000).

Eight trials reported the age of participants (Alviarez 2007; Clark 1997; Clark 1999; Clark 2001; ICTUS 2012; Seifaddini 2017; Tazaki 1988; Warach 2000). In six trials, the mean age of participants was 69.27 years old (standard deviation [SD]: 2.05, and median was 68.86) in the citicoline groups while the mean age in the placebo groups was 70.54 years old (SD: 2.02 and median was 70.69 ) (Alviarez 2007; Clark 1997; Clark 1999; Clark 2001; ICTUS 2012; Warach 2000). Seifaddini 2017 reported that $84.3 \%$ and $93.75 \%$ of the participants were 40 or more years old in the citicoline and placebo groups, respectively. Tazaki 1988 stated that $91 \%$ and $96.32 \%$ of participants were between 50 and 90 years old in the citicoline and placebo groups, respectively.
Eight trials reported the sex of participants (Alviarez 2007; Clark 1997; Clark 1999; Clark 2001; ICTUS 2012; Seifaddini 2017; Tazaki 1988; Warach 2000). The average percentage of male participants who received citicoline was 57.34 (median: 54.5 ) versus a mean of 50.28 (median 48.6) in the placebo group.

The description of the relevant clinical variables of the participants varied across the trials. Five trials included participants with a history of TIA (Alviarez 2007; Clark 1999; Clark 2001; ICTUS 2012; Warach 2000), three trials reported a history of stroke or TIA (ICTUS 2012; Clark 1997; Clark 2001), five trials reported participants with diabetes (Alviarez 2007, Clark 1997; Clark 2001; ICTUS 2012; Seifaddini 2017), six trials fixed participants with blood hypertension (Alviarez 2007; Clark 1997; Clark 1999; Clark 2001; ICTUS 2012; Seifaddini 2017), two trials recorded participants with a history of smoking (Alviarez 2007; Clark 1997), one trial noted a history of hyperlipidemia (Seifaddini 2017), and three trials included participants with a history of cardiac disorders (Clark 1997; Clark 2001; ICTUS 2012).

Of the 10 included trials, all reported the inclusion criteria (Alviarez 2007; Clark 1997; Clark 1999; Clark 2001; Ghosh 2015; Guillen 1995; ICTUS 2012; Seifaddini 2017; Tazaki 1988; Warach 2000), and nine stated the exclusion criteria (Alviarez 2007; Clark 1997; Clark 1999; Clark 2001; Ghosh 2015; ICTUS 2012; Seifaddini 2017; Tazaki 1988; Warach 2000).

\section{Interventions}

\section{Experimental drug}

Nine trials used citicoline alone as the experimental group (Alviarez 2007; Clark 1997; Clark 1999; Clark 2001; Guillen 1995; ICTUS 2012; Seifaddini 2017; Tazaki 1988; Warach 2000). One trial combined citicoline with standard stroke therapy (Ghosh 2015).

The route of administration of citicoline varied across the included trials: combined i.e. either intravenously or orally (Alviarez 2007; Ghosh 2015; ICTUS 2012), intravenous only (Guillen 1995; Seifaddini 2017; Tazaki 1988), and oral (Clark 1997; Clark 1999; Clark 2001; Warach 2000). The daily total dose of citicoline by any administration route was not similar across the trials $-500 \mathrm{mg}$, $1000 \mathrm{mg}, 2000 \mathrm{mg}$, and $3000 \mathrm{mg}$. The duration of administration and the daily total dose of citicoline used by intravenous route was dissimilar: $1000 \mathrm{mg}$ by seven days (Seifaddini 2017), $1000 \mathrm{mg}$ by 14 days (Tazaki 1988), 2000 mg during three days (Alviarez 2007; ICTUS 2012), $2000 \mathrm{mg}$ by five days (Ghosh 2015), and $3000 \mathrm{mg}$ by 10 days (Guillen 1995). Thus, the range of duration of intravenous administration was three to 14 days. Likewise, the duration of administration and the daily total dose of citicoline used by oral route varied: 500 mg for six weeks (Clark 1997; Clark 1999; Warach 2000), 1000 mg during six weeks (Alviarez 2007; Warach 2000), 1000 
mg during three weeks (Ghosh 2015), $2000 \mathrm{mg}$ by six weeks (Clark 1997; Clark 2001; ICTUS 2012).

\section{Control group}

Eight trials used placebo as the control group (Alviarez 2007; Clark 1997; Clark 1999; Clark 2001; ICTUS 2012; Seifaddini 2017; Tazaki 1988; Warach 2000). Three trials stated that appearance was identical and indistinguishable between the comparison groups (Clark 1999; ICTUS 2012; Tazaki 1988). One trial used physiological saline as placebo (Tazaki 1988). Two trials used standard or conventional therapy as control group (Ghosh 2015; Guillen 1995). One trial described the composition of standard stroke therapy used as control (Ghosh 2015).

\section{Co-intervention}

Three trials reported using co-interventions (Alviarez 2007; ICTUS 2012; Tazaki 1988). Two trials described the type of co-intervention (Alviarez 2007; ICTUS 2012); but only one trial reported use of intravenous thrombolysis (ICTUS 2012).

\section{Outcomes}

The mean of the number of the outcomes was 4.6 (range: 1 to 9). Six trials stated which were primary or secondary outcomes (Clark 1997; Clark 1999; Clark 2001; Ghosh 2015; ICTUS 2012; Warach 2000). Of them, five trials selected relevant clinical outcomes as the primary option (Clark 1997; Clark 1999; Clark 2001; Ghosh 2015, ICTUS 2012). Four trials assessed the degree of disability or dependence in daily activities according to the modified Rankin scale (Alviarez 2007; Clark 1999; Clark 2001; ICTUS 2012). Seven trials appraised the functional recovery with the Barthel Index (Alviarez 2007; Ghosh 2015; Guillen 1995; ICTUS 2012; Clark 1997; Clark 1999; Clark 2001). Four trials evaluated neurological function with the National Institutes of Health Stroke Scale (NIHSS) (Clark 1999; Clark 2001; ICTUS 2012; Warach 2000). Three trials considered all-cause mortality as a secondary outcome (Clark 1999; Clark 2001; ICTUS 2012). One trial included adverse events as an outcome (ICTUS 2012). Six trials included only one primary outcome (Clark 1997; Clark 1999; Clark 2001; Ghosh 2015; ICTUS 2012; Warach 2000), and one trial stated four primary outcomes (Seifaddini 2017).
1997; Clark 1999; Clark 2001; ICTUS 2012; Tazaki 1988). Four trials reported the sample size estimation a priori (Clark 1999; Clark 2001; ICTUS 2012; Warach 2000). One trial likely did a sample size estimation before it started (Seifaddini 2017). Drug companies supported six included trials (Alviarez 2007; Clark 1997; Clark 1999; Clark 2001; ICTUS 2012; Warach 2000). It remained unknown in four trials (Ghosh 2015; Guillen 1995; Seifaddini 2017; Tazaki 1988). One trial declared the role of its sponsor (ICTUS 2012). Two trials clearly stated financial disclosures (ICTUS 2012; Warach 2000). At least one author of the following trials was an employee or consultant of the drug company that sponsored the trial (Alviarez 2007; ICTUS 2012).

One trial stated an amendment of the protocol (Warach 2000). There was no information in terms of the impact of the amendment over the final results. This trial noted no trial number identifier.

One trial was stopped on the recommendation of the Data and Safety Monitoring Board at the third interim analysis, because the statistical stopping boundary for futility had been crossed (ICTUS 2012). This trial reported the trial identifier number.

\section{Excluded studies}

We excluded seven RCTs which were conducted without imaging (Dereux 1987; Dereux 1987; ECCS- AIS 2012; Garcia Pastor 2004; Goas 1980; Melnikova 2011; Panteleienko 2009). See Characteristics of excluded studies.

\section{Studies awaiting classification}

We identified one study in this category (Hassan 2019).

\section{Ongoing trials}

We identified two ongoing trials (CTRI/2018/02/011900; IRCT201601289014N90). See Characteristics of ongoing studies table for details.

\section{Risk of bias in included studies}

We have summarized risks of bias in the included trials in Figure 2 and Figure 3, and we have provided more details in the Characteristics of included studies table.

\section{Miscellaneous}

Two trials reported the identifier trial number register (ICTUS 2012; Seifaddini 2017). Five trials reported the trial conduct data (Clark

\section{Figure 2. Risk of bias graph: review authors' judgments about each risk of bias item presented as percentages across all included studies.}

Random sequence generation (selection bias) Allocation concealment (selection bias) Blinding of participants and personnel (performance bias): All outcomes Blinding of outcome assessment (detection bias): All outcomes Incomplete outcome data (attrition bias): All outcomes Selective reporting (reporting bias) Other bias

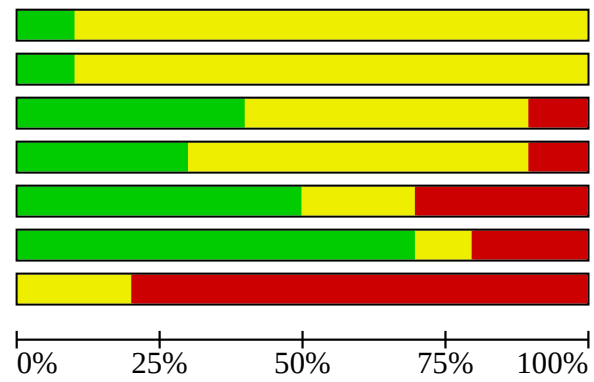


Figure 3. Risk of bias summary: review authors' judgments about each risk of bias item for each included study.

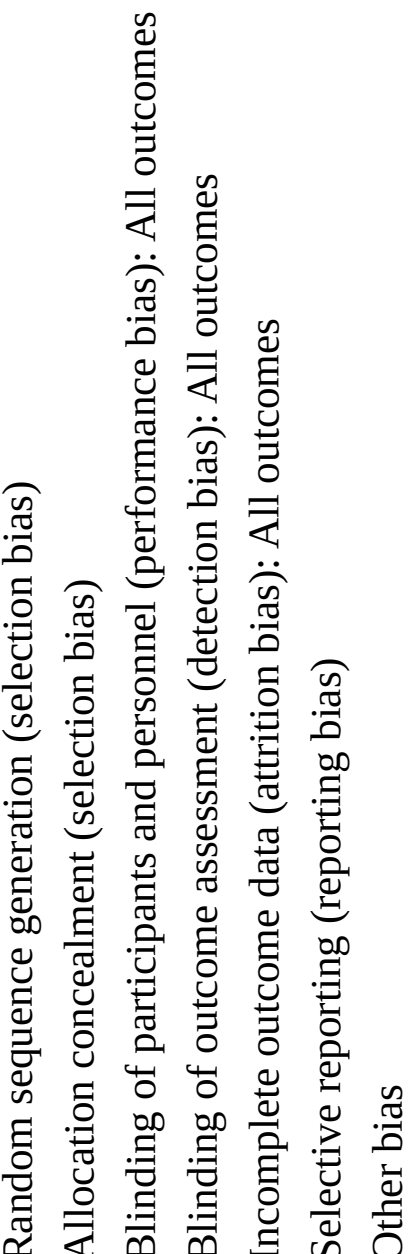

Alviarez 2007

Clark 1997

Clark 1999

Clark 2001

Ghosh 2015

Guillen 1995

ICTUS 2012

Seifaddini 2017

Tazaki 1988

Warach 2000

\begin{tabular}{|c|c|c|c|c|c|}
\hline ? & ? & ? & $?$ & & \\
\hline ? & ? & ? & $?$ & +6 & \\
\hline$?$ & $?$ & + & $?$ & +3 & + \\
\hline ? & $?$ & + & $?$ & +6 & + \\
\hline ? & $?$ & - & - & + & \\
\hline$?$ & ? & ? & ? & ? & ? \\
\hline+ & + & + & + & -1 & + \\
\hline ? & ? & ? & ? & ? & \\
\hline ? & ? & + & + & + & + \\
\hline$?$ & $?$ & $?$ & & & \\
\hline
\end{tabular}




\section{Allocation}

\section{Random sequence generation}

We rated one trial as having a low risk of selection bias because the trial authors used a centralized randomization process with an interactive voice response system (ICTUS 2012). Nine trials had unclear risk of bias for this domain due to the lack of a clear description of how the random sequence generation was conducted (Alviarez 2007; Clark 1997; Clark 1999; Clark 2001; Ghosh 2015; Guillen 1995; Seifaddini 2017; Tazaki 1988; Warach 2000).

\section{Allocation concealment}

We considered risk of bias arising from the method of allocation concealment to be low in one trial. This judgment is based on the interactive voice response system used for reducing the risk of selection bias (ICTUS 2012). Nine trials did not report the randomization process methodology: thus, we considered risk of bias arising from the method of allocation concealment to be unclear (Alviarez 2007; Clark 1997; Clark 1999; Clark 2001; Ghosh 2015; Guillen 1995; Seifaddini 2017; Tazaki 1988; Warach 2000).

\section{Blinding}

\section{Blinding of participants and personnel (performance bias)}

We rated risk of bias due to lack of blinding of participants and personnel as low in four trials as they provide an appropriate description of the blinding: the experimental drug and control were indistinguishable, personnel were masked (Clark 1999; Clark 2001; ICTUS 2012; Tazaki 1988). We judged five trials as unclear risk for performance bias due to the absence of an adequate description for blinding of participants and personnel (Alviarez 2007; Clark 1997; Guillen 1995; Seifaddini 2017; Warach 2000). One trial had a high risk of bias for this domain due to the following description: "the authors evaluated the outcome themselves, were not blinded to the treatment" (Ghosh 2015).

\section{Blinding of outcome assessment (detection bias)}

Three trials clearly reported outcome assessment as blinded, and we considered detection bias to be low because the personnel carrying out the clinical assessment were blinded (ICTUS 2012; Tazaki 1988; Warach 2000). We rated six trials as having an unclear risk of bias for blinding of outcome assessors due to lack of information about the blinding of the personnel (Alviarez 2007; Guillen 1995; Seifaddini 2017; Clark 1997; Clark 1999; Clark 2001). We considered one trial to have a high risk of detection bias because it did not report blinding for outcome assessment (Ghosh 2015).

\section{Incomplete outcome data}

We rated risk of attrition bias as low in five trials (Clark 1997; Clark 1999; Clark 2001; Ghosh 2015; Tazaki 1988). Two trials had an unclear risk of bias for this domain: one trial reported no information about this because it was published as an abstract, whereas the other trial assessed physiological outcomes (Guillen 1995: Seifaddini 2017). We considered three trials as having a high risk of bias for attrition bias due to the percentage of dropouts, which were $16 \%, 23 \%$ and $19 \%$, respectively (Alviarez 2007; ICTUS 2012; Warach 2000)

\section{Selective reporting}

We considered seven trials as having a low risk for selective outcome reporting bias due to reported information about the prefixed outcomes for this Cochrane Review. That information allowed us to pool the data (Alviarez 2007; Clark 1997; Clark 1999; Clark 2001; ICTUS 2012; Tazaki 1988; Warach 2000). We considered one trial as having an unclear risk of bias for this domain; trial information was reported in an abstract (Guillen 1995). We judged two trials as having a high risk of reporting bias because neither appropriate data about outcomes nor information about outcomes required in this Cochrane Review were available (Ghosh 2015; Seifaddini 2017). Two trials reported their trial registration number (ICTUS 2012; Seifaddini 2017).

\section{Other potential sources of bias}

We detected bias either in the presentation of the data or in the design of trials (Alviarez 2007; Ghosh 2015; Guillen 1995; Seifaddini 2017; Tazaki 1988, Clark 1997), in the measurements and confounding biases due to lack of information regarding the impact of the amendment of the trial protocol (Warach 2000), funding bias due to many trial authors receiving either consultation fees or honoraria from the trial sponsor, and one trial author was a fulltime employee of the sponsor (Alviarez 2007; ICTUS 2012; Clark 1997). We considered two trials as having an unclear risk for other potential sources of bias (funding bias) (Clark 1999; Clark 2001).

Based on the protocol for this Cochrane Review, which stated "We will consider trials at low risk of bias to be those that used an adequate system to generate their allocation sequence, had adequate allocation concealment, adequate blinding, adequate handling of incomplete outcome data, were free of selective outcome reporting and were free of other bias", we considered all trials to have a high risk of bias.

\section{Effects of interventions}

See: Summary of findings 1 Citicoline compared with placebo or standard treatment for treating people with acute ischemic stroke

The results are based on 4281 randomized participants in nine trials (Alviarez 2007; Clark 1997; Clark 1999; Clark 2001; Ghosh 2015; Guillen 1995; ICTUS 2012; Tazaki 1988; Warach 2000). One included trial only supplied information about hemodynamic cerebral outcomes (Seifaddini 2017). All trials compared citicoline versus placebo or no intervention. Table 1 shows a summary of meta-analyses with $95 \% \mathrm{Cl}$ comparing the fixed-effect with random-effects models of the intervention results.

\section{Primary}

\section{All-cause mortality}

\section{Citicoline versus placebo}

A pooled analysis of eight trials found no difference in all-cause mortality comparing citicoline with placebo (399/2313 [17.3\%] versus $379 / 2049$ [18.5\%]; RR fixed-effect $0.94,95 \%$ Cl 0.83 to $1.07 ; 1^{2}$ $=0 \%$; low-quality evidence due to risk of bias) (Alviarez 2007; Clark 1997; Clark 1999; Clark 2001; Ghosh 2015; ICTUS 2012; Tazaki 1988; Warach 2000) (Analysis 1.1). Bayes factor was 0.33 which means that the evidence favors moderatelly null hypothesis over alternative hypothesis. Trial Sequential Analysis suggested no more trials are needed (Figure 4; Summary of findings 1). 
Figure 4. Trial Sequential Analysis for citicoline versus placebo or no intervention on all-cause mortality. The diversity-adjusted required information size (DARIS) was calculated based on an expected relative risk reduction (RRR) of $14 \%$ from proportion event in control (PC) group of $18.5 \%$ with an alpha of $5 \%$ and beta of $20 \%$. Cumulative Z-curve (blue line) reached futility area after seven trials, which means that no more trials are needed.

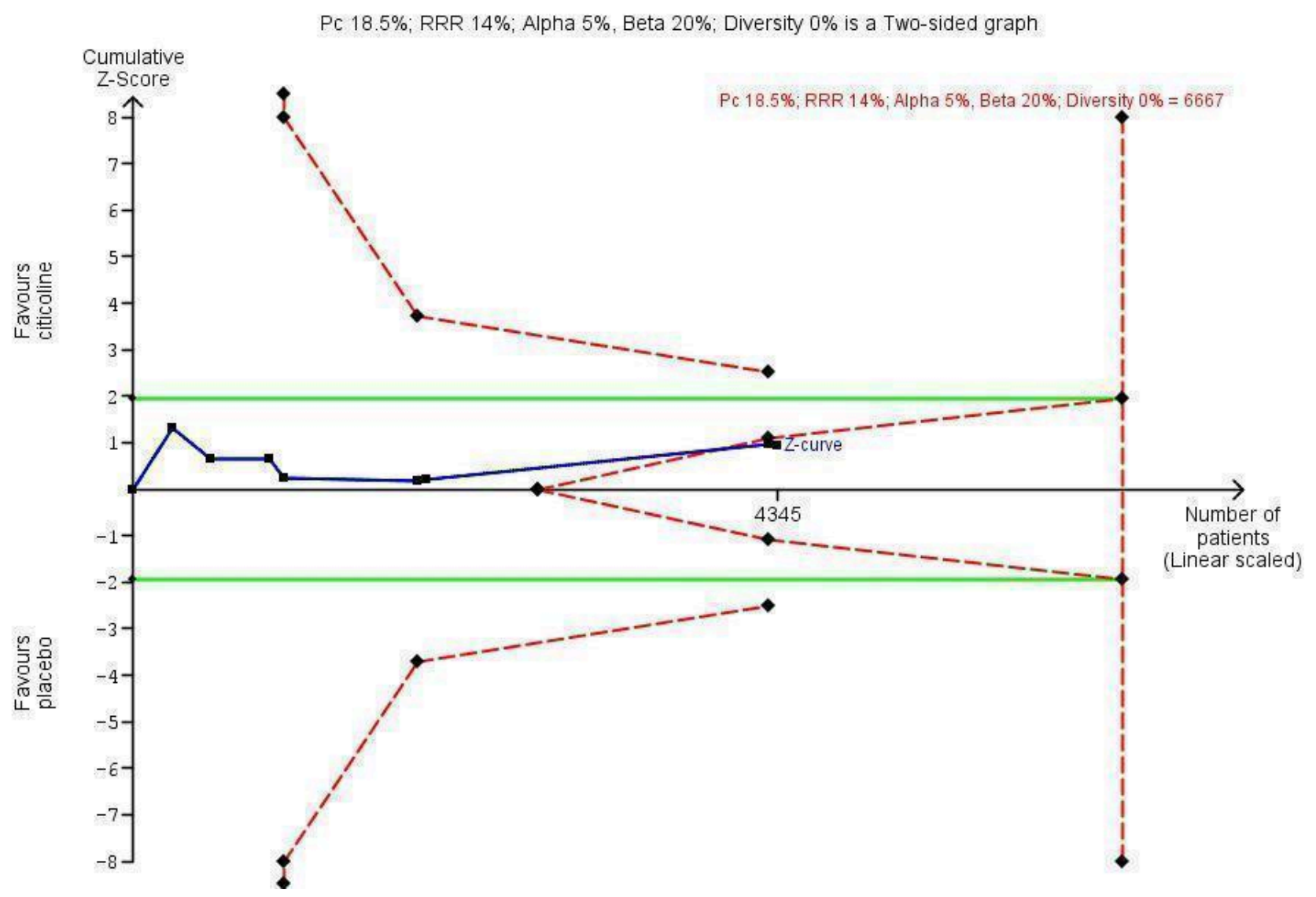

\section{Subgroup analysis}

Trials without support from pharmaceutical companies versus trials supported by pharmaceutical companies

Two trials conducted without support from pharmaceutical companies found no difference comparing citicoline with placebo in terms of all-cause mortality (13/161 [8.07\%] versus 19/174 [10.91 \%]: RR 0.78, 95\% Cl 0.41 to 1.49; $\left.\right|^{2}=0 \%$ ) (Ghosh 2015; Tazaki 1988). Pooled data of six trials supported by pharmaceutical companies showed no difference comparing citicoline with placebo in terms of all-cause mortality (386/2152 [17.93\%] versus 360/1875 [19.2\%]: RR 0.95, 95\% Cl 0.83 to 1.08; I $^{2}=0 \%$ ) (Alviarez 2007; Clark 1997; Clark 1999; Clark 2001; ICTUS 2012; Warach 2000). Test for subgroup differences: $\mathrm{Chi}^{2}=0.34, \mathrm{df}=1(\mathrm{P}=0.56), \mathrm{I}^{2}=0 \%$. See Analysis 1.2.

\section{Trials with $\leq 200$ participants versus trials with $>200$ participants}

Pooled analysis of three trials which included 200 or fewer participants showed no difference comparing citicoline with placebo in terms of all-cause mortality (20/118 [16.94\%] versus $17 / 122$ [13.93\%]: RR 1.26, 95\% Cl 0.70 to $2.29 ; 1^{2}=0 \%$ ) (Alviarez 2007; Ghosh 2015; Warach 2000). Pooled data of five trials which recruited more than 200 participants showed no difference comparing citicoline versus placebo in terms of all-cause mortality (379/2195 [17.26\%] versus $362 / 1927$ [18.78\%]: RR $0.93,95 \% \mathrm{Cl} 0.81$ to $1.06 ; \mathrm{I}^{2}$
= 0\%) (Clark 1997; Clark 1999; Clark 2001; ICTUS 2012; Tazaki 1988). Test for subgroup differences: $\mathrm{Chi}^{2}=0.99, \mathrm{df}=1(\mathrm{P}=0.32), \mathrm{I}^{2}=0 \%$. See Analysis 1.3.

\section{Sensitivity analyses}

Assessing the impact of missing outcome data

Meta-analysis of four trials not reporting missing data showed no difference comparing citicoline versus placebo in terms of all-cause mortality (159/942 [16.87\%] versus $117 / 673$ [17.38\%]; RR 0.99, 95\% Cl 0.79 to 1.23; $I^{2}=0 \%$ ) (Clark 1997; Clark 1999; Clark 2001; Ghosh 2015). Pooled data of four trials reporting missing data showed no difference comparing citicoline versus placebo in terms of allcause mortality (240/1371 [17.5\%] versus 262/1376 [19.04\%]; RR $0.92,95 \% \mathrm{Cl} 0.78$ to $1.07 ; 1^{2}=0 \%$ ) (Alviarez 2007; ICTUS 2012; Tazaki 1988; Warach 2000). Test for subgroup differences: $\mathrm{Chi}^{2}=0.28, \mathrm{df}=$ $1(P=0.59) ; I^{2}=0 \%$. See Analysis 1.4 .

Assessing the impact of the missing outcome data: best-case scenario

Pooling of four trials without missing data found no difference between comparison groups in relation to all-cause mortality (RR 0.99, 95\% 0.80 to 1.24; $\left.\right|^{2}=0 \%$ ) (Clark 1997; Clark 1999; Clark 2001; Ghosh 2015). Meta-analysis of four trials reporting missing data showed a reduction of $58 \%$ of the risk of all-cause mortality with citicoline use versus placebo use (RR $0.42,95 \% \mathrm{Cl} 0.37$ to $0.49 ; \mathrm{I}^{2}=$ 
0\%) (Alviarez 2007; ICTUS 2012; Tazaki 1988; Warach 2000). Test for subgroup differences: $\mathrm{Chi}^{2}=41.51, \mathrm{df}=1(\mathrm{P}<0.00001) ; \mathrm{I}^{2}=97.6 \%$. See Analysis 1.5.

Assessing the impact of the missing outcome data: worst-case scenario In relation to all-cause mortality a pool of four trials without missing data found no difference between comparison groups (RR 0.99, 95\% 0.79 to $1.23 ; I^{2}=0 \%$ ) (Clark 1997; Clark 1999; Clark 2001; Ghosh 2015). Meta-analysis of four trials reporting missing data found an increase of $104 \%$ of the risk of all-cause mortality in the citicoline group compared with placebo (RR $2.04,95 \% \mathrm{Cl} 1.79$ to $2.332 ; \mathrm{I}^{2}=$ 0\%) (Alviarez 2007; ICTUS 2012; Tazaki 1988; Warach 2000). Test for subgroup differences: $\mathrm{Chi}^{2}=41.51, \mathrm{df}=1(\mathrm{P}<0.00001) ; \mathrm{I}^{2}=97.6 \%$. See Analysis 1.6.

Assessing the impact of the missing outcome data: the Gamble-Hollis analysis

With regard to all-cause mortality, pooling four trials without missing data found no difference between comparison groups (RR
0.99, $95 \% 0.79$ to $1.23 ; I^{2}=0 \%$ ) (Clark 1997; Clark 1999; Clark 2001; Ghosh 2015). Meta-analysis of four trials found no difference between comparison groups (RR $0.86,95 \% \mathrm{Cl} 0.45$ to $1.64 ; \mathrm{I}^{2}=$ 0\%) (Alviarez 2007; ICTUS 2012; Tazaki 1988; Warach 2000). Test for subgroup differences: $\mathrm{Chi}^{2}=0.15, \mathrm{df}=1(\mathrm{P}=0.70) ; \mathrm{I}^{2}=0 \%$. See Analysis 1.7.

\section{Degree of disability or dependence in daily activities}

\section{Citicoline versus placebo}

Four trials showed that citicoline may not increase the proportion of patients with a moderate or lower degree of disability or dependence compared with placebo, according to the Rankin Scale (414/1906 [21.7\%] versus 339/1762 [19.2\%]; RR fixed-effect 1.11, $95 \% \mathrm{Cl} 0.97$ to $1.26 ;\left.\right|^{2}=1 \%$; low-quality evidence due to risk of bias) (Alviarez 2007; Clark 1999; Clark 2001; ICTUS 2012) (Analysis 1.8). Bayes factor was 1.81 which means that the evidence anecdotally favors alternative hypothesis over null hypothesis. Trial Sequential Analysis suggested no more trials are required (Figure 5; Summary of findings 1 ).

Figure 5. Trial Sequential Analysis for citicoline versus placebo or no intervention on degree of disability or dependence in daily activities according to the modified Rankin scale. The diversity-adjusted required information size (DARIS) was calculated based on an expected relative risk reduction (RRR) of $19 \%$ from proportion event in control (Pc) group of $19.95 \%$ with an alpha of $5 \%$ and beta of $20 \%$. Cumulative Z-curve (blue line) reached futility area after four trials, which means that no more trials are needed.

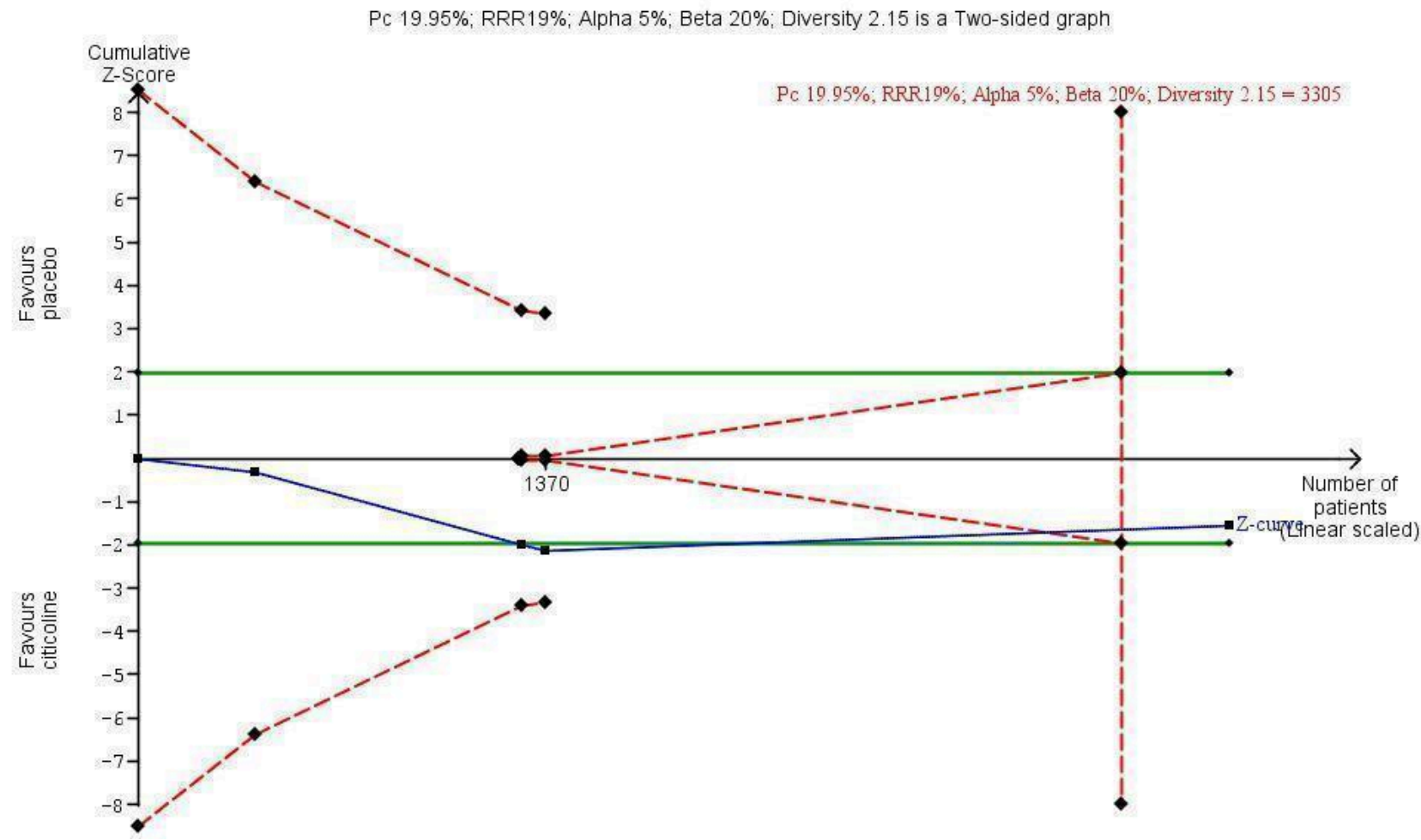

Subgroup analysis

Trials with $\leq 200$ participants versus trials with $>200$ participants

One trial with 200 or fewer participants found no difference in the proportion of patients with a moderate or lower degree of disability or dependence compared with placebo, according to the Rankin Scale (13/38 [34.2\%] versus 10/39 [25.6\%]; RR 1.33, 95\%
$\mathrm{Cl} 0.67$ to 2.67 ) (Alviarez 2007). A meta-analysis including three trials that included 200 or more participants showed no difference comparing citicoline with placebo in the proportion of patients with a moderate or lower degree of disability or dependence $(401 / 1868$ [34.2\%] versus $329 / 1723$ [25.6\%]; RR $1.10,95 \% \mathrm{Cl} 0.96$ to $1.25 ; \mathrm{I}^{2}$ = 27\%) (ICTUS 2012; Clark 1999; Clark 2001). Test for subgroup differences: $\mathrm{Chi}^{2}=0.29, \mathrm{df}=1(\mathrm{P}=0.59) ; \mathrm{I}^{2}=0 \%$. See Analysis 1.9. 


\section{Sensitivity analysis}

\section{Assessing the impact of missing outcome data}

Meta-analysis of two trials which did not report missing data showed no difference comparing citicoline with placebo in the proportion of patients with a moderate or lower degree of disability or dependence compared with placebo, according to the Rankin Scale (190/720 [23.4\%] versus 121/573 [21.1\%]; RR 1.23, 95\% Cl 1.01 to $1.50 ; I^{2}=0 \%$ ) (Clark 1999; Clark 2001). Pooled data of two trials that reported missing data found no difference comparing citicoline versus placebo in the proportion of patients with a moderate or lower degree of disability or dependence $(224 / 1186$ [18.9\%] versus $218 / 1189$ [18.3\%]; RR $1.03,95 \% \mathrm{Cl} 0.87$ to $1.22 ; \mathrm{I}^{2}=$ 0\%) (Alviarez 2007; ICTUS 2012). Test for subgroup differences: $\mathrm{Chi}^{2}$ $=1.74, \mathrm{df}=1(\mathrm{P}=0.19) ; \mathrm{I}^{2}=42.4 \%$. See Analysis 1.10 .

\section{Assessing the impact of missing outcome data: best-case scenario}

According to a best-case scenario assessment of the impact of missing data, there was no difference in two trials which did not report missing data comparing citicoline with placebo regarding the proportion of patients with a moderate or lower degree of disability or dependence compared with placebo, according to the Rankin Scale (RR 1.23, 95\% Cl 1.00 to $1.50 ; I^{2}=0 \%$ ) (Clark 1999; Clark 2001). By contrast, meta-analysis of two trials that reported missing data showed that citicoline may result in a slight reduction in the proportion of patients with a moderate or lower degree of disability or dependence compared with placebo (RR $0.44,95 \% \mathrm{Cl}$ 0.39 to $0.51 ; I^{2}=67 \%$ ) (Alviarez 2007; ICTUS 2012). Test for subgroup differences: $\mathrm{Chi}^{2}=67.32, \mathrm{df}=1(\mathrm{P}<0.00001) ; \mathrm{I}^{2}=98.5 \%$. See Analysis 1.11 .

\section{Assessing the impact of missing outcome data: worst-case scenario}

According to a worst-case scenario assessment of the impact of missing data, there was no difference in two trials which did not report missing data comparing citicoline with placebo regarding the proportion of patients with a moderate or lower degree of disability or dependence compared with placebo, according to the Rankin Scale (RR 1.23, 95\% Cl 1.00 to $1.50 ; I^{2}=0 \%$ ) (Clark 1999; Clark 2001). Pooled data of two trials reporting missing data showed that citicoline may result in an increase in the proportion of patients with a moderate or lower degree of disability or dependence compared with placebo (RR $2.33,95 \% \mathrm{Cl} 2.03$ to $2.69 ; \mathrm{I}^{2}=0 \%$ ) (Alviarez 2007; ICTUS 2012). Test for subgroup differences: $\mathrm{Chi}^{2}=$ $26.45, \mathrm{df}=1(\mathrm{P}<0.00001) ; \mathrm{I}^{2}=96.2 \%$. See Analysis 1.12 .

\section{Assessing the impact of missing outcome data: the Gamble-Hollis analysis}

An assessment of the impact of missing outcome data according the Gamble-Hollis analysis showed no difference comparing citicoline with placebo in the proportion of patients with a moderate or lower degree of disability or dependence compared with placebo, neither in trials which did not report missing data (RR $1.23,95 \% \mathrm{Cl} 1.00$ to $\left.1.50 ; I^{2}=0 \%\right)(C l a r k 1999 ;$ Clark 2001), nor in those reporting missing data (RR 1.14, $95 \% \mathrm{Cl} 0.54$ to $2.42 ; I^{2}=0 \%$ ) (Alviarez 2007; ICTUS 2012). Test for subgroup differences: $\mathrm{Chi}^{2}=0.03, \mathrm{df}=1(\mathrm{P}=0.86) ; \mathrm{I}^{2}$ $=0 \%$. See Analysis 1.13 .

\section{Secondary \\ Adverse events \\ Citicoline versus placebo \\ Severe adverse events}

Pooled analyses either with three or two trials found no difference comparing citicoline versus placebo in terms of the following severe adverse events.

- Cardiovascular (RR 1.04, 95\% Cl 0.84 to 1.29; 299 events, 3591 participants; $\left.\right|^{2}=0 \%$; low-quality evidence due to risk of bias and imprecision (Clark 1999; Clark 2001; ICTUS 2012).

- Central nervous system (including hemorrhagic or ischemic stroke) (RR 1.30, 95\% Cl 1.07 to 1.59; 406 events, 3591 participants; $I^{2}=93 \%$; low-quality evidence due to risk of bias and imprecision (ICTUS 2012; Clark 1999; Clark 2001).

- Respiratory (including pneumonia) (RR $1.01,95 \% \mathrm{Cl} 0.78$ to 1.31 ; 406 events, 3591 participants; $I^{2}=0 \%$; low-quality evidence due to risk of bias and imprecision (Clark 1999; Clark 2001; ICTUS 2012).

- Gastrointestinal (RR 0.64, 95\% Cl 0.40 to 1.00; 65 events, 1370 participants; $I^{2}=69 \%$; low-quality evidence due to risk of bias and imprecision (Alviarez 2007; Clark 1999; Clark 2001).

- Musculoskeletal (RR 1.52, 95\% Cl 0.50 to $4.60 ; 15$ events, 1293 participants; $\left.\right|^{2}=0 \%$; low-quality evidence due to risk of bias and imprecision (Clark 1999; Clark 2001).

- Renal and urologic disorders (RR 2.04, 95\% Cl 0.99 to 4.22; 39 events, 1560 participants; $I^{2}=0 \%$; low-quality evidence due to risk of bias and imprecision (Clark 1999; Clark 2001; Tazaki 1988).

- Hematological disorders (RR 1.27, 95\% Cl 0.46 to $3.51 ; 16$ events, 1560 participants; $I^{2}=0 \%$; low-quality evidence due to risk of bias and imprecision (Clark 1999; Clark 2001; Tazaki 1988).

Test for subgroup differences: $\mathrm{Chi}^{2}=12.54, \mathrm{df}=7(\mathrm{P}=0.08) ; \mathrm{I}^{2}=$ $44.2 \%$. See Analysis 1.14. Summary of findings 1.

One trial reporting severe hepatic dysfunction showed no difference between comparison groups (RR 1.47, 95\% $\mathrm{Cl} 0.48$ to 4.49; 7 events, 267 participants; $I^{2}=0 \%$; low-quality evidence due to risk of bias and imprecision (Tazaki 1988).

\section{Non-severe adverse events}

One trial including 2298 participants supplied data regarding nonsevere adverse events (ICTUS 2012). There was no difference between comparison groups regarding cardiac disorders (RR 0.94, $95 \% \mathrm{Cl} 0.82$ to $1.08 ; 572$ events), pyrexia (RR $1.02,95 \% \mathrm{Cl} 0.87$ to 1.19; 512 events), constipation (RR $1.03,95 \% \mathrm{Cl} 0.88$ to $1.20 ; 484$ events), urinary tract infections (RR $1.06,95 \% \mathrm{Cl} 0.89$ to $1.26 ; 426$ events), headache (RR $0.96,95 \% \mathrm{Cl} 0.79$ to $1.18 ; 314$ events), nausea and vomiting symptoms (RR $0.95,95 \% \mathrm{Cl} 0.77$ to 1.16 ; 315 events), agitation (RR $1.20,95 \% \mathrm{Cl} 0.94$ to 1.54; 229 events), hemorrhagic transformation of the stroke (RR $0.98,95 \% \mathrm{Cl} 0.74$ to $1.29 ; 184$ events), pneumonia (RR $1.02,95 \% \mathrm{Cl} 0.73$ to $1.41 ; 135$ events), and hypotension (RR $0.92,95 \% \mathrm{Cl} 0.63$ to $1.36 ; 100$ events). See Analysis 1.15. We rated the quality of evidence for non-severe adverse events as low due to risk of bias and imprecision.

Table 2 shows the information about harms as reported in the trials. 


\section{Functional recovery}

\section{Citicoline versus placebo}

One trial assessing functional recovery with the a cut-off in the Barthel Index of 50 points found no difference comparing citicoline with placebo (16/38 [42.1\%] versus 13/39 [33.3\%]; RR fixed-effect $1.26,95 \% \mathrm{Cl} 0.71$ to 2.26 ; low-quality evidence due to risk of bias and imprecision) (Alviarez 2007). Four trials assessing the functional recovery with a cut-off in the Barthel Index of 95 or more points found no difference comparing citicoline with placebo (676/2062 [32.8\%] versus 549/1788 [30.7\%]; RR 1.03, 95\% Cl 0.94 to $1.13 ; I^{2}=24 \%$; low-quality evidence due to risk of bias). The Bayes factor was 0.75 which means that the evidence favors moderatelly the null hypothesis over the alternative hypothesis (Clark 1997; Clark 1999; Clark 2001; ICTUS 2012). One trial with a cut-off in the Barthel Index of 85 to 100 points found no difference favoring citicoline versus placebo (10/28 [35.7\%] versus 4/35 [11.4\%]; RR $3.13,95 \% \mathrm{Cl} 1.10$ to 8.91 ; low-quality evidence due to risk of bias and imprecision) (Ghosh 2015). Test for subgroup differences: $\mathrm{Chi}^{2}$ $=4.69, \mathrm{df}=2(\mathrm{P}=0.10), \mathrm{I}^{2}=57.3 \%$. See Analysis 1.16 . Summary of findings 1 .

Based on a P value $<0.05$, Guillen 1995 reported improvements of functional recovery in a narrative way.

\section{Neurological function}

\section{Citicoline versus placebo}

Five trials assessed neurological function with the National Institutes of Health Stroke Scale at a cut-off point of $\leq 1$ points. A pooled analysis of these trials showed that citicoline, compared to placebo, may not increase the proportion patients with minor impairment (514/2114 [24.3\%] versus 412/1836 [22.4\%]; RR fixedeffect $1.08,95 \% \mathrm{Cl} 0.96$ to $1.21 ; \mathrm{I}^{2}=27 \%$; low-quality evidence due to risk of bias). The Bayes factor was 1.32 which means that the evidence anecdotally favors the alternative hypothesis over the null hypothesis (Clark 1997; Clark 1999; Clark 2001; ICTUS 2012; Warach 2000). See Analysis 1.17. Summary of findings 1.

\section{Quality of life}

\section{Citicoline versus placebo}

None of the trials reported information about this outcome. See Summary of findings 1.

\section{DISCUSSION}

\section{Summary of main results}

This Cochrane Review about citicoline for treating people with acute ischemic stroke includes 10 trials randomizing 4281 participants. These trials evaluated citicoline that was given orally, intravenously or both compared with placebo or standard care therapy. Citicoline doses ranged between 500 and $2000 \mathrm{mg}$ per day. Four out of 10 trials reported an a priori sample size estimation. Drug companies sponsored six trials. There were six multicenter trials, of which two were international. Trials were conducted in nine countries in either outpatient (ambulatory) or inpatient settings. Overall, we assessed these trials as having a high risk of bias. The main results yielded from the meta-analysis are as follows.
- None of the pooled analyses found differences between citicoline and their comparison groups regarding all-cause mortality, disability or dependence (according to $<3$ scores in the modified Rankin scale), functional recovery (assessed with the Barthel Index), neurological impairment (according to $\leq 1$ scores in the National Institutes of Health Stroke Scale), or severe adverse events. Quality of evidence for effects of interventions was low due to either limitations in the design and execution of the trials or very low number of events and smallness of sample sizes.

- One trial reporting information about non-severe adverse events identified no differences. The quality of evidence was low due to high risk of bias and a very low number of events. Table 2 shows how such harmful events were reported in the included trials.

- Two trials pooled not using the Barthel Index at a cut-off point of 50 points or a cut-off point of 85 to 100 points found no difference between comparison groups and the evidence was of low quality due to high risk of bias and very low number of events and smallness of sample sizes.

- No trial assessed the effects of interventions over the quality of life.

See Summary of findings 1 for details.

\section{Overall completeness and applicability of evidence}

This Cochrane Review has not found evidence that citicoline is useful for treating people with acute ischemic stroke. Although there were no trials at low risk of bias, this statement is based on either sensitivity analyses or subgroup analyses from trials that included a broad range of participants with different co-morbidities who received different treatment approaches. Furthermore, the Trial Sequential Analyses for citicoline versus placebo or no intervention showed that no more studies are required for assessing either all-cause mortality or degree of disability or dependence in daily activities according to the modified Rankin scale.

Only $40 \%$ of the trials included in this Cochrane Review reported sample size estimation a priori (Clark 1999; Clark 2001; ICTUS 2012; Warach 2000), which coincides with findings by other researchers (Chan 2008; Mhaskar 2012). Therefore, the clinical significance of the trials without a sample size estimation is uncertain (Alviarez 2007; Clark 1997; Ghosh 2015; Guillen 1995; Tazaki 1988). Also, these trials reported no threshold for detecting differences between comparison groups, which is a component for estimating the sample size (Mascha 2018; Sormani 2017).

Table 3 provides details related to the sample size, number of outcomes, and conclusions of the included trials in this Cochrane Review (Alviarez 2007; Clark 1997; Clark 1999; Clark 2001; Ghosh 2015; Guillen 1995; ICTUS 2012; Seifaddini 2017; Tazaki 1988; Warach 2000). Another pitfall found in the included trials is that one out of six trials that did not do a formal estimation of sample size reported two or more outcomes (Table 3), which could yield an increasing risk of false positives and false negatives: familywise error rate (Delorme 2016; Senn 2007; van der Laan 2004). By using Trial Sequential Analysis this review has determined an optimal information size providing sufficient protection to reduce overestimation or random errors (Thorlund 2011b). 
We were not able to do show a meta-analysis about the adverse events or harms with all the included trials. This could be for many reasons: a lack of standardization of definitions and analyses of the adverse events (Ioannidis 2014), the shortage of homogeneity and plenty of variability in reporting harm data (Ioannidis 2009; Pitrou 2009), the different times for conducting the trials (1988 to 2017), and failure to collect the harm data (Allen 2018; Yang 2019). Table 2 shows how this issue was reported in each included trial.

\section{Quality of the evidence}

Summary of findings 1 shows the quality of evidence for citicoline compared with placebo or standard treatment for treating people with acute ischemic stroke. We considered the quality of the evidence available for this comparison as low. This was due to unclear risk of bias in almost all domains of the trials for the outcomes assessed (all-cause mortality, degree of disability or dependence in daily activities, functional recovery, and neurological function). Due to limitations in design, execution, and imprecision (small low number of events leading to wide confidence intervals), the quality of evidence for serious adverse events was rated as low.

\section{Potential biases in the review process}

Both outcome reporting and attrition biases act as information suppressors, as does publication bias of any etiology (Ioannidis 2010). Based on this argument, the question arises: could the amount of effect of the intervention have been different if the percentage of those information suppressor biases had been different? It should be noted that there were three trials with loss of information that fluctuated between $16 \%$ and $23 \%$ (Alviarez 2007; ICTUS 2012; Warach 2000). Two of them were small trials, and therefore low powered for detecting differences between citicoline and the control groups (Alviarez 2007; Warach 2000). In addition, two clinical trials supplied no information to the preset outcomes of this Cochrane Review (Guillen 1995; Seifaddini 2017). If, on the basis of not providing information to the outcomes of this Cochrane Review, we had excluded two trials (Guillen 1995; Seifaddini 2017), the effect of the intervention would have been the same. This is explained by the fact that none of them provided information about the relevant pre-established clinical outcomes in this review. This would have introduced publication bias, however, from which this review is at low risk. This Cochrane Review rated $30 \%$ of trials as having unclear or high risk of selective outcome reporting bias and $50 \%$ of trials as having unclear or high risk of attrition bias (Figure 2; Figure 3). This is a limitation which is described and reflected in the quality of the evidence assessment (Summary of findings 1 ).

\section{Agreements and disagreements with other studies or reviews}

Our results are similar to six non-Cochrane Reviews and pooled analyses (Dávalos 2002; Lee 2010; Liu 2011; Saver 2002; Secades 2016; Shi 2016). We identified differences in their eligibility criteria with respect to our Cochrane Review: 1) participants suffering ischemic and hemorrhagic stroke (Lee 2010; Shi 2016); 2) inclusion of non-RCTs (Lee 2010; Secades 2016); 3) use of different scales for assessing clinical benefits of citicoline (Secades 2016); 4) RCTs with no imaging confirmation of stroke (Secades 2016; Shi 2016); 5) forest plot using the same placebo group three times in different subgroups for the same outcome (Shi 2016); and 6) use of odds ratio for measuring treatment effect (Dávalos 2002; Secades 2016; Shi 2016).

\section{AUTHORS' CONCLUSIONS}

\section{Implications for practice}

This review assessed the clinical benefits and harms of citicoline compared with placebo or any other standard treatment for people with acute ischemic stroke. The findings of the review suggest that, based on low-certainty evidence, there may be little to no difference between citicoline and its controls regarding all-cause mortality, disability or dependence in daily activities, functional recovery, neurological function and severe adverse events. None of the included trials assessed quality of life and the safety profile of citicoline remains unknown.

\section{Implications for research}

The harms profile of citicoline remains unknown, because the resulting evidence is of low quality due to limitations in the design and execution of the trials, the very low number of events, and the smallness of sample sizes, even after meta-analysis. The results provided by the Trial Sequential Analysis methodology support the conclusions of the best quality clinical trials included in this Cochrane Review. The question is, is there a need for a new study when none of the included RCTs reached the top line of statistical significance; that is, the $\mathrm{P}$ value (alpha error), the fundamental component for calculating the sample size? Even for the most important primary outcome of this Cochrane Review, all-cause mortality, the z-curve reached the area of futility with a cumulative $65 \%$ of the sample size estimation for Trial Sequential Analysis (4345/6667). This Cochrane Review found no trial assessing quality of life. We do not believe that this lack of information on the quality of life outcome justifies a well-powered randomized controlled trial comparing citicoline versus placebo in accordance with the Standard Protocol Items: Recommendations for Interventional Trials (SPIRIT 2013) and Consolidated Standards of Reporting Trials (CONSORT 2010) recommendations.

\section{ACKNOWLEDGEMENTS}

We express our gratitude to Joshua David Cheyne, Information Specialist, Cochrane Stroke Group who, along with Ivan Solà, designed and ran the search strategy. We thank Peter Langhorne, Daniel Bereczki, and Aryelly Rodriguez who participated in the peer-review process for improving the quality of this Cochrane Review.

We express our gratitude to Aryelly Rodriguez for allowing us to use the median calculator to express the accuracy of the assumed risk in the summary of findings.

We also express our gratitude to:

- Dr Shaukat Ali Jawaid, Chief Editor, Pakistan Journal of Medical Sciences for sending us the full text of Yusuf 2001;

- Dr Si Jia Zhu, Centre for Evidence-Based Chinese Medicine, Beijing University of Chinese Medicine, Beijing, China, for translating all the Chinese studies;

- Dr María M González Yibirín, co-author of Alviarez 2007, for sending relevant information about the trial. 
In addition, we thank Cochrane's Copy Edit Support Team for its work in preparing this review for publication. 


\section{RE F E R E N C E S}

\section{References to studies included in this review}

Alviarez 2007 \{published data only\}

Alvairez E, Gonzalez M. Effectiveness and tolerability of citicoline in acute ischemic stroke, randomized, double-blind study compared with placebo [Efectividad y tolerabilidad de la citicolina en el ictus isquémico agudo, estudio aleatorizado, doble ciego comparado con placebo]. Archivos Venezolanos de Farmacología y Terapéutica 2007;26(2):127-30. [ISSN 0798-0264]

\section{Clark 1997 \{published data only\}}

Clark WM, Warach SJ, Pettigrew LC, Gammans RE, Sabounjian LA, Citicoline Stroke Study Group. A randomized dose-response trial of citicoline in acute ischemic stroke patients. Neurology 1997;49(3):671-8. [PMID: 9305321]

\section{Clark 1999 \{published data only\}}

Clark WM, Williams BJ, Selzer KA, Zweifler RM, Sabounjian LA, Gammans RE. A randomized efficacy trial of citicoline in patients with acute ischemic stroke. Stroke 1999;30(12):2592-7. [PMID: 10582983]

\section{Clark 2001 \{published data only\}}

Clark WM, Wechsler LR, Sabounjian LA, Schwiderski UE. A phase III randomized efficacy trial of $2000 \mathrm{mg}$ citicoline in acute ischemic stroke patients. Neurology 2001;57(9):1595-602. [PMID: 11706098]

\section{Ghosh 2015 \{published data only\}}

Ghosh S, Das SK, Nath T, Ghosh KC, Bhattacharyya R, Mondal GP. The effect of citicoline on stroke: a comparative study from the Eastern part of India. Neurology India 2015;63(5):697-701. [PMID: 26448227]

\section{Guillen 1995 \{published data only\}}

Guillen F, Buendia C, Herrera J. CDP-choline in the treatment of acute ischaemic stroke. Journal of Neurology 1995;242 Suppl 2:S76.

\section{ICTUS 2012 \{published data only\}}

Dávalos A, Alvarez-Sabín J, Castillo J, Díez-Tejedor E, Ferro J, Martínez-Vila E, International Citicoline Trial on acUte Stroke (ICTUS) trial investigators. Citicoline in the treatment of acute ischaemic stroke: an international, randomised, multicentre, placebo-controlled study (ICTUS trial). Lancet 2012;380(9839):349-57. [PMID: 22691567]

\section{Seifaddini 2017 \{published data only\}}

Seifaddini R, Moghadam AH, Iranmanesh F, Arvan H, Naghibzadeh-Tahami A. The effects of citicoline on cerebrovascular hemodynamic status in ischemic stroke patients. Journal of Kerman University of Medical Sciences 2017;24(6):480-6.

\section{Tazaki 1988 \{published data only\}}

Tazaki Y, Sakai F, Otomo E, Kutsuzawa T, Kameyama M, Omae T, et al. Treatment of acute cerebral infarction with a choline precursor in a multicenter double-blind placebo-controlled study. Stroke 1988;19(2):211-6. [PMID: 3278412]
Warach 2000 \{published data only\}

Warach S, Pettigrew LC, Dashe JF, Pullicino P, Lefkowitz DM, Sabounjian L, Citicoline 010 Investigators. Effect of citicoline on ischemic lesions as measured by diffusion-weighted magnetic resonance imaging. Annals of Neurology 2000;48(5):713-22. [PMID: 11079534]

\section{References to studies excluded from this review}

\section{Dereux 1987 \{published data only\}}

Dereux J-F, Gallois P. Comparison of the results with corticotrophin and citicoline in the initial stage of cerebral infarction. Gazette Medicale 1987;94(4):82-5. [CN-00324812]

\section{Djoenady 1981 \{published data only\}}

Djoenaidi W, Susilo H, Hakim AA, Batubara A, Koentioro EA. A double-blind controlled trial of cytidine-diphosphatecholine (CDPcholine) on thrombotic stroke patients. 12th World Congress of Neurology, Kyoto (Japan), September (Abstract 869) 1981.

\section{ECCS- AIS 2012 \{published data only\}}

Goel D. ECCT-HIS. Edaravone-Citicoline comparative trial in head injury and stroke. Available at www.strokecenter.org/ trials/clinicalstudies/edaravone-citicoline-comparative-trial-inhead-injury-and-stroke.

* Mittal M, Goel D, Bansal KK, Puri P. Edaravone - citicoline comparative study in acute ischemic stroke (ECCS-AIS). Journal of the Association of Physicians of India 2012;60(11):36-8. [PMID: 23767201]

\section{Garcia Pastor 2004 \{published data only\}}

Garcia Pastor A, Diaz Otero F, Gil Nunez AC, Villanueva Osorio JA. Tolerability and efficacy of the combination of piracetam and citicoline in acute ischemic stroke. A randomized comparative open study. Stroke 2004;35(6):e286.

\section{Goas 1980 \{published data only\}}

Goas JY, Bastard J, Missoum A. Results after 90 days of stroke treatment with CDP-choline concerning a double-blind test [Bilan a 90 jours du traitement des accidents vasculaires cerebraux par la CDP-choline. A propos d' un essai en double insu]. International Symposium. Brain Suffering and Precursor of Phospholipids. Paris 1980, January 18;109-21. 1980:123-8.

Melnikova 2011 \{published data only\}

Melnikova EV, Shmonin AA, Kulagin PA, Stukova LN, Mischenko KA. Neuroprotection effectiveness depends on the size and location of the ischemic stroke focus. Cerebrovascular Diseases 2011;31 Suppl 2:132.

Panteleienko 2009 \{published data only\}

Panteleienko L, Sokolova L. Patients treated with citicoline in acute phase of ischemic stroke report better quality of life. European Journal of Neurology 2009;16(S3):412. 


\section{References to studies awaiting assessment}

Hassan 2019 \{published data only\}

Hassan A, Hassoun HK, Sameer A, Hadi NR, Allebban Z. Effect of citicoline on cerebral hemodynamics and vasoreactivity using transcranial doppler in acute ischemic stroke patients: clinical trial. International Journal of Pharmaceutical Research 2019;11(2):262-9. [DOI: 10.31838/ijpr/2019.11.02.045]

\section{References to ongoing studies}

\section{CTRI/2018/02/011900 \{published data only\}}

Agarwal A, Vishnu VY, Bhatia R, Goyal V, Singh MB, Joseph L, et al. [Abstract 431] Citicoline in acute ischemic stroke - a randomized control trial. International Journal of Stroke 2018;13(2S):104

\section{IRCT201601289014N90 \{published data only\}}

Ongoing study. Expected recruitment start date: 20 February 2016Expected recruitment end date: 18 February 2017. Contact author for more information.

\section{Additional references}

\section{Allen 2018}

Allen EN, Chandler Cl, Mandimika N, Leisegang C, Barnes K. Eliciting adverse effects data from participants in clinical trials. Cochrane Database of Systematic Reviews 2018, Issue 1. Art. No: MR000039. [DOI: 10.1002/14651858.MR000039.pub2] [PMID: 29372930]

\section{Altman 1998}

Altman DG, Deeks JJ, Sackett DL. Odds ratios should be avoided when events are common. BMJ 1998;317(7168):1318. [PMID: 9804732]

\section{Astrup 1981}

Astrup J, Siesjo BK, Symon L. Thresholds in cerebral ischemia - the ischemic penumbra. Stroke 1981;12(6):723-5. [PMID: 6272455]

\section{Astrup 1982}

Astrup J. Energy-requiring cell functions in the ischemic brain. Their critical supply and possible inhibition in protective therapy. Journal of Neurosurgery 1982;56(4):482-97. [PMID: 6278105]

\section{Atkins 2004}

Atkins D, Best D, Briss PA, Eccles M, Falck-Ytter Y, Flottorp S, et al. GRADE Working Group. Grading quality of evidence and strength of recommendations. BMJ 2004;328(7454):1490. [PMID: 15205295]

\section{Avarez-Sabín 2013}

Ávarez-Sabín J, Román GC. The role of citicoline in neuroprotection and neurorepair in ischemic stroke. Brain Sciences 2013;3(3):1395-414. [PMID: 24961534]

\section{Barnes 1998}

Barnes DE, Bero LA. Why review articles on the health effects of passive smoking reach different conclusions. JAMA 1998;279(19):1566-70. [PMID: 9605902]

\section{Bath 2011}

Bath P, Hogg C, Tracy M, Pocock S. Calculation of numbersneeded-to-treat in parallel group trials assessing ordinal outcomes: case examples from acute stroke and stroke prevention. International Journal of Stroke 2011;6(6):472-9. [PMID: 21645271]

\section{Bath 2012}

Bath PM, Lees KR, Schellinger PD, Altman H, Bland M, Hogg C, et al. Statistical analysis of the primary outcome in acute stroke trials. Stroke 2012;43(4):1171-8. [PMID: 22426314]

\section{Bland 2000}

Bland JM, Altman DG. Statistics notes. The odds ratio. BMJ 2000;320(7247):1468. [PMID: 10827061]

\section{Brok 2008}

Brok J, Thorlund K, Gluud C, Wetterslev J. Trial Sequential Analysis reveals insufficient information size and potentially false positive results in many meta-analyses. Journal of Clinical Epidemiology 2008;61(8):763-9. [PMID: 18411040]

\section{Brok 2009}

Brok J, Thorlund K, Wetterslev J, Gluud C. Apparently conclusive meta-analyses may be inconclusive: Trial Sequential Analysis adjustment of random error risk due to repetitive testing of accumulating data in apparently conclusive neonatal meta-analyses. International Journal of Epidemiology 2009;38(1):287-98. [PMID: 18824466]

\section{Carroll 2011}

Carroll DG. Functional evaluation: the Barthel index. www.strokecenter.org/wp-content/uploads/2011/08/ barthel_reprint.pdf (accessed 25 May 2017).

\section{Cassella 2017}

Cassella CR, Jagoda A. Ischemic stroke: advances in diagnosis and management. Emergency Medicine Clinics of North America 2017;35(4):911-30. [PMID: 28987436]

\section{Chaimani 2014}

Chaimani A, Mavridis D, Salanti G. A hands-on practical tutorial on performing meta-analysis with Stata. Evidence-based Mental Health 2014;17(4):111-6. [PMID: 25288685]

\section{Chan 2008}

Chan AW, Hrobjartsson A, Jorgensen KJ, Gotzsche PC, Altman DG. Discrepancies in sample size calculations and data analyses reported in randomised trials: comparison of publications with protocols. BMJ 2008;337:a2299. [PMID: 19056791]

\section{Chen 2016}

Chen X, Wang K. The fate of medications evaluated for ischemic stroke pharmacotherapy over the period 1995-2015. Acta Pharmaceutica Sinica B 2016;6(6):522-30. [PMID: 27818918] 


\section{Clark 2009}

Clark WM. Efficacy of citicoline as an acute stroke treatment. Expert Opinion on Pharmacotherapy 2009;10(5):839-46. [PMID: $19351232]$

\section{CONSORT 2010}

CONSORT. Consolidated Standards of Reporting Trials. www.consort-statement.org/ (accessed 8 July 2020).

\section{CTU 2011}

Copenhagen Trial Unit. TSA - Trial Sequential Analysis. ctu.dk/ tsa/ (accessed 25 May 2017).

\section{Dávalos 2002}

Dávalos A, Castillo J, Alvarez-Sabin J, Secades JJ, Mercadal J, Lopez S, et al. Oral citicoline in acute ischemic stroke: an individual patient data pooling analysis of clinical trials. Stroke 2002;33(12):2850-7. [PMID: 12468781]

\section{Davies 1998}

Davies HT, Crombie IK, Tavakoli M. When can odds ratios mislead? BMJ 1998;316(7136):989-91. [PMID: 9550961]

\section{Deeks 2017}

Deeks JJ, Higgins JPT, Altman DG (editors) on behalf of the Cochrane Statistical Methods Group. Chapter 9: Analysing data and undertaking meta-analyses. In: Higgins JPT, Churchill R, Chandler J, Cumpston MS (editors), Cochrane Handbook for Systematic Reviews of Interventions version 5.2.0 (updated June 2017), Cochrane, 2017.The Cochrane Collaboration, 2017. Available from www.training.cochrane.org/handbook.

\section{Delorme 2016}

Delorme P, de Micheaux PL, Liquet B, Riou J. Type-II generalized family-wise error rate formulas with application to sample size determination. Statistics in Medicine 2016;35(16):2687-714. [PMID: 26914402]

\section{Dienes 2008}

Dienes Z. Understanding Psychology as a Science: An Introduction to Scientific and Statistical Inference. 1st edition. London: Palgrave Macmillan, 2008. [9780230542303]

\section{Dienes 2014}

Dienes Z. Using Bayes to get the most out of non-significant results. Frontiers in Psychology 2014;5:781. [DOI: 10.3389/ fpsyg.2014.00781] [PMC4114196]

\section{Dienes 2018}

Dienes Z, Mclatchie N. Four reasons to prefer Bayesian analyses over significance testing. Psychonomic Bulletin and Review 2018;25(1):207-18. [PMID: 28353065]

\section{FDA 2019}

US Food and Drug Administration. www.fda.gov/inspectionscompliance-enforcement-and-criminal-investigations/warningletters/pure-nootropics-llc-565425-02052019 2019.

\section{Friedrich 2011}

Friedrich JO, Adhikari NK, Beyene J. Ratio of means for analyzing continuous outcomes in meta-analysis performed as well as mean difference methods. Journal of Clinical Epidemiology 2011;64(5):556-64. [PMID: 21447428]

\section{Furukawa 1999}

Furukawa TA. From effect size into number needed to treat. Lancet 1999;353(9165):1680. [PMID: 10335798]

\section{Furukawa 2011}

Furukawa TA, Leucht S. How to obtain NNT from Cohen's d: comparison of two methods. PLoS One 2011;6(4):e19070. [PMID: 21556361]

\section{Gamble 2005}

Gamble C, Hollis S. Uncertainty method improved on bestworst case analysis in a binary meta-analysis. Journal of Clinical Epidemiology 2005;58(6):579-88. [PMID: 15878471]

\section{Goodman 1999}

Goodman SN. Toward evidence-based medical statistics. 2: The Bayes factor. Annals of Internal Medicine 1999;130(12):1005-13. [PMID: 10383350]

\section{Goodman 2005}

Goodman SN. Introduction to Bayesian methods I: measuring the strength of evidence. Clinical Trials 2005;2(4):282-90. [PMID: 16281426]

\section{GRADEpro GDT 2015 [Computer program]}

McMaster University (developed by Evidence Prime) GRADEpro GDT. Version accessed 29 May 2018. Hamilton (ON): McMaster University (developed by Evidence Prime), 2015. Available at gradepro.org.

\section{Grieb 2014}

Grieb P. Neuroprotective properties of citicoline: facts, doubts and unresolved issues. CNS Drugs 2014;28(3):185-93. [PMID: 24504829 ]

\section{Hankey 2017}

Hankey GJ. Stroke. Lancet 2017;389(10069):641-54. [PMID: 27637676]

\section{Harrison 2013}

Harrison JK, McArthur KS, Quinn TJ. Assessment scales in stroke: clinimetric and clinical considerations. Clinical Interventions in Aging 2013;8:201-11. [PMID: 23440256]

\section{Higgins 2003}

Higgins JP, Thompson SG, Deeks JJ, Altman DG. Measuring inconsistency in meta-analyses. BMJ 2003;327(7414):557-60. [PMID: 12958120]

\section{Higgins 2011a}

Higgins JP, Green S, editor(s). Cochrane Handbook for Systematic Reviews of Interventions Version 5.1.0 (updated March 2011). The Cochrane Collaboration, 2011. Available from handbook.cochrane.org.

\section{Higgins 2011b}

Higgins JP, Deeks JJ, editor(s). Chapter 7: Selecting studies and collecting data. In: Higgins JP, Green S editor(s). Cochrane 
Handbook for Systematic Reviews of Interventions Version 5.1.0 (updated March 2011). The Cochrane Collaboration, 2011. Available from handbook.cochrane.org.

\section{Higgins 2011c}

Higgins JP, Altman DG, Sterne JA, editor(s). Chapter 8: Assessing risk of bias in included studies. In: Higgins JP, Green S editor(s). Cochrane Handbook for Systematic Reviews of Interventions. Version 5.1.0 (updated March 2011). The Cochrane Collaboration. Available from handbook.cochrane.org.

\section{Higgins 2019}

Higgins JPT, Li T, Deeks JJ (editors). Chapter 6: Choosing effect measures and computing estimates of effect. In: Higgins JPT, Thomas J, Chandler J, Cumpston M, Li T, Page MJ, Welch VA, editors(s). Cochrane Handbook for Systematic Reviews of Interventions. 2nd edition. Chichester (UK): John Wiley \& Sons, 2019:143-176.

\section{Hillis 2015}

Hillis AE, Baron JC. Editorial: the ischemic penumbra: still the target for stroke therapies? Frontiers in Neurology 2015;6:85. [PMID: 25954244]

\section{Hoffmann 2014}

Hoffmann TC, Glasziou PP, Boutron I, Milne R, Perera R, Moher D, et al. Better reporting of interventions: template for intervention description and replication (TIDieR) checklist and guide. BMJ 2014;348:g1687. [PMID: 24609605]

\section{Hoffmann 2017}

Hoffmann TC, Oxman AD, loannidis JP, Moher D, Lasserson TJ, Tovey DI, et al. Enhancing the usability of systematic reviews by improving the consideration and description of interventions. BMJ 2017;357:j2998. [PMID: 28729459]

\section{Hollis 1999}

Hollis S, Campbell F. What is meant by intention to treat analysis? Survey of published randomised controlled trials. BMJ (Clinical Research Ed) 1999;319(7211):670-4. [PMID: 10480822]

\section{Imberger 2015}

Imberger G, Gluud C, Boylan J, Wetterslev J. Systematic reviews of anesthesiologic interventions reported as statistically significant: problems with power, precision, and type 1 error protection. Anesthesia and Analgesia 2015;121(6):1611-22. [PMID: 26579662]

\section{Imberger 2016}

Imberger G, Thorlund K, Gluud C, Wetterslev J. False-positive findings in Cochrane meta-analyses with and without application of Trial Sequential Analysis: an empirical review. BMJ Open 2016;6(8):e011890. [PMID: 27519923]

\section{IntHout 2016}

IntHout J, loannidis JP, Rovers MM, Goeman JJ. Plea for routinely presenting prediction intervals in meta-analysis. $B M J$ Open 2016;6(7):e010247. [PMID: 27406637]

\section{loannidis 2009}

Ioannidis JP. Adverse events in randomized trials: neglected, restricted, distorted, and silenced. Archives of Internal Medicine 2009;169(19):1737-9. [PMID: 19858427]

\section{loannidis 2010}

Ioannidis JP. Meta-research: The art of getting it wrong. Research synthesis methods 2010;1(3-4):169-84. [PMID: 26061464]

\section{loannidis 2014}

Ioannidis JP. How to make more published research true. PLoS Medicine 2014;11(10):e1001747. [PMID: 25334033]

\section{Jakobsen 2014}

Jakobsen JC, Wetterslev J, Winkel P, Lange T, Gluud C. Thresholds for statistical and clinical significance in systematic reviews with meta-analytic methods. BMC Medical Research Methodology 2014;14:120. [PMID: 25416419]

\section{Johnston 2016}

Johnston BC, Alonso-Coello P, Friedrich JO, Mustafa RA, Tikkinen KA, Neumann I, et al. Do clinicians understand the size of treatment effects? A randomized survey across 8 countries. Canadian Medical Association Journal 2016;188(1):25-32. [PMID: 26504102]

\section{Lan 1983}

Lan GK, DeMets DL. Discrete sequential boundaries for clinical trials. Biometrika 1983;70(3):659-63. [DOI: 10.1093/ biomet/70.3.659]

\section{Laupacis 1988}

Laupacis A, Sackett DL, Roberts RS. An assessment of clinically useful measures of the consequences of treatment. New England Journal of Medicine 1988;318(26):1728-33. [PMID: 3374545]

\section{Lee 2010}

Lee M, Towfighi A, Saver JL. Choline precursors in acute and subacute ischemic and hemorrhagic stroke: an updated meta-analysis of randomized controlled trials. Stroke 2010;41 (4):e263 (Abstract 33).

\section{Lefebvre 2011}

Lefebvre C, Manheimer E, Glanville J. Chapter 6: Searching for studies. In: Higgins JP, Green S, editor(s). Cochrane Handbook for Systematic Reviews of Interventions Version 5.1.0 (updated March 2011). The Cochrane Collaboration, 2011. Available from handbook.cochrane.org.

\section{Lineberry 2016}

Lineberry N, Berlin JA, Mansi B, Glasser S, Berkwits M, Klem C, et al. Recommendations to improve adverse event reporting in clinical trial publications: a joint pharmaceutical industry/ journal editor perspective. BMJ 2016;355:i5078. [PMID: 27697753] 


\section{Liu 2011}

Liu L, Shi Z, Yan Q, Guo J. Cytidine diphosphate choline for acute stroke: a meta-analysis. Chinese Journal of Evidencebased Medicine 2011;11(4):404-12.

\section{Lundh 2017}

Lundh A, Lexchin J, Mintzes B, Schroll JB, Bero L. Industry sponsorship and research outcome. Cochrane Database of Systematic Reviews 2017, Issue 2. Art. No: MR000033. [DOI: 10.1002/14651858.MR000033.pub3]

\section{Mahoney 1965}

Mahoney FI, Barthel DW. Functional evaluation: the Barthel index. Maryland State Medical Journal 1965;14:61-5. [PMID: 14258950]

\section{Manning 2014}

Manning NW, Campbell BC, Oxley TJ, Chapot R. Acute ischemic stroke: time, penumbra, and reperfusion. Stroke 2014;45(2):640-4. [PMID: 24399376]

\section{Martynov 2015}

Martynov MY, Gusev EJ. Current knowledge on the neuroprotective and neuroregenerative properties of citicoline in acute ischemic stroke. Journal of Experimental Pharmacology 2015;7:17-28. [PMID: 27186142]

\section{Mascha 2018}

Mascha EJ, Vetter TR. Significance, errors, power, and sample size: The blocking and tackling of statistics. Anesthesia and Analgesia 2018;126(2):691-8. [PMID: 29346210]

\section{McArthur 2014}

McArthur KS. Improving efficiency in stroke trials: an exploration of methods to improve the use of the modified Rankin Scale in acute stroke trials. theses.gla.ac.uk/5350 2014:1-261.

\section{Mhaskar 2012}

Mhaskar R, Djulbegovic B, Magazin A, Soares HP, Kumar A. Published methodological quality of randomized controlled trials does not reflect the actual quality assessed in protocols. Journal of Clinical Epidemiology 2012;65(6):602-9. [PMID: 22424985]

\section{NIHSS}

NIH Stroke Scale/Score (NIHSS). www.mdcalc.com/nih-strokescale-score-nihss (accessed 6 April 2018).

\section{Overgaard 2014}

Overgaard K. The effects of citicoline on acute ischemic stroke: a review. Journal of Stroke and Cerebrovascular Diseases 2014;23(7):1764-9. [PMID: 24739589]

\section{Patel 2017}

Patel RA, McMullen PW. Neuroprotection in the treatment of acute ischemic stroke. Progress in Cardiovascular Diseases 2017;59(6):542-8. [PMID: 28465001]

\section{Peters 2008}

Peters JL, Sutton AJ, Jones DR, Abrams KR, Rushton L. Contour-enhanced meta-analysis funnel plots help distinguish publication bias from other causes of asymmetry. Journal of Clinical Epidemiology 2008;61(10):991-6. [PMID: 18538991]

\section{Pitrou 2009}

Pitrou I, Boutron I, Ahmad N, Ravaud P. Reporting of safety results in published reports of randomized controlled trials. Archives of Internal Medicine 2009;169(19):1756-61. [PMID: 19858432]

\section{Porta 2014}

Porta M. A Dictionary of Epidemiology. 6th edition. New York: Oxford University Press, 2014. [ISBN 978-0-19-997672-0]

\section{Portegies 2016}

Portegies ML, Koudstaal PJ, Ikram MA. Cerebrovascular disease. In: Aminoff MJ, Boller F, Swaa DF, editors(s). Handbook of Clinical Neurology. Vol. 138. Radarweg, Amsterdam, Netherlands: Elsevier, 2016:239-61. [ISBN: 978-0-12-802973-2] [PMID: 27637962]

\section{Rajah 2017}

Rajah GB, Ding Y. Experimental neuroprotection in ischemic stroke: a concise review. Neurosurgical Focus 2017;42(4):E2. [PMID: 28366067]

\section{Review Manager 2014 [Computer program]}

Nordic Cochrane Centre, The Cochrane Collaboration Review Manager 5 (RevMan 5). Version 5.3. Copenhagen: Nordic Cochrane Centre, The Cochrane Collaboration, 2014.

\section{Riley 2011}

Riley RD, Higgins JP, Deeks JJ. Interpretation of random effects meta-analyses. BMJ 2011;342:d549. [PMID: 21310794]

\section{Sackett 1996}

Sackett DL, Deeks J, Altman DG. Down with odds ratios! Evidence-based Medicine 1996;1:164-6.

\section{Saver 2002}

Saver JL, Wilterdink J. Choline precursors in acute and subacute human stroke: a meta-analysis. Stroke 2002;33(1):353.

\section{Schünemann 2011a}

Schünemann HJ, Oxman AD, Vist GE, Higgins JP, Deeks JJ, Glasziou P, et al. Chapter 12: Interpreting results and drawing conclusions. In: Higgins JP, Green S, editor(s). Cochrane Handbook for Systematic Reviews of Interventions Version 5.1.0 (updated March 2011). The Cochrane Collaboration, 2011. Available from handbook.cochrane.org.

\section{Schünemann 2011b}

Schünemann HJ, Oxman AD, Vist GE, Higgins JP, Deeks JJ, Glasziou P, et al In: Higgins JP, Green S, editor(s) Cochrane Handbook for Systematic Reviews of Interventions Version 510 (updated March 2011) The Cochrane Collaboration, 2011. Chapter 11: Interpreting results and drawing conclusions. Available from handbook.cochrane.org. 


\section{Scott 1997}

Scott SC, Goldberg MS, Mayo NE. Statistical assessment of ordinal outcomes in comparative studies. Journal of Clinical Epidemiology 1997;50(1):45-55. [PMID: 9048689]

\section{Secades 2016}

Secades JJ, Alvarez-Sabin J, Castillo J, Diez-Tejedor E, MartinezVila E, Rios J, et al. Citicoline for acute ischemic stroke: a systematic review and formal meta-analysis of randomized, double-blind, and placebo-controlled trials. Journal of Stroke and Cerebrovascular Diseases 2016;25(8):1984-96. [PMID: 27234918]

\section{Senn 2007}

Senn S, Bretz F. Power and sample size when multiple endpoints are considered. Pharmaceutical Satistics 2007;6(3):161-70. [PMID: 17674404]

\section{Shi 2016}

Shi PY, Zhou XC, Yin XX, Xu LL, Zhang XM, Bai HY. Early application of citicoline in the treatment of acute stroke: $A$ meta-analysis of randomized controlled trials. Journal of Huazhong University of Science and Technology. Medical Sciences 2016;36(2):270-7. [MEDLINE: 27072975 ]

\section{Sormani 2017}

Sormani MP. The most frequently asked question to a statistician: the sample size. Multiple Sclerosis 2017;23(5):644-6. [PMID: 28273773]

\section{SPIRIT 2013}

SPIRIT. Standard Protocol Items: Recommendations for Interventional Trials. www.spirit-statement.org/ (accessed 8 July 2020).

\section{STATA}

StataCorp LLC. Stata 14. www.stata.com.

\section{Sterne 2001}

Sterne JA, Bradburn MJ, Egger M. Meta-analysis in StataTM . In: Egger M, Smith DS, and Altman DG, editors(s). Systematic Reviews in Health Care: Meta-analysis in Context. 2nd edition. London (UK): BMJ Books, 2001:347-69. [978-0-7279-1488-0]

\section{Sterne 2011}

Sterne JA, Sutton AJ, Ioannidis JP, Terrin N, Jones DR, Lau J, et al. Recommendations for examining and interpreting funnel plot asymmetry in meta-analyses of randomised controlled trials. BMJ 2011;343:d4002. [PMID: 21784880]

\section{Thorlund 2010}

Thorlund K, Anema A, Mills E. Interpreting meta-analysis according to the adequacy of sample size. An example using isoniazid chemoprophylaxis for tuberculosis in purified protein derivative negative HIV-infected individuals. Clinical Epidemiology 2010;2:57-66. [PMID: 20865104]

\section{Thorlund 2011a}

Thorlund K, Engstrøm J, Wetterslev J, Brok J, Imberger G, Gluud C. User manual for Trial Sequential Analysis (TSA). ctu.dk/ tsa/files/tsa_manual.pdf 2011 (accessed 6 March 2017).

\section{Thorlund 2011b}

Thorlund K, Imberger G, Walsh M, Chu R, Gluud C, Wetterslev J, et al. The number of patients and events required to limit the risk of overestimation of intervention effects in meta-analysis--a simulation study. PloS One 2011;6(10):e25491. [PMID: 22028777]

\section{van der Laan 2004}

van der Laan MJ, Dudoit S, Pollard KS. Augmentation procedures for control of the generalized family-wise error rate and tail probabilities for the proportion of false positives. Statistical Applications in Genetics and Molecular Biology 2004;3:Article 15. [PMID: 16646793]

\section{van Swieten 1988}

van Swieten JC, Koudstaal PJ, Visser MC, Schouten HJ, van Gijn J. Interobserver agreement for the assessment of handicap in stroke patients. Stroke 1988;19(5):604-7. [PMID: 3363593]

\section{Wang 2016}

Wang H, Naghavi M, Allen C, Barber RM, Bhutta ZA, Carter A, GBD 2015 Mortality and Causes of Death Collaborators. Global, regional, and national life expectancy, all-cause mortality, and cause-specific mortality for 249 causes of death, 1980-2015: a systematic analysis for the Global Burden of Disease Study 2015. Lancet 2016;388:1459-544. [PMID: 27733281 ]

\section{Wang 2017}

Wang Y, Liu H, Lin Y, Liu G, Chu H, Zhao P, et al. Network-based approach to identify potential targets and drugs that promote neuroprotection and neurorepair in acute ischemic stroke. Scientific Reports 2017;7:40137. [PMID: 28054643]

\section{Wardlaw 2014}

Wardlaw JM, Murray V, Berge E, del Zoppo JG. Thrombolysis for acute ischaemic stroke. Cochrane Database of Systematic Reviews 2014, Issue 7. Art. No: CD000213. [DOI: 10.1002/14651858.CD000213.pub3]

\section{Wetterslev 2008}

Wetterslev J, Thorlund K, Brok J, Gluud C. Trial Sequential Analysis may establish when firm evidence is reached in cumulative meta-analysis. Journal of Clinical Epidemiology 2008;61(1):64-75. [PMID: 18083463]

\section{Wetterslev 2009}

Wetterslev J, Thorlund K, Brok J, Gluud C. Estimating required information size by quantifying diversity in random-effects model meta-analyses. BMC Medical Research Methodology 2009;9:86. [PMID: 20042080]

\section{Wetterslev 2017}

Wetterslev J, Jakobsen JC, Gluud C. Trial Sequential Analysis in systematic reviews with meta-analysis. BMC Medical Research Methodology 2017;17(1):39. [PMID: 28264661]

\section{Yan 2017}

Yan LL, Li C, Chen J, Luo R, Bettger J, Zhu Y, et al. Stroke. In: Prabhakaran D, Anand S, Gaziano TA, Mbanya JC, Wu Y, Nugent R, editors(s). Disease Control Priorities (openknowledge.worldbank.org/handle/10986/28875). 3rd 
edition. Vol. 5. Washington (DC): World Bank, 2017:157-76. [ISBN (electronic): 978-1-4648-0520-2]

\section{Yang 2019}

Yang F, Wittes J, Pitt B. Beware of on-treatment safety analyses. Clinical Trials 2019;16(1):63-70. [PMID: 30445833]

\section{References to other published versions of this review Marti-Carvajal 2018}

Marti-Carvajal AJ, Valli C, Sola I, Marti-Fabregas J, Bonfill Cosp X. Citicoline for treating people with acute ischemic stroke.

Cochrane Database of Systematic Reviews 2018, Issue 7. Art. No: CD013066. [DOI: 10.1002/14651858.CD013066]

* Indicates the major publication for the study

\section{CHARACTERISTICS OF STUDIES}

Characteristics of included studies [ordered by study ID]

Alviarez 2007

\section{Study characteristics}

- Pethods $\quad$ - Multicenter study: no (1 center)
- International: no
- Country: Venezuela
- Treatment duration: 6 weeks
- Follow-up period: not reported
- Timing for starting citicoline treatment: unclear
- Type of trial (superiority, equivalence or non-inferiority trial): not reported

\footnotetext{
Participants

- Randomized: 77

- Citicoline group: 38

- Placebo group: 39

- Analyzed: 65

- Citicoline group: 31

- Placebo group: 34

- Age (likely mean; dispersion measure not described)

- Citicoline group: 69.23 (10.7)

- Placebo group: 70.38 (11.1)

- Sex (men, \%):

- Citicoline group: $58.06(18 / 31)$

- Placebo group: 44.11 (15/34)

- National Institutes of Health Stroke Scale: not stated

- Stroke evolution time (likely mean; dispersion measure not described)

- Citicoline group: 6.1 (1.7) hours

- Placebo group: 6 (1.63) hours

- Systolic blood pressure (likely mean; dispersion measure not described)

- Citicoline group:156.13 (19.4) (mmHg)

- Placebo group: 154.74 (21.85) (mmHg)

- Diastolic blood pressure (likely mean; dispersion measure not described)

- Citicoline group: 96.03 (14.4) (mmHg)

- Placebo group: 95.88 (14.59) (mmHg)

- Blood hypertension

- Citicoline group: $59 \%$

- Placebo group: $65 \%$

- TIA

- Citicoline group: $35.5 \%$
} 
Alviarez 2007 (Continued)

- Placebo group: $41.6 \%$

- Diabetes Mellitus

- Citicoline group: $13 \%$

- Placebo group: $23.5 \%$

- Smoking history

- Citicoline group: $5 \%$

- Placebo group: $8.8 \%$

- Inclusion criteria

- Any age

- Diagnosis of acute Ischemic stroke of middle cerebral artery origin, defined by neuroimaging studies with a time of evolution of less than 8 hours (therapeutic window)

- National Institutes of Health Stroke Scale $\geq 5$ with at least 2 points in the motor sections

- Ambulatory and functionally independent before the accident

- Reliable in terms of taking the medication

- Informed consent accepted

- Exclusion criteria

- Intracerebral hemorrhage, or intraparenchymal cerebral hemorrhage

- Chronic liver disease

- Chronic kidney disease

- Chronic heart failure

- Patients taking clonidine, reserpine, methyldopa, antiepileptics, antidepressants or neuroleptics

- Patients with psychosis, brain tumor, vascular malformations, cardiac arrhythmias, toxic metabolic encephalopathy

- Patients with recent or planned thrombolytic therapy

Interventions

- Experimental: citicoline, $2000 \mathrm{mg}$, endovenous by day $(2 \times 500 \mathrm{mg}$ ampoules) during 3 days. Then, 2 tablets $(2 \times 500 \mathrm{mg})$ oral/ twice during 6 weeks. No information was supplied regarding drug manufacture company

- Control: placebo (not described)

- Co-intervention: antiplatelet agent (acetylsalicylic acid, $325 \mathrm{mg}$, calcium channel blockers (90 mg), vitamin $\mathrm{E}(400 \mathrm{mg})$

Trial author stated no information about calcium channel blockers and vitamin $\mathrm{E}$.

Treatment duration: 6 weeks.

\section{Outcomes}

Outcomes were not classified as primary or secondary: degree of disability or dependence in daily activities according to the modified Rankin scale, functional recovery assessed with the Barthel Index, and neurological function assessed with the National Institutes of Health Stroke Scale (NIHSS), and cerebral neuroimaging

- Identifier trial number register: not stated
- Trial conduction dates: not given
- A priori sample estimation: no
- Financial disclosures: it was not stated tacitly or explicitly. However, 1 trial author had links with Lab-
oratorios Leti, S.A.V.
- Other disclosures: none
- Funding/support: not stated tacitly or explicitly

\section{Risk of bias}

\begin{tabular}{lll}
\hline Bias & Authors' judgement & Support for judgement \\
\hline $\begin{array}{ll}\text { Random sequence genera- } \\
\text { tion (selection bias) }\end{array}$ & Unclear risk & $\begin{array}{l}\text { Quote: "Patients were allocated in two groups: citicoline and placebo" (Page } \\
128, \text { translated from Spanish) }\end{array}$ \\
\hline
\end{tabular}


Alviarez 2007 (Continued)

Insufficient information to permit judgment of 'low risk' or 'high risk'

There is imbalance between groups regarding transient cerebrovascular disease history, diabetes mellitus, and smoking history

\begin{tabular}{|c|c|c|}
\hline $\begin{array}{l}\text { Allocation concealment } \\
\text { (selection bias) }\end{array}$ & Unclear risk & $\begin{array}{l}\text { There was no mention about allocation concealment } \\
\text { Insufficient information to permit judgment of 'low risk' or 'high risk' }\end{array}$ \\
\hline $\begin{array}{l}\text { Blinding of participants } \\
\text { and personnel (perfor- } \\
\text { mance bias) } \\
\text { All outcomes }\end{array}$ & Unclear risk & $\begin{array}{l}\text { Trial was reported as double blind but authors described no blinding ap- } \\
\text { proach } \\
\text { Insufficient information to permit judgment of 'low risk' or 'high risk' }\end{array}$ \\
\hline $\begin{array}{l}\text { Blinding of outcome as- } \\
\text { sessment (detection bias) } \\
\text { All outcomes }\end{array}$ & Unclear risk & $\begin{array}{l}\text { Trial was reported as double blind but authors described no blinding ap- } \\
\text { proach } \\
\text { Insufficient information to permit judgment of 'low risk' or 'high risk' }\end{array}$ \\
\hline $\begin{array}{l}\text { Incomplete outcome data } \\
\text { (attrition bias) } \\
\text { All outcomes }\end{array}$ & High risk & $\begin{array}{l}\text { Dropouts: } 16 \%(12 / 77) \text { : deaths }(\mathrm{N}=9) \\
\text { Dropouts citicoline group: } 3 \\
\text { Dropouts placebo group: } 9\end{array}$ \\
\hline $\begin{array}{l}\text { Selective reporting (re- } \\
\text { porting bias) }\end{array}$ & Low risk & Trial authors reported clinically relevant endpoints \\
\hline Other bias & High risk & $\begin{array}{l}\text { Bias in the presentation of the data (trial authors mentioned no group for the } 9 \\
\text { deaths) } \\
\text { Funding bias }\end{array}$ \\
\hline
\end{tabular}

Clark 1997

\section{Study characteristics}

- Parallel design (4 arms)
- Multicenter study: yes (21 centers)
- International: no
- Country: USA
- Treatment duration: 6 weeks
- Tollow-up period: 6 weeks
- Type of trial (superiority, equivalence or non-inferiority trial): not stated

\begin{aligned} \hline Participants & Enrolled and randomized: 259 \\ & - Citicoline $(500 \mathrm{mg}): 62 \\ &$ - Citicoline $(1000 \mathrm{mg}): 66 \\ &$ - Citicoline $(2000 \mathrm{mg}): 66 \\ &$ Age (year, mean) \\ & - Citicoline $(500 \mathrm{mg}): 66 \\ &$ - Citicoline $(1000 \mathrm{mg}): 67 \\ &$ - Citicoline $(2000 \mathrm{mg}): 68 \\ &$ - Placebo: 70\end{aligned}


Clark 1997 (Continued)

- Sex (men, \%)

- Citicoline (500 mg): $48.38 \%(30 / 62)$

- Citicoline (1000 mg): 53.03\% (35/66)

- Citicoline (2000 mg): $40.90 \%(27 / 66)$

- Placebo: $44.61 \%(29 / 61)$

- Baseline National Institutes of Health stroke scale score (mean)

- Citicoline (500 mg): 11.6

- Citicoline (1000 mg): 13.2

- Citicoline (2000 mg): 13.6

- Placebo: 13

- Baseline Rankin scale value (mean)

- Citicoline (500 mg): 3.6

- Citicoline (1000 mg): 3.7

- Citicoline $(2000 \mathrm{mg}): 3.8$

- Placebo: 3.6

- Blood hypertension (\%)

- Citicoline (500 mg): 58

- Citicoline (1000 mg): 76

- Citicoline (2000 mg): 68

- Placebo: 66

- Previous stroke or TIA (\%)

- Citicoline (500 mg): 18

- Citicoline (1000 mg): 26

- Citicoline $(2000 \mathrm{mg}): 38$

- Placebo: 20

- Myocardial infarction previous (\%)

- Citicoline (500 mg): 24

- Citicoline (1000 mg): 17

- Citicoline (2000 mg): 18

- Placebo: 37

- Diabetes

- Citicoline (500 mg): 23

- Citicoline (1000 mg): 33

- Citicoline (2000 mg): 39

- Placebo: 66

- Smoking (\%)

- Citicoline (500 mg): 29

- Citicoline (1000 mg): 27

- Citicoline $(2000 \mathrm{mg}): 21$

- Placebo: 23

- Inclusion criteria

- Focal neurologic deficit > 60 minutes

- Computerized tomography (or magnetic resonance imaging) compatible with clinical diagnosis or acute stroke of middle cerebral artery origin

- National Institutes of Health stroke scale 2 with at least 2 points from section 5 and 6 (motor)

- Ambulatory and functionally independent prior to stroke

- Rankin scale score 52 pre-stroke

- Randomized within 24 hours of stroke

- Exclusion criteria

- Evidence of brain tumor or cerebral edema with subsequent effects

- Previous disorder that would impair interpretation of neurologic scales 
Clark 1997 (Continued)

- Neurologic signs and symptoms that improve during baseline screening

- Preexisting medical or psychiatric conditions that may interfere with suitability or participation

- Patients who require surgery

\begin{tabular}{|c|c|}
\hline Interventions & $\begin{array}{l}\text { - Experimental: citicoline (tablets; } 500 \mathrm{mg} \text { each). No information was supplied regarding drug manu- } \\
\text { facturer } \\
\text { - Citicoline ( } 500 \mathrm{mg}): 1 \text { tablet }(500 \mathrm{mg} \text { ) once a day } \\
\text { - Citicoline ( } 1000 \mathrm{mg}): 1 \text { tablet twice day } \\
\text { - Citicoline ( } 2000 \mathrm{mg}): 2 \text { tablets twice day } \\
\text { - Treatment duration: } 6 \text { weeks } \\
\text { - Control: placebo. No information was supplied about taste or physical appearance regarding placebo } \\
\text { - Co-intervention: it was not stated }\end{array}$ \\
\hline Outcomes & $\begin{array}{l}\text { - Primary: } \\
\text { - Functional outcome as determined by the Barthel Index (Barthel Index was classified into } 5 \text { strata: } \\
\text { - death or zero, } 5 \text { to } 40,45 \text { to } 60,65 \text { to } 80,85 \text { to } 100 \text { ). } \\
\text { - Pecondary: } \\
\text { - Patients who had a favorable outcome (Barthel Index of } 95 \text { or } 100 \text { at } 12 \text { weeks) } \\
\text { - Differences between each dose level and placebo on behavioral and cognitive function with use of } \\
\text { a neuropsychological test battery } \\
\text { - Differences between each dose level and placebo in the National Institutes of Health stroke scale } \\
\text { score, specifically the percentage of patients who had a favorable outcome, defined as a National } \\
\text { Institutes of Health stroke scale score of } \leq 1 \\
\text { - Number of days from stroke to hospital discharge }\end{array}$ \\
\hline Notes & $\begin{array}{l}\text { - Identifier trial number register: not stated } \\
\text { - Trial conduction dates: June } 1994 \text { to August } 1995 \\
\text { - A priori sample estimation: no } \\
\text { - Financial disclosures: it was not stated tacitly or explicitly. However, many trial authors had links to } \\
\text { Interneuron Pharmaceuticals Inc. } 3 \text { trial authors were paid scientific advisors to Interneuron Pharma- } \\
\text { ceuticals Inc } \\
\text { - Other disclosures: none } \\
\text { - Funding/support: it was not stated tacitly or explicitly }\end{array}$ \\
\hline
\end{tabular}

\section{Risk of bias}

\begin{tabular}{|c|c|c|}
\hline Bias & Authors' judgement & Support for judgement \\
\hline $\begin{array}{l}\text { Random sequence genera- } \\
\text { tion (selection bias) }\end{array}$ & Unclear risk & $\begin{array}{l}\text { Quote: "... were randomized ..." (page 673) } \\
\text { Insufficient information to permit judgment of 'low risk' or 'high risk' }\end{array}$ \\
\hline $\begin{array}{l}\text { Allocation concealment } \\
\text { (selection bias) }\end{array}$ & Unclear risk & Insufficient information to permit judgment of 'low risk' or 'high risk' \\
\hline $\begin{array}{l}\text { Blinding of participants } \\
\text { and personnel (perfor- } \\
\text { mance bias) } \\
\text { All outcomes }\end{array}$ & Unclear risk & $\begin{array}{l}\text { Quote: "... double-blind ..." (page 672) } \\
\text { Insufficient information to permit judgment of 'low risk' or 'high risk' }\end{array}$ \\
\hline $\begin{array}{l}\text { Blinding of outcome as- } \\
\text { sessment (detection bias) } \\
\text { All outcomes }\end{array}$ & Unclear risk & $\begin{array}{l}\text { Quote: "... double-blind ..." (page 672) } \\
\text { Insufficient information to permit judgment of 'low risk' or 'high risk' }\end{array}$ \\
\hline
\end{tabular}


Clark 1997 (Continued)

Incomplete outcome data Low risk

(attrition bias)

All outcomes

Selective reporting (re- Low risk $\quad$ Trial authors reported clinically relevant endpoints
porting bias)

Other bias High risk Design bias

Funding bias

\section{Clark 1999}

\section{Study characteristics}

$\begin{array}{ll}\text { - Pethods } & \text { Parallel design ( } 2 \text { arms) } \\ \text { - Multicenter study: yes (31 centers) } \\ \text { - International: no } \\ \text { - Treatment duration: } 6 \text { weeks } \\ \text { - Follow-up period: } 6 \text { weeks } \\ \text { - Timing for starting citicoline treatment: unclear } \\ \text { - Type of trial (superiority, equivalence or non-inferiority trial): not stated }\end{array}$

Participants

- Enrolled and randomized: 394 (middle cerebral artery territory with National Institutes of Health Stroke Scale)

- Citicoline (500 mg): 267

- Placebo: 127

- Age (year, mean)

- Citicoline (500 mg): 70

- Placebo: 71

- Sex (men, \%)

- Citicoline (500 mg): 46

- Placebo: 49

- Time to treatment (hours, mean)

- Citicoline (500 mg): 11.7

- Placebo: 12.3

- Baseline National Institutes of Health stroke scale score (mean)

- Citicoline $(500 \mathrm{mg}): 11.6$

- Placebo: 13

- Baseline Rankin scale value (mean): not reported

- Blood hypertension (\%)

- Citicoline $(500 \mathrm{mg}): 70$

- Placebo: 72

- Previous stroke or TIA (\%)

- Citicoline (500 mg): 35

- Placebo: 37

- Myocardial infarction previous: not reported

- Diabetes: not reported

- Smoking: not reported

- Inclusion criteria 
Clark 1999 (Continued)

- Age $\geq 18$ years

- Randomized within 24 hours of stroke

- Focal neurological deficit lasting at $\geq 60$ minutes

- Computerized tomography (or magnetic resonance imaging) compatible with clinical diagnosis of acute ischemic stroke

- Stroke clinically assessed to be in the middle cerebral artery territory

- National Institutes of Health stroke scale $\geq 5$ with at least 2 points from sections 5 and 6 (motor)

- Ambulatory and functionally independent before stroke: Rankin scale score $\leq 2$ (slight disability) before stroke

- Exclusion criteria

- Computerized tomography (or magnetic resonance imaging) evidence of brain tumor, brain stem or cerebellar infarction, subarachnoid hemorrhage, or primary intracerebral hemorrhage

- Severe coexisting systemic disease that limits life expectancy

- History of ventricular dysrhythmias, acute myocardial infarction, or any severe cardiovascular condition that would interfere with participation: previous disorder which would impair interpretation of neurological scales, neurological signs and symptoms that improve during baseline screening, preexisting medical conditions that may interfere with participation

- Patients who require surgery within 24 hours

- Patients with recent or planned thrombolytic use

$\begin{array}{ll}\text { - Interventions } & \text { Intervention: oral citicoline, } 500 \mathrm{mg} \text {, likely once per day } \\ \text { - Control: oral placebo } \\ \text { - Co-intervention: not reported } \\ \text { - Treatment duration: } 6 \text { weeks } \\ \text { Citicoline and placebo were a soft-gelatin capsule with identical appearance and consistency }\end{array}$

Outcomes

- Primary

- Functional outcome as determined by the Barthel Index at 12 weeks (the Barthel Index was classified into 5 strata (death or zero, 5 to 40,45 to 60,65 to 80,85 to 100 )

- Secondary

- Categorized Barthel Index at the other weeks

- Patients who had a full recovery (Barthel Index 95 or 100 at 12 weeks)

- Treatment differences on the Modified Rankin scale

- Treatment differences on neurological behavioral, and cognitive function by use of the NIHSS and Mini-Mental State Examination

- Mortality

- Treatment differences in the percentage of patients who had a full recovery defined as an NIHSS score of $\leq 1$

- Number of days from stroke to hospital discharge

- Relative rate of improvement for the Barthel Index, Rankin scale, and National Institutes of Health stroke scale between the groups. Additional post hoc outcome analyses were performed on a subgroup of patients with moderate to large strokes

- Identifier trial number register: not stated
- Trial conduction dates: from 30 June 1996 to 12 June 1997
- A priori sample estimation: yes
- Financial disclosures: no
- Other disclosures: no disclosures reported
- Funding/support: likely Interneuron Pharmaceuticals, Inc, Lexington, MA

\section{Risk of bias}




\section{Clark 1999 (Continued)}

Random sequence genera- Unclear risk tion (selection bias)
Quote: "The patients were randomly assigned within each center with the use of a blocked randomization" (Page 2593)

Insufficient information to permit judgment of 'low risk' or 'high risk'. Trial authors did not explain the procedure to obtain the "blocked randomization".

Insufficient information to permit judgment of 'low risk' or 'high risk'

Trial authors did not report how allocation concealment was conducted

Quote: "... either placebo or citicoline $(500 \mathrm{mg})$ in a soft-gelatin capsule (identical in appearance and consistency)." (page 2593) and personnel (perfor-

Low risk mance bias)

All outcomes

\begin{tabular}{lll}
\hline Blinding of outcome as- & Unclear risk & Insufficient information to permit judgment of 'low risk' or 'high risk' \\
sessment (detection bias) & & \\
All outcomes & Trial authors reported no information about blinding of outcome assessment
\end{tabular}

Low risk

Incomplete outcome data Low risk
(attrition bias)

All outcomes

\begin{tabular}{ll}
\hline $\begin{array}{l}\text { Selective reporting (re- } \\
\text { porting bias) }\end{array}$ & Low risk
\end{tabular}

\begin{tabular}{lll}
\hline Other bias & Unclear risk & Likely funding bias \\
\hline
\end{tabular}

\section{Clark 2001}

\section{Study characteristics}

\begin{tabular}{|c|c|}
\hline Methods & $\begin{array}{l}\text { - Parallel design ( } 2 \text { arms) } \\
\text { - Multicenter study: yes ( } 118 \text { centers) } \\
\text { - International: yes } \\
\text { - Country: USA and Canada } \\
\text { - Treatment duration: } 6 \text { weeks } \\
\text { - Follow-up period: } 6 \text { weeks } \\
\text { - Timing for starting citicoline treatment: unclear } \\
\text { - Type of trial (superiority, equivalence or non-inferiority trial): superiority }\end{array}$ \\
\hline Participants & $\begin{array}{l}\text { - Randomized: } 899 \\
\text { - Citicoline (2000 mg): } 453 \\
\text { - Placebo: } 446 \\
\text { - Received medication } \\
\text { - Citicoline ( } 2000 \mathrm{mg} \text { ): } 453 \\
\text { - Placebo: } 446 \\
\text { - Age (mean, years) } \\
\text { - Citicoline ( } 2000 \mathrm{mg} \text { ): } 68 \\
\text { - Placebo: } 67 \\
\text { - Sex (men, } \% \text { ) } \\
\text { - Citicoline (2000 mg): } 50 \\
\text { - Placebo: } 54 \\
\text { - Time to treatment (mean, hours) }\end{array}$ \\
\hline
\end{tabular}


- Citicoline (2000 mg): 13.2

- Placebo: 13.3

- Received tissue plasminogen activator (\%)

- Citicoline (2000 mg): 13

- Placebo: 11

- Baseline National Institutes of Health Stroke Scale Score

- Citicoline (2000 mg): 13 (median), 13.9 (mean)

- Placebo: 14 (median), 14.5 (mean).

- Hypertension

- Citicoline (2000 mg): 74

- Placebo: 70

- Previous stroke or TIA

- Citicoline (2000 mg): 31

- Placebo: 35

- Cardiac disease

- Citicoline (2000 mg): 49

- Placebo: 49

- Diabetes

- Citicoline (2000 mg): 25

- Placebo: 28

- Inclusion criteria

- Age 18 to 85 years

- Randomized within 24 hours of stroke

- Focal neurologic deficit lasting at least 60 minutes

- Computerized tomography (or magnetic resonance imaging) compatible with clinical diagnosis of acute ischemic stroke

- Stroke clinically thought to be in the middle cerebral artery territory

- National Institutes of Health Stroke Scale 8 with at least 2 points from sections 5 and 6 (motor)

- Ambulatory and functionally independent prior to stroke with Rankin scale score 1 (no significant disability) pre stroke

- Exclusion criteria

- Computerized tomography (or magnetic resonance imaging evidence of brain tumor, brainstem or cerebellar infarction, significant cerebral edema, subarachnoid hemorrhage, or primary intracerebral hemorrhage

- Severe co-existing systemic disease that limits life expectancy

- History of ventricular dysrhythmia, acute myocardial infarction, or severe cardiovascular condition that would interfere with participation

- Previous disorder that would impair interpretation of neurologic scales

- Neurologic signs and symptoms that improve during baseline screening

- Pre-existing medical conditions that may interfere with participation

- Surgery required within 24 hours

- "Off label" thrombolytic use; tissue plasminogen activator as approved for stroke was accepted

- Notable stroke lesions exclusively in the white matter, brainstem, cerebellum, or thalamus on standard radiologic assessments

- 1 of the clinical syndromes suggestive of lacunare infarcts

- Obtunded, presented with forced eye deviation, or total gaze paresis and dense hemiplegia as measured by the National Institutes of Health Stroke Scale

- Co-intervention: a nasogastric tube was placed for delivery of the study drug if patient was unable to swallow 
Clark 2001 (Continued)

Participants should be inpatients at the start of the study medication treatment

- Primary
- Improving from baseline on their National Institutes of Health Stroke Scale by 7 points at week 12
- Secondary
- Return to their pre-stroke Barthel index score at 12 weeks
- Improvement of 1 or 2 points on the Clinician's Global Impressions scale at 12 weeks
- Mortality
- Differences at 12 weeks using an overall response analysis based on NIHSS improvement $\geq 7$
- Barthel index return to pre-stroke values
- Clinician's Global Impressions improvement of 1 or 2 , and Clinician's Global Impressions severity
- improvement of $\geq 2$

$\begin{array}{ll}\text { Notes } & \text { Identifier trial number: not stated } \\ \text { - Trial conduction dates: } 3 \text { August } 1998 \text { to } 17 \text { November } 1999 \\ \text { - A priori sample estimation: yes } \\ \text { - Financial disclosures: no } \\ \text { - Other disclosures: no other disclosures reported }\end{array}$

\section{Risk of bias}

\begin{tabular}{|c|c|c|}
\hline Bias & Authors' judgement & Support for judgement \\
\hline \multirow[t]{2}{*}{$\begin{array}{l}\text { Random sequence genera- } \\
\text { tion (selection bias) }\end{array}$} & Unclear risk & $\begin{array}{l}\text { Quote: "The patients were randomly allocated within each center using a } \\
\text { blocked randomization ..." and "Patients were randomly allocated and strati- } \\
\text { fied into two categories ..." (Page 1597) }\end{array}$ \\
\hline & & Insufficient information to permit judgment of 'low risk' or 'high risk' \\
\hline $\begin{array}{l}\text { Allocation concealment } \\
\text { (selection bias) }\end{array}$ & Unclear risk & Insufficient information to permit judgment of 'low risk' or 'high risk' \\
\hline $\begin{array}{l}\text { Blinding of participants } \\
\text { and personnel (perfor- }\end{array}$ & Low risk & $\begin{array}{l}\text { Quote: "The sites were not aware of the patient's group assignment." (Page } \\
\text { 1597) }\end{array}$ \\
\hline All outcomes & & $\begin{array}{l}\text { Intervention and placebo were identical in appearance and consistency (Page } \\
\text { 1597) }\end{array}$ \\
\hline $\begin{array}{l}\text { Blinding of outcome as- } \\
\text { sessment (detection bias) } \\
\text { All outcomes }\end{array}$ & Unclear risk & Insufficient information to permit judgment of 'low risk' or 'high risk' \\
\hline $\begin{array}{l}\text { Incomplete outcome data } \\
\text { (attrition bias) } \\
\text { All outcomes }\end{array}$ & Low risk & - \\
\hline $\begin{array}{l}\text { Selective reporting (re- } \\
\text { porting bias) }\end{array}$ & Low risk & Trial reported information about relevant clinical outcomes \\
\hline Other bias & Unclear risk & Likely funding bias \\
\hline
\end{tabular}


Ghosh 2015

\section{Study characteristics}

\begin{tabular}{|c|c|}
\hline Methods & $\begin{array}{l}\text { - Parallel design ( } 2 \text { arms) } \\
\text { - Multicenter study: no (1 center) } \\
\text { - International: no } \\
\text { - Country: India } \\
\text { - Treatment duration: } 30 \text { days } \\
\text { - Follow-up period: } 90 \text { days } \\
\text { - Timing for starting citicoline treatment: unclear } \\
\text { - Type of trial (superiority, equivalence or non-inferiority trial): not reported }\end{array}$ \\
\hline Participants & $\begin{array}{l}\text { - Randomized: } 100 \\
\text { - Citicoline group: } 50 \\
\text { - } 63 \text { participants were diagnosed having ischemic stroke. } \\
\text { * Citicoline: } 28 \\
\text { * Control: } 35 \\
\text { The trial authors did not describe age, sex, baseline National Institutes of Health Stroke Scale score, } \\
\text { Barthel Index score, hypertension, diabetes mellitus, or dyslipidemia data for the participants with is- } \\
\text { chemic stroke } \\
\text { - Inclusion criteria } \\
\text { - Stroke participants, both ischemic and hemorrhagic } \\
\text { - Stroke established by a computed tomographic } \\
\text { - Within } 48 \text { hours of onset of the stroke } \\
\text { - Exclusion criteria } \\
\text { - Critically ill patients with other systemic diseases } \\
\text { - People with end-stage renal disease, advanced hepatic disease, psychiatric illness, recurrent } \\
\text { stroke, severe cardiovascular disease associated with arrhythmias } \\
\text { - TIA }\end{array}$ \\
\hline Interventions & $\begin{array}{l}\text { - Experimental group: citicoline plus standard stroke therapy } \\
\text { - Intravenous infusion of citicoline: } 1000 \mathrm{mg} \text { twice daily during } 5 \text { days } \\
\text { - Oral citicoline: } 500 \mathrm{mg} \text { BID daily for } 25 \text { days } \\
\text { - Standard stroke therapy: antihypertensives, osmotic diuretics, lipid-lowering agents, statins, and } \\
\text { if necessary, aspirin or clopidogrel } \\
\text { - Control group (standard stroke therapy) } \\
\text { - Antihypertensives, osmotic diuretics, lipid-lowering agents, statins, and if necessary, aspirin or } \\
\text { clopidogrel } \\
\text { - Duration of treatment: } 30 \text { days } \\
\text { - No patient received intravenous thrombolysis }\end{array}$ \\
\hline Outcomes & - Primary: Barthel Index score \\
\hline Notes & $\begin{array}{l}\text { - Identifier trial number: not stated } \\
\text { - Trial conduction dates: January } 2014 \text { to January } 2015 \\
\text { - A priori sample estimation: no } \\
\text { - Financial disclosures: declared nil financial support } \\
\text { - Other disclosures: did not report any disclosure } \\
\text { - Funding/support: declared nil sponsorship. }\end{array}$ \\
\hline
\end{tabular}

\section{Risk of bias}


Ghosh 2015 (Continued)

\begin{tabular}{|c|c|c|}
\hline Bias & Authors' judgement & Support for judgement \\
\hline $\begin{array}{l}\text { Random sequence genera- } \\
\text { tion (selection bias) }\end{array}$ & Unclear risk & $\begin{array}{l}\text { Quote: "The selected } 100 \text { patients, were randomized ..." } \\
\text { Insufficient information to permit judgment of 'low risk' or 'high risk' }\end{array}$ \\
\hline $\begin{array}{l}\text { Allocation concealment } \\
\text { (selection bias) }\end{array}$ & Unclear risk & $\begin{array}{l}\text { Quote: "The selected } 100 \text { patients, were randomized ..." } \\
\text { Insufficient information to permit judgment of 'low risk' or 'high risk' }\end{array}$ \\
\hline $\begin{array}{l}\text { Blinding of participants } \\
\text { and personnel (perfor- } \\
\text { mance bias) } \\
\text { All outcomes }\end{array}$ & High risk & $\begin{array}{l}\text { Quote: "... the authors evaluated the outcome themselves, were not blinded to } \\
\text { the treatment administered and were involved in the management of the pa- } \\
\text { tients." }\end{array}$ \\
\hline $\begin{array}{l}\text { Blinding of outcome as- } \\
\text { sessment (detection bias) } \\
\text { All outcomes }\end{array}$ & High risk & $\begin{array}{l}\text { Quote: "... the authors evaluated the outcome themselves, were not blinded to } \\
\text { the treatment administered and were involved in the management of the pa- } \\
\text { tients." }\end{array}$ \\
\hline $\begin{array}{l}\text { Incomplete outcome data } \\
\text { (attrition bias) } \\
\text { All outcomes }\end{array}$ & Low risk & - \\
\hline $\begin{array}{l}\text { Selective reporting (re- } \\
\text { porting bias) }\end{array}$ & High risk & $\begin{array}{l}\text { There was no information about either the National Institutes of Health Stroke } \\
\text { Scale or the Barthel Index score baseline, nor adverse events for participants } \\
\text { with ischemic stroke }\end{array}$ \\
\hline Other bias & High risk & $\begin{array}{l}\text { Bias in the presentation of the data } \\
\text { Design bias }\end{array}$ \\
\hline
\end{tabular}

Guillen 1995

\section{Study characteristics}

\begin{tabular}{ll}
\hline Methods & Parallel design (2 arms) \\
- Multicenter study: no \\
- International: no \\
- Country: Spain \\
- Treatment duration: 10 days \\
- Follow-up period: unknown \\
- Timing for starting citicoline treatment: unclear \\
- Type of trial (superiority, equivalence or non-inferiority trial): not reported \\
- CDP-choline: 40 \\
* Control (conventional treatment): 40 \\
$*$ Demographic variables: not stated \\
Participants \\
- Either sex \\
- Over 65 years old \\
- Acute stage of ischemic stroke as confirmed by computer tomography \\
\hline
\end{tabular}

Interventions

- Experimental group: CDP-choline: $1000 \mathrm{mg}$, intravenously, each 8 hours by 10 days 
Guillen 1995 (Continued)

- Comparison group: conventional treatment which was not described

- Co-intervention: fluid maintenance therapy and low doses of heparin

Outcomes This issue was not explicitly reported. Trial authors assessed: Glasgow Coma scale, Mathew's scale, Barthel's scale and the Red Cross scales and tolerability

\begin{tabular}{ll}
\hline Notes & Identifier trial number register: not reported \\
- Trial conduction dates: not reported \\
- A priori sample estimation: no \\
- Fundincial disclosures: not mentioned \\
- Role of the sponsor: not apply \\
- Data gathered from a conference proceedings \\
\hline
\end{tabular}

\section{Risk of bias}

\begin{tabular}{lll}
\hline Bias & Authors' judgement & Support for judgement \\
\hline $\begin{array}{l}\text { Random sequence genera- } \\
\text { tion (selection bias) }\end{array}$ & Unclear risk & $\begin{array}{l}\text { Quote: "... groups arranged at random and a control group ..." (page S76) } \\
\text { Insufficient information to permit judgment of 'low risk' or 'high risk' }\end{array}$ \\
\hline $\begin{array}{l}\text { Allocation concealment } \\
\text { (selection bias) }\end{array}$ & Unclear risk & Insufficient information to permit judgment of 'low risk' or 'high risk' \\
\hline $\begin{array}{l}\text { Blinding of participants } \\
\text { and personnel (perfor- } \\
\text { mance bias) } \\
\text { All outcomes }\end{array}$ & Unclear risk & Insufficient information to permit judgment of 'low risk' or 'high risk' \\
\hline
\end{tabular}

\begin{tabular}{lll}
\hline $\begin{array}{l}\text { Blinding of outcome as- } \\
\text { sessment (detection bias) } \\
\text { All outcomes }\end{array}$ & Unclear risk & Insufficient information to permit judgment of 'low risk' or 'high risk' \\
\hline $\begin{array}{l}\text { Incomplete outcome data } \\
\begin{array}{l}\text { (attrition bias) } \\
\text { All outcomes }\end{array}\end{array}$ & Unclear risk & Insufficient information to permit judgment of 'low risk' or 'high risk' \\
\hline $\begin{array}{l}\text { Selective reporting (re- } \\
\text { porting bias) }\end{array}$ & Unclear risk & Insufficient information to permit judgment of 'low risk' or 'high risk' \\
\hline Other bias & High risk & Bias in the presentation of the data \\
\hline
\end{tabular}

\section{ICTUS 2012}

\section{Study characteristics}

\begin{tabular}{ll}
\hline Methods & Parallel design (2 arms) \\
- Multicenter study: yes ( 59 centers) \\
- International: yes \\
- Country: Germany, Portugal, and Spain \\
- Follow-up period: 6 weeks \\
- Timing for starting citicoline treatment: first 24 hours after the onset of symptoms
\end{tabular}


- Randomized: 2298

- Citicoline (2000 mg): 1148

- Placebo: 1150

- Received medication: 2288

- Citicoline (2000 mg): 1140 (99.3\%)

- Placebo: 1148 (99.82\%)

- Included into per protocol analysis: $75.48 \%$ (1727/2288)

- Citicoline (2000 mg): 50.55\% (873/1727)

- Placebo: $49.44 \%$ (854/1727)

- Age (mean, years, SD)

- Citicoline (2000 mg): 72.9 (11.8)

- Placebo: 72.8 (12.1)

- Sex (men, \%)

- Citicoline $(2000 \mathrm{mg}): 51.2$

- Placebo: 48.2

- Time to treatment (mean, hours)

- Citicoline (2000 mg): $\leq 12$ (911 [79.4\%]); > 12 (237 [20.6\%])

- Placebo: $\leq 12$ (916 [79.7\%]); > 12 (234 [20.3\%])

- Received tissue plasminogen activator (\%)

- Citicoline (2000 mg): 532 (46.3)

- Placebo: 532 (46.3)

- Baseline National Institutes of Health Stroke Scale Score (median)

- Citicoline (2000 mg): 15 (IQR: 11 to 19)

- Placebo: 15 (IQR: 11 to 19$)$

- Hypertension (\%)

- Citicoline (2000 mg): 841 (73.3)

- Placebo: 830 (72.2)

- Previous TIA (\%)

- Citicoline (2000 mg): 99 (8.6)

- Placebo: 101 (8.8\%)

- Previous stroke (\%)

- Citicoline (2000 mg): 162 (14.1)

- Placebo: 147 (12.8)

- Cardiac disease (\%)

- Citicoline (2000 mg): 200 (17.4)

- Placebo: 188 (16.4)

- Diabetes (\%)

- Citicoline (2000 mg): 273 (23.8)

- Placebo: 290 (25.2)

- Inclusion criteria

- Men or women, > 18 years old

- Participants must be treated within 24 hours of their initial stroke symptoms onset

- Participants with a measurable focal neurological deficit lasting for a minimum of 60 minutes

- Participants must have a computerized tomography scan and/or conventional magnetic resonance imaging compatible with the clinical diagnosis of acute ischemic stroke prior to being randomized

- Participants must have an acute ischemic stroke referable to the middle cerebral artery territory

- At inclusion, $\mathrm{NIH}>7$, with at least 2 of these points from sections 5 \& 6 (motor)

- Immediately (i.e. minutes) pre-stroke, modified Rankin score $<2$

- Women of childbearing potential must have a negative pregnancy test prior to enrollment 
- Signed informed consent

- Exclusion criteria

- Participants in coma: participants having a score of 2 or higher in the items regarding the level of consciousness in the National Institutes of Health Stroke Scale score (1a)

- Computerized tomography scan or conventional magnetic resonance imaging evidence of brain tumor, cerebral edema with a clinically significant mass midline shift with compression of the ventricles, brainstem or cerebellar infarction, subarachnoid and/or intracerebral and/or intraventricular hemorrhage

- History of ventricular dysrhythmias, acute myocardial infarction within 72 hours prior to enrollment, unstable angina, decompensated congestive heart failure or any other acute, severe, uncontrollable or sustained cardiovascular condition that, in the Investigator's opinion, may interfere with effective participation in the study

- Previous disorders that may confound the interpretation of the neurological scales

- Drug-addiction-related disorders

- Pre-existing dementia, when dementia implies a disability, measured as a score of 2 or higher in the previous modified Rankin score

- Pre-existing medical condition that, in the Investigator's opinion, may interfere with the patient's suitability and participation in the study

- Participants participating in another clinical trial or receiving a non-approved drug (clinical investigational drug) less than 30 days prior to screening

- Participants under current treatment with citicoline

\section{See Notes}

Interventions
- Experimental drug: citicoline (CDP-choline, Nicholin, Takeda Chemical Industries, Ltd., Osaka, Japan): 1000 every 12 hours, diluted in a $100 \mathrm{~mL}$ saline solution bag and infused during 30 to 60 minutes, during 3 days and then $1000 \mathrm{mg}$ orally ( 2 tablets $\times 500 \mathrm{mg}$ ) every 12 hours, until completed 6 weeks of treatment. In participants with swallowing problems, tablets were dissolved in 30 to $60 \mathrm{~mL}$ of tepid water and administered through a nasogastric tube

- Control: placebo as experimental drug. Control and experimental drug were identical and indistinguishable, either ampoules or tablets

- Co-intervention: every participant received stroke care according to local treatment practice, including tissue plasminogen activator for eligible patients presenting within 4.5 hours after the onset of the stroke
Outcomes

\section{Notes}

- Primary: recovery at 90 days as measured by a global test combining the favorable responses from all 3 outcome scales: Barthel index (95 to 100), modified Rankin score (0 to 1), and National Institutes of Health Stroke Scale Score (0 to 1 ) assessed at week 12

- Secondary:

- Rate of favorable response in Barthel index

- Rate of favorable response in modified Rankin score

- Rate of favorable response in National Institutes of Health Stroke Scale Score

- The between-groups comparison of the full distribution of the modified Rankin score scores, and the absolute difference in the National Institutes of Health Stroke Scale Score between baseline and 3 months

- Death

- Serious adverse events and non-serious adverse events

Note: Quote: "As a post-hoc analysis, and in accordance with reviewers' recommendations, and CONSORT guidelines, we updated the previous tabulated meta-analysis for acute ischemic stroke, which defined success as mRs $0-2 . "$

- This trial was stopped on 21 Octuber 2011 by recommendations from the data and safety monitoring board at the third interim analysis because the statistical stopping boundary for futility had been crossed. It was based on complete data for 2078 patients, The follow-up was stopped for 220 participants already randomized, but it was suggested that analysis should include all randomized participants $(\mathrm{N}=2298)$ 
- Between the second and third interim analyses, there was an amendment of the protocol by recommendation of the trial steering committee. However the amendment included no changes to eligibility criteria, clinical outcomes, or statistical analysis

- Identifier trial number: NCT00331890

- Trial conduction dates: 26 November 2006 to 27 Octuber 2011

- A priori sample estimation: yes

- Financial disclosures: yes. Many trial authors had received either consultation fees or honoraria from sponsor. 1 trial author is a full-time employee of the sponsor

- Funding/support: Ferrer Grupo

- Role of the sponsor: Quote: "The sponsor of the study had no role in study design, data collection, data analysis, data interpretation, or writing of the report." (page 353). Sponsor supplied citicoline and placebo

\section{Risk of bias}

\begin{tabular}{lll}
\hline Bias & Authors' judgement & Support for judgement \\
\hline $\begin{array}{l}\text { Random sequence genera- } \\
\text { tion (selection bias) }\end{array}$ & Low risk & $\begin{array}{l}\text { Quote: "The randomisation process was centralised using an interactive voice } \\
\text { response system (IVRS), under a minimisation process ..." (Page 350) }\end{array}$ \\
& $\begin{array}{l}\text { There is doubt about the effectiveness of the minimization process to guaran- } \\
\text { tee an appropriate random allocation of the participants }\end{array}$
\end{tabular}

\begin{tabular}{|c|c|c|}
\hline $\begin{array}{l}\text { Allocation concealment } \\
\text { (selection bias) }\end{array}$ & Low risk & $\begin{array}{l}\text { Quote: "The randomisation process was centralised using an interactive voice } \\
\text { response system (IVRS), under a minimisation process ..." (Page 350) }\end{array}$ \\
\hline
\end{tabular}

There is doubt about the effectiveness of the minimization process to guarantee an appropriate random allocation of the participants

\begin{tabular}{|c|c|c|}
\hline $\begin{array}{l}\text { Blinding of participants } \\
\text { and personnel (perfor- } \\
\text { mance bias) }\end{array}$ & Low risk & $\begin{array}{l}\text { Quote: "Patients, researchers, caregivers, individuals assessing the outcomes } \\
\text { data managers, and members of the trial steering committee were masked to } \\
\text { group assignment." (Page 351) }\end{array}$ \\
\hline All outcomes & & $\begin{array}{l}\text { Control and experimental drug were identical and indistinguishable, either } \\
\text { ampoules or tablets }\end{array}$ \\
\hline
\end{tabular}

\begin{tabular}{|c|c|c|}
\hline $\begin{array}{l}\text { Blinding of outcome as- } \\
\text { sessment (detection bias) }\end{array}$ & Low risk & Quote: "... individuals assessing the outcomes, data managers, ..." (Page 351) \\
\hline
\end{tabular}

\footnotetext{
All outcomes
}

Incomplete outcome data High risk
(attrition bias)

(attrition bias)

- Dropouts: 561

All outcomes

- citicoline group: $23.25 \%(267 / 1148)$

- placebo group: $25.56 \%$ (294/1150)

- Included into per protocol analysis: $75.48 \%$ (1727/2288)

- Citicoline (2000 mg): 50.55\% (873/1727)

- Placebo: $49.44 \%(854 / 1727)$

\begin{tabular}{|c|c|c|}
\hline $\begin{array}{l}\text { Selective reporting (re- } \\
\text { porting bias) }\end{array}$ & Low risk & $\begin{array}{l}\text { Trial has information about relevant clinical outcomes, such as described in } \\
\text { the protocol }\end{array}$ \\
\hline
\end{tabular}

Other bias High risk Funding bias (1 trial author is a full-time employee of the sponsor)

\section{Study characteristics}

Citicoline for treating people with acute ischemic stroke (Review)

Copyright $\odot 2020$ The Cochrane Collaboration. Published by John Wiley \& Sons, Ltd. 
Seifaddini 2017 (Continued)

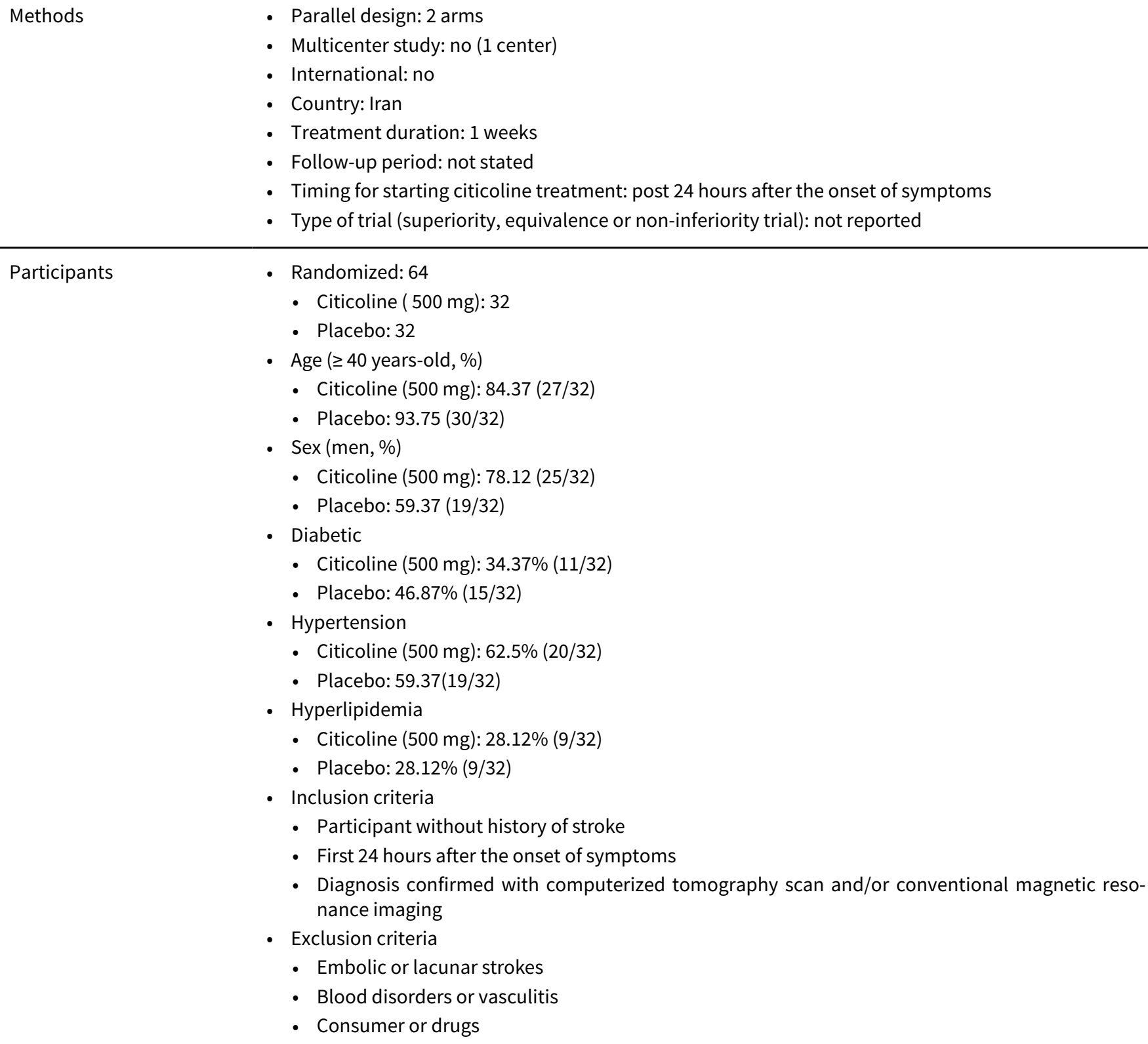

Interventions

- Experimental: citicoline $(500 \mathrm{mg} /$ day), starting on the second day of hospitalization, intravenous during 1 week. Additional information about citicoline is unknown

- Comparison: placebo. Additional information about placebo is unknown

- Duration of treatment: 1 week

- Co-intervention: standard treatment, but not stated. Trial authors excluded those participants receiving recombinant tissue plasminogen activator

Outcomes

- Cerebral hemodynamic

- Peak systolic velocity

- Mean flow velocity

- Pulsatility index

- Resistance index.

$\begin{array}{ll}\text { Notes } & \text { Identifier trial number: IRCT 201705278430N9 } \\ & \text { - Trial conduction dates: just reports the year - } 2017\end{array}$


Seifaddini 2017 (Continued)

- A priori sample estimation: likely yes. Only about power and statistical significance level

- Financial disclosures: not stated

- Funding/support: Neurologic Research Center of Kerman University of Medical Sciences

- Role of the sponsor: not stated

\section{Risk of bias}

\begin{tabular}{|c|c|c|}
\hline Bias & Authors' judgement & Support for judgement \\
\hline $\begin{array}{l}\text { Random sequence genera- } \\
\text { tion (selection bias) }\end{array}$ & Unclear risk & $\begin{array}{l}\text { Quote: " ... were divided randomly into two equal groups ..." (Pag 481) } \\
\text { Insufficient information to permit judgment of 'low risk' or 'high risk' }\end{array}$ \\
\hline $\begin{array}{l}\text { Allocation concealment } \\
\text { (selection bias) }\end{array}$ & Unclear risk & $\begin{array}{l}\text { It was not reported } \\
\text { Insufficient information to permit judgment of 'low risk' or 'high risk' }\end{array}$ \\
\hline $\begin{array}{l}\text { Blinding of participants } \\
\text { and personnel (perfor- } \\
\text { mance bias) } \\
\text { All outcomes }\end{array}$ & Unclear risk & $\begin{array}{l}\text { Quote "This double-blind ..." (Pag 481) } \\
\text { Insufficient information to permit judgment of 'low risk' or 'high risk' }\end{array}$ \\
\hline $\begin{array}{l}\text { Blinding of outcome as- } \\
\text { sessment (detection bias) } \\
\text { All outcomes }\end{array}$ & Unclear risk & Insufficient information to permit judgment of 'low risk' or 'high risk' \\
\hline $\begin{array}{l}\text { Incomplete outcome data } \\
\text { (attrition bias) } \\
\text { All outcomes }\end{array}$ & Unclear risk & $\begin{array}{l}\text { Insufficient information to permit judgment of 'low risk' or 'high risk' } \\
\text { There is confusion regarding the timing of exclusion of the participants who } \\
\text { received recombinant tissue plasminogen activator }\end{array}$ \\
\hline $\begin{array}{l}\text { Selective reporting (re- } \\
\text { porting bias) }\end{array}$ & High risk & This trial only reported data about physiological variables \\
\hline Other bias & High risk & $\begin{array}{l}\text { Design bias } \\
\text { Bias in the presentation of the data. There is confusion regarding the timing of } \\
\text { exclusion of the participants who received recombinant tissue plasminogen } \\
\text { activator }\end{array}$ \\
\hline
\end{tabular}

Tazaki 1988

\section{Study characteristics}

- Pethods
- Multicenter study: yes (63 centers)
- International: no
- Country: Japan
- Follow-up period: not stated
- Timing for starting citicoline treatment: unclear
- Type of trial (superiority, equivalence or non-inferiority trial): not stated

Participants

- Randomized: 272

- Citicoline (1000 mg): 133 
Tazaki 1988 (Continued)

- Placebo: 139

- Anayzed: $98.16 \%(267 / 272)$

- Citicoline (1000 mg): 131

- Placebo: 136

- Age (50 to 90 years old)

- Citicoline: $91 \%$

- Placebo: $96.32 \%$

- Sex (men, \%)

- Citicoline $66.41(87 / 131)$

- Placebo: 68.38 (93/136)

- Both: $67.41 \%$

- Inclusion criteria

- Clinical evidence of cerebral infarction occurring within 14 days of admission to the study

- Clinical diagnosis of cerebral infarction confirmed by computed tomography of the brain

- Mild to moderate impairment of consciousness indicated by the Japanese Coma Scale (Appendix 13)

- Exclusion criteria

- Participants with total aphasia, subarachnoid or intracerebral hemorrhage, or indications for neurosurgical intervention

- Experimental drug: CDP-choline. It was prepared in $20 \mathrm{ml}$ ampoules containing $1000 \mathrm{mg}$ CDP-choline, diluted with $500 \mathrm{ml}$ physiological saline or $5 \%$ dextrose in sterile water and was administered by intravenous drip once daily for 14 days

- Control: placebo (physiological saline), in same way as experimental drug

- Co-intervention: no restrictions on the use of concurrent drugs if they were thought to be indicated, but it should be recorded in detail

Suitable provisions were made so that CDP-choline could not be distinguished from the placebo

\begin{tabular}{ll}
\hline Outcomes & The level of consciousness was assessed in 10 grades according to the Japanese Coma Scale \\
- Global improvement rating \\
\hline Notes & - Idebal usefulness rating \\
- Trial conduction dates: November 1982 to February 1985 \\
- A priori sample estimation: no \\
- Financial disclosures: not stated \\
- Funding/support: not stated \\
- Role of the sponsor: does not apply
\end{tabular}

\section{Risk of bias}

Bias Authors' judgement Support for judgement

Random sequence genera- Unclear risk tion (selection bias)
Quote: "... randomly assigned to treatment ... or physiological saline (placebo) ..." (Page 211)

Insufficient information to permit judgment of 'low risk' or 'high risk'

\begin{tabular}{lll}
\hline $\begin{array}{l}\text { Allocation concealment } \\
\text { (selection bias) }\end{array}$ & Unclear risk & Insufficient information to permit judgment of 'low risk' or 'high risk' \\
\hline $\begin{array}{l}\text { Blinding of participants } \\
\begin{array}{l}\text { and personnel (perfor- } \\
\text { mance bias) }\end{array}\end{array}$ & Low risk & $\begin{array}{l}\text { Quote: "... central coordinator of the study who was also blinded to the treat- } \\
\text { ment assigned ..." (Page 211) }\end{array}$
\end{tabular}

Citicoline for treating people with acute ischemic stroke (Review) 
Tazaki 1988 (Continued)

All outcomes
Quote: "Suitable provisions were made so that CDP-choline could not be distinguished from the placebo" (Page 211)

\begin{tabular}{|c|c|c|}
\hline $\begin{array}{l}\text { Blinding of outcome as- } \\
\text { sessment (detection bias) }\end{array}$ & Low risk & $\begin{array}{l}\text { Quote: "Those carrying out the clinical assessments in the study were also } \\
\text { blinded to the treatment assigned." (Page } 211 \text { ) }\end{array}$ \\
\hline
\end{tabular}

All outcomes

Incomplete outcome data Low risk
(attrition bias)

(attrition bias)

All outcomes
- Dropouts: $1.83 \%(5 / 272)$

- Citicoline (1000 mg): 2

- Placebo: 3

\begin{tabular}{lll}
\hline $\begin{array}{l}\text { Selective reporting (re- } \\
\text { porting bias) }\end{array}$ & Low risk & $\begin{array}{l}\text { There was relevant information about the major clinical outcomes and ad- } \\
\text { verse events. However, this trial reported other measures for assessing clinical } \\
\text { effectiveness }\end{array}$ \\
\hline Other bias & High risk & Design bias \\
\hline
\end{tabular}

\section{Warach 2000}

\section{Study characteristics}

\begin{tabular}{|c|c|}
\hline Methods & $\begin{array}{l}\text { - Parallel design ( } 2 \text { arms) } \\
\text { - Multicenter study: no (16 centers) } \\
\text { - International: no } \\
\text { - Country: USA } \\
\text { - Treatment duration: } 6 \text { weeks } \\
\text { - Follow-up period: } 12 \text { weeks } \\
\text { - Timing for starting citicoline treatment: unclear } \\
\text { - Type of trial (superiority, equivalence or non-inferiority trial): not reported }\end{array}$ \\
\hline Participants & $\begin{array}{l}\text { - Type of participants: acute stroke participants when treated within } 24 \text { hours (screened: 2300; random- } \\
\text { ized: } 100) \\
\text { - Citicoline ( } 500 \mathrm{mg}): 50 \\
\text { - Placebo: } 50 \\
\text { - Analyzed } \\
\text { - Citicoline ( } 500 \mathrm{mg}): 41 \\
\text { - Placebo: } 40 \\
\text { - Age (year, mean, SE) } \\
\text { - Citicoline ( } 500 \mathrm{mg}): 68.5(1.7) \\
\text { - Placebo: } 72.1(1.9) \\
\text { - Sex (men, \%) } \\
\text { - Citicoline ( } 500 \mathrm{mg}): 56 \\
\text { - Placebo: } 47 \\
\text { - Prior stroke or TIA (\%) } \\
\text { - Citicoline ( } 500 \mathrm{mg}): 49 \\
\text { - Placebo: } 35 \\
\text { - Left hemisphere stroke (\%) } \\
\text { - Citicoline ( } 500 \mathrm{mg}): 63 \\
\text { - Placebo: } 53 \\
\text { - Baseline National Institutes of Health Stroke scale score (mean, SE) } \\
\text { - Citicoline ( } 500 \mathrm{mg}): 11.5 \text { (0.7) } \\
\text { - Placebo: } 12.7(0.9)\end{array}$ \\
\hline
\end{tabular}


Warach 2000 (Continued)

- Baseline lesion (cc) (mean, SE)

- Citicoline (500 mg): 25.7 (3.4)

- Placebo: 31.9 (5.7)

- Time (hours) stroke to scan (mean, SE)

- Citicoline (500 mg): 13.5 (0.9)

- Placebo: 11.9 (1.0)

- Time (hours) scan to treatment (mean, SE)

- Citicoline (500 mg): 1.6 (0.1)

- Placebo: 1.5 (0.1)

- Time (hours) stroke to treatment (mean, SE)

- Citicoline (500 mg): 15.1 (0.9)

- Placebo: 13.5 (1.0)

- Inclusion criteria

- Age 18 years or older

- Clinical diagnosis of ischemic stroke and symptoms first observed 24 hours or less

- Score on the National Institutes of Health stroke scale score of at least 5 (with at least 2 points due to motor deficit)\$

- An ischemic lesion on the initial diffusion-weighted magnetic resonance imaging involving hemispheric gray matter, specifically the cerebral cortex and/or basal ganglia, of 1 cc or greater and 66 cc or less within the territory of the middle cerebral artery.

After Clark 1999, the protocol was amended:

\$: the minimum National Institutes of Health stroke scale score was raised to 8

\#: the maximum lesion volume at enrollment was raised to $120 \mathrm{cc}$, and the localization was expanded

to include all hemispheric gray matter

- Exclusion criteria

- Participants with a Rankin score greater than or equal to 3 before the index stroke

- Comorbid medical condition compromising study participation or confounding data interpretation

- Contraindication to magnetic resonance imaging

- Experimental use of thrombolytics

- Previous participation in a prior citicoline study

Interventions

- Experimental: citicoline, 1 tablet (500 mg), daily for 6 weeks

- Control: placebo. Additional information was not supplied

- Co-intervention: not reported

Outcomes

- Primary

* Change in lesion volume from baseline to week 12

- Secondary

* Quote: "effect of co-variates on lesion change as well as the correlation of imaging results (using both primary and derived measures) to clinical outcomes (using an improvement on the NIHSS of seven points or greater)."

Notes

- There is no information regarding the impact of the amendment of this protocol

- Identifier trial number: not stated

- Trial conduction dates: not given

- A priori sample estimation: yes. It was not estimated for clinical outcomes

- Financial disclosures: 1 author was a consultant for Interneuron Pharmaceuticals, Lexington, MA, during the time Warach 2000 was conducted

- Other disclosures: none

- Funding/support: Interneuron Pharmaceuticals, Lexington, MA 
Warach 2000 (Continued)

- Role of sponsor: not stated

\section{Risk of bias}

\begin{tabular}{|c|c|c|}
\hline Bias & Authors' judgement & Support for judgement \\
\hline $\begin{array}{l}\text { Random sequence genera- } \\
\text { tion (selection bias) }\end{array}$ & Unclear risk & $\begin{array}{l}\text { Quote: "... } 6 \text { weeks after randomization." (Page } 715 \text { ) } \\
\text { Insufficient information to permit judgment of 'low risk' or 'high risk' }\end{array}$ \\
\hline $\begin{array}{l}\text { Allocation concealment } \\
\text { (selection bias) }\end{array}$ & Unclear risk & Insufficient information to permit judgment of 'low risk' or 'high risk' \\
\hline $\begin{array}{l}\text { Blinding of participants } \\
\text { and personnel (perfor- } \\
\text { mance bias) } \\
\text { All outcomes }\end{array}$ & Unclear risk & $\begin{array}{l}\text { Quote: "... double-blind fashion for } 6 \text { weeks ..." (Page } 715 \text { ) } \\
\text { Insufficient information to permit judgment of 'low risk' or 'high risk' } \\
\text { Trial authors provided no information regarding how to guarantee appropriate } \\
\text { blinding }\end{array}$ \\
\hline $\begin{array}{l}\text { Blinding of outcome as- } \\
\text { sessment (detection bias) } \\
\text { All outcomes }\end{array}$ & Low risk & $\begin{array}{l}\text { Quote: "Those performing image reading and quantification were blinded to } \\
\text { both treatment assignment and clinical status of patients." (Page 715) }\end{array}$ \\
\hline $\begin{array}{l}\text { Incomplete outcome data } \\
\text { (attrition bias) } \\
\text { All outcomes }\end{array}$ & High risk & $\begin{array}{l}\text { - Dropouts: } 19 \%(19 / 100) \\
\text { - Citicoline ( } 500 \mathrm{mg}): 18 \%(9 / 50) \\
\text { - Placebo: } 20 \%(10 / 50)\end{array}$ \\
\hline $\begin{array}{l}\text { Selective reporting (re- } \\
\text { porting bias) }\end{array}$ & Low risk & $\begin{array}{l}\text { There was information regarding death, NIH Stroke Scale score and adverse } \\
\text { events }\end{array}$ \\
\hline Other bias & High risk & $\begin{array}{l}\text { Measurements and confounding biases: there is no information regarding the } \\
\text { impact of the amendment of this protocol } \\
\text { Funding bias }\end{array}$ \\
\hline
\end{tabular}

IQR: interquartile range

SD: standard deviation

SE: standard error

TIA: transient ischemic attack

Characteristics of excluded studies [ordered by study ID]

\begin{tabular}{ll}
\hline Study & Reason for exclusion \\
\hline Dereux 1987 & RCT; reported no clinical diagnosis with imaging \\
\hline Djoenady 1981 & RCT; reported no clinical diagnosis with imaging \\
\hline ECCS- AlS 2012 & RCT; reported no clinical diagnosis with imaging \\
\hline Garcia Pastor 2004 & RCT; reported no clinical diagnosis with imaging \\
\hline Goas 1980 & RCT; reported no clinical diagnosis with imaging \\
\hline Melnikova 2011 & RCT; reported no clinical diagnosis with imaging \\
\hline
\end{tabular}




\section{Study}

Reason for exclusion

Panteleienko 2009
$\mathrm{RCT}$; reported no clinical diagnosis with imaging

$\mathrm{RCT}$ : randomized controlled trial

Characteristics of studies awaiting classification [ordered by study ID]

Hassan 2019

\begin{tabular}{ll}
\hline Methods & Awaiting classification \\
\hline Participants & \\
\hline Interventions & \\
\hline Outcomes & \\
\hline Notes
\end{tabular}

Characteristics of ongoing studies [ordered by study ID]

CTRI/2018/02/011900

\begin{tabular}{|c|c|}
\hline Study name & Citicoline in acute ischemic stroke - a randomized control trial \\
\hline Methods & $\begin{array}{l}\text { - Randomized } \\
\text { - } 2 \text { arms }\end{array}$ \\
\hline Participants & $\begin{array}{l}\text { - Acute ischemic stroke } \\
\text { - Age > } 18 \text { years } \\
\text { - Satisfying criteria for reperfusion therapy (thrombolysis or thrombectomy) }\end{array}$ \\
\hline Interventions & $\begin{array}{l}\text { - Citicoline arm: } 1 \text { gm intravenous therapy for } 3 \text { days followed by oral treatment (1000 mg twice } \\
\text { daily) for } 39 \text { days } \\
\text { - Placebo arm: no more information }\end{array}$ \\
\hline Outcomes & $\begin{array}{l}\text { - Primary outcome is change in stroke volume from baseline to week } 6 \\
\text { - Secondary outcomes are mRS 0-2, NIHSS 0-2, Barthel Index more than or equal to } 95 \text { and mor- } \\
\text { tality at } 90 \text { days }\end{array}$ \\
\hline Starting date & Not reported \\
\hline Contact information & $\begin{array}{l}\text { A Agarwal } \\
\text { All India Institute of Medical Sciences, Neurology, New Delhi }\end{array}$ \\
\hline Notes & $\begin{array}{l}\text { Estimated sample size: } 116 \text { participants in } 2 \text { years } \\
\text { Information gathered from World Stroke Congress 2018, Montreal } \\
\text { (journals.sagepub.com/doi/10.1177/1747493018789543) }\end{array}$ \\
\hline
\end{tabular}


IRCT201601289014N90

\begin{tabular}{|c|c|}
\hline Study name & $\begin{array}{l}\text { - Scientific title: Effect of citicoline versus placebo on clinical signs in patients with acute ischemic } \\
\text { and hemorrhagic stroke: a triple blind control trial } \\
\text { - Public title: Effect of citicoline versus placebo on clinical signs in patients with acute ischemic and } \\
\text { hemorrhagic stroke }\end{array}$ \\
\hline Methods & $\begin{array}{l}\text { - Purpose: treatment } \\
\text { - Parallel-design } \\
\text { - Randomized } \\
\text { - Binding: triple blind control trial } \\
\text { - Phase: } 2 \\
\text { - Sample size (target sample size): } 160\end{array}$ \\
\hline Participants & $\begin{array}{l}\text { - Age: between } 18 \text { years-old and } 85 \text { years old } \\
\text { - Sex: both } \\
\text { - Inclusion criteria } \\
\text { - Age of } 18 \text { to } 85 \text { years } \\
\text { - Acute stroke } \\
\text { - NIHSS score between } 6 \text { to } 22 \\
\text { - Exclusion criteria: } \\
\text { - History of stroke } \\
\text { - Renal or liver disorder } \\
\text { - Neoplasia } \\
\text { - Active infectious disease during last month } \\
\text { - Trauma or surgery during last month } \\
\text { - History of collagen vascular disease } \\
\text { - Immunosuppressive medications or corticosteroid } \\
\text { - Signs of brain hernia } \\
\text { - Convulsion at the time of stroke } \\
\text { - Neurologic disease or dementia } \\
\text { - Pregnancy or breastfeeding } \\
\text { - Receiving vasodilator medications }\end{array}$ \\
\hline Interventions & $\begin{array}{l}\text { - Experimental group: infusion of citicoline } 1 \mathrm{gr} \text { in normal saline (overall } 20 \mathrm{~mL} \text { ) once daily for } 10 \\
\text { days } \\
\text { - Control group: infusion of } 20 \mathrm{~mL} \text { normal saline once daily for } 10 \text { days }\end{array}$ \\
\hline Outcomes & $\begin{array}{l}\text { - Primary outcomes (at baseline and } 10 \text { and } 90 \text { days after intervention) } \\
\text { - Bational Institutes of Health Stroke Scale } \\
\text { - Modified Rankin Scale } \\
\text { - Secondary outcomes: not stated }\end{array}$ \\
\hline
\end{tabular}

Starting date

Expected recruitment start date: 20 February 2016

Expected recruitment end date: 18 February 2017

Contact information

Dr Shahir Mazaheri, Sina Hospital, Mirzadeh Eshghi Ave. Hamadan, Iran (Islamic Republic of)

E-mail: sh.mazaheri@umsha.ac.ir

Phone: +98 8138274184 
IRCT201601289014N90 (Continued)

Notes

Sponsors/Funding sources: Vice-chancellor for Research the Technology, Hamadan University of Medical Sciences, Dr Saeid Bashirian, Hamadan, University of Medical Scienc1868e165s, Shahid Fahmideh Ave., Hamadan, Iran (Islamic Republic of)

DATA AND ANALYSES

Comparison 1. Citicoline versus placebo or not intervention

\begin{tabular}{|c|c|c|c|c|}
\hline Outcome or subgroup title & No. of studies & $\begin{array}{l}\text { No. of partici- } \\
\text { pants }\end{array}$ & Statistical method & Effect size \\
\hline 1.1 All-cause mortality & 8 & 4362 & $\begin{array}{l}\text { Risk Ratio (M-H, Fixed, } \\
95 \% \mathrm{Cl})\end{array}$ & $0.94[0.83,1.07]$ \\
\hline 1.1.1 Citicoline 500 mg/day & 2 & 494 & $\begin{array}{l}\text { Risk Ratio (M-H, Fixed, } \\
95 \% \mathrm{Cl})\end{array}$ & $1.07[0.70,1.62]$ \\
\hline 1.1.2 Citicoline $1000 \mathrm{mg} /$ day & 1 & 272 & $\begin{array}{l}\text { Risk Ratio (M-H, Fixed, } \\
95 \% \mathrm{Cl})\end{array}$ & $0.57[0.22,1.50]$ \\
\hline 1.1.3 Citicoline 500,1000 or $2000 \mathrm{mg} /$ day & 1 & 259 & $\begin{array}{l}\text { Risk Ratio (M-H, Fixed, } \\
95 \% \mathrm{Cl})\end{array}$ & $1.01[0.52,1.94]$ \\
\hline 1.1.4 Citicoline 2000 mg/day & 4 & 3337 & $\begin{array}{l}\text { Risk Ratio (M-H, Fixed, } \\
95 \% \mathrm{Cl})\end{array}$ & $0.94[0.81,1.08]$ \\
\hline 1.2 All-cause mortality: subgroup analysis & 8 & 4362 & $\begin{array}{l}\text { Risk Ratio (M-H, Fixed, } \\
95 \% \mathrm{Cl})\end{array}$ & $0.94[0.83,1.07]$ \\
\hline $\begin{array}{l}\text { 1.2.1 Trials without support by pharma- } \\
\text { ceutical companies }\end{array}$ & 2 & 335 & $\begin{array}{l}\text { Risk Ratio (M-H, Fixed, } \\
95 \% \mathrm{Cl})\end{array}$ & $0.78[0.41,1.49]$ \\
\hline $\begin{array}{l}\text { 1.2.2 Trials supported by pharmaceutical } \\
\text { companies }\end{array}$ & 6 & 4027 & $\begin{array}{l}\text { Risk Ratio (M-H, Fixed, } \\
95 \% \mathrm{Cl})\end{array}$ & $0.95[0.83,1.08]$ \\
\hline 1.3 All-cause mortality: subgroup analysis & 8 & 4362 & $\begin{array}{l}\text { Risk Ratio (M-H, Fixed, } \\
95 \% \mathrm{Cl})\end{array}$ & $0.94[0.83,1.07]$ \\
\hline 1.3.1 Trials with $\leq 200$ participants & 3 & 240 & $\begin{array}{l}\text { Risk Ratio (M-H, Fixed, } \\
95 \% \mathrm{Cl})\end{array}$ & $1.26[0.70,2.29]$ \\
\hline 1.3.2 Trials with $>200$ participants & 5 & 4122 & $\begin{array}{l}\text { Risk Ratio (M-H, Fixed, } \\
95 \% \mathrm{Cl})\end{array}$ & $0.93[0.81,1.06]$ \\
\hline $\begin{array}{l}\text { 1.4 All-cause mortality: sensitivity analy- } \\
\text { sis: impact of missing outcome data }\end{array}$ & 8 & 4362 & $\begin{array}{l}\text { Risk Ratio (M-H, Fixed, } \\
95 \% \mathrm{Cl})\end{array}$ & $0.94[0.83,1.07]$ \\
\hline 1.4.1 Trials non-reporting missing data & 4 & 1615 & $\begin{array}{l}\text { Risk Ratio (M-H, Fixed, } \\
95 \% \mathrm{Cl})\end{array}$ & $0.99[0.79,1.23]$ \\
\hline
\end{tabular}




\begin{tabular}{|c|c|c|c|c|}
\hline Outcome or subgroup title & No. of studies & $\begin{array}{l}\text { No. of partici- } \\
\text { pants }\end{array}$ & Statistical method & Effect size \\
\hline 1.4.2 Trials reporting missing data & 4 & 2747 & $\begin{array}{l}\text { Risk Ratio (M-H, Fixed, } \\
95 \% \mathrm{Cl})\end{array}$ & $0.92[0.78,1.07]$ \\
\hline $\begin{array}{l}1.5 \text { All-cause mortality: sensitivity analy- } \\
\text { sis: best-case scenario }\end{array}$ & 8 & & $\begin{array}{l}\text { Risk Ratio (IV, Fixed, 95\% } \\
\mathrm{Cl} \text { ) }\end{array}$ & Subtotals only \\
\hline 1.5.1 Trials without missing data & 4 & & $\begin{array}{l}\text { Risk Ratio (IV, Fixed, 95\% } \\
\mathrm{Cl} \text { ) }\end{array}$ & $0.99[0.80,1.24]$ \\
\hline 1.5.2 Trial with missing data & 4 & & $\begin{array}{l}\text { Risk Ratio (IV, Fixed, 95\% } \\
\mathrm{CI} \text { ) }\end{array}$ & $0.42[0.37,0.49]$ \\
\hline $\begin{array}{l}\text { 1.6 All-cause mortality: sensitivity analy- } \\
\text { sis: worst-case scenario }\end{array}$ & 8 & & $\begin{array}{l}\text { Risk Ratio (IV, Fixed, 95\% } \\
\mathrm{Cl} \text { ) }\end{array}$ & Subtotals only \\
\hline 1.6.1 Trials without missing data & 4 & & $\begin{array}{l}\text { Risk Ratio (IV, Fixed, 95\% } \\
\mathrm{CI} \text { ) }\end{array}$ & $0.99[0.79,1.23]$ \\
\hline 1.6.2 Trial with missing data & 4 & & $\begin{array}{l}\text { Risk Ratio (IV, Fixed, 95\% } \\
\mathrm{CI} \text { ) }\end{array}$ & $2.04[1.79,2.33]$ \\
\hline $\begin{array}{l}\text { 1.7 All-cause mortality: sensitivity analy- } \\
\text { sis: the Gamble-Hollis analysis }\end{array}$ & 8 & & $\begin{array}{l}\text { Risk Ratio (IV, Fixed, 95\% } \\
\mathrm{CI} \text { ) }\end{array}$ & Subtotals only \\
\hline 1.7.1 Trials without missing data & 4 & & $\begin{array}{l}\text { Risk Ratio (IV, Fixed, 95\% } \\
\mathrm{CI} \text { ) }\end{array}$ & $0.99[0.79,1.23]$ \\
\hline 1.7.2 Trial with missing data & 4 & & $\begin{array}{l}\text { Risk Ratio (IV, Fixed, 95\% } \\
\mathrm{CI} \text { ) }\end{array}$ & $0.86[0.45,1.64]$ \\
\hline $\begin{array}{l}\text { 1.8 Patients with moderate or lower de- } \\
\text { gree of disability or dependence (accord- } \\
\text { ing to }<3 \text { scores in the modified Rankin } \\
\text { scale) }\end{array}$ & 4 & 3668 & $\begin{array}{l}\text { Risk Ratio (M-H, Fixed, } \\
95 \% \mathrm{Cl})\end{array}$ & $1.11[0.97,1.26]$ \\
\hline $\begin{array}{l}\text { 1.9 Patients with moderate or lower de- } \\
\text { gree of disability or dependence (accord- } \\
\text { ing to }<3 \text { scores in the modified Rankin } \\
\text { scale): subgroup analysis }\end{array}$ & 4 & 3668 & $\begin{array}{l}\text { Risk Ratio (M-H, Fixed, } \\
95 \% \mathrm{Cl})\end{array}$ & $1.11[0.97,1.26]$ \\
\hline 1.9.1 Trials with $\leq 200$ participants & 1 & 77 & $\begin{array}{l}\text { Risk Ratio (M-H, Fixed, } \\
95 \% \mathrm{Cl})\end{array}$ & $1.33[0.67,2.67]$ \\
\hline 1.9.2 Trials with $>200$ participants & 3 & 3591 & $\begin{array}{l}\text { Risk Ratio (M-H, Fixed, } \\
95 \% \mathrm{Cl})\end{array}$ & $1.10[0.96,1.25]$ \\
\hline $\begin{array}{l}1.10 \text { Patients with moderate or lower de- } \\
\text { gree of disability or dependence (accord- } \\
\text { ing to }<3 \text { scores in the modified Rankin } \\
\text { scale): sensitivity analysis: impact of } \\
\text { missing outcome data }\end{array}$ & 4 & & $\begin{array}{l}\text { Risk Ratio (M-H, Fixed, } \\
95 \% \mathrm{Cl})\end{array}$ & Subtotals only \\
\hline 1.10.1 Trials without missing data & 2 & 1293 & $\begin{array}{l}\text { Risk Ratio (M-H, Fixed, } \\
95 \% \mathrm{Cl})\end{array}$ & $1.23[1.01,1.50]$ \\
\hline
\end{tabular}




\begin{tabular}{|c|c|c|c|c|}
\hline Outcome or subgroup title & No. of studies & $\begin{array}{l}\text { No. of partici- } \\
\text { pants }\end{array}$ & Statistical method & Effect size \\
\hline 1.10.2 Trials with missing data & 2 & 2375 & $\begin{array}{l}\text { Risk Ratio (M-H, Fixed, } \\
95 \% \mathrm{Cl})\end{array}$ & $1.03[0.87,1.22]$ \\
\hline $\begin{array}{l}1.11 \text { Patients with moderate or lower de- } \\
\text { gree of disability or dependence (accord- } \\
\text { ing to }<3 \text { scores in the modified Rankin } \\
\text { scale): sensitivity analysis: best-case sce- } \\
\text { nario }\end{array}$ & 4 & & $\begin{array}{l}\text { Risk Ratio (IV, Fixed, 95\% } \\
\mathrm{CI} \text { ) }\end{array}$ & Subtotals only \\
\hline 1.11.1 Trial without missing data & 2 & & $\begin{array}{l}\text { Risk Ratio (IV, Fixed, 95\% } \\
\mathrm{CI} \text { ) }\end{array}$ & $1.23[1.00,1.50]$ \\
\hline 1.11.2 Trial with missing data & 2 & & $\begin{array}{l}\text { Risk Ratio (IV, Fixed, 95\% } \\
\mathrm{CI})\end{array}$ & $0.44[0.39,0.51]$ \\
\hline $\begin{array}{l}1.12 \text { Patients with moderate or lower de- } \\
\text { gree of disability or dependence (accord- } \\
\text { ing to }<3 \text { scores in the modified Rankin } \\
\text { scale): sensitivity analysis: worst-case } \\
\text { scenario }\end{array}$ & 4 & & $\begin{array}{l}\text { Risk Ratio (IV, Fixed, 95\% } \\
\mathrm{CI} \text { ) }\end{array}$ & Subtotals only \\
\hline 1.12.1 Trial without missing data & 2 & & $\begin{array}{l}\text { Risk Ratio (IV, Fixed, 95\% } \\
\mathrm{Cl} \text { ) }\end{array}$ & $1.23[1.00,1.50]$ \\
\hline 1.12.2 Trial with missing data & 2 & & $\begin{array}{l}\text { Risk Ratio (IV, Fixed, 95\% } \\
\mathrm{CI} \text { ) }\end{array}$ & $2.33[2.03,2.69]$ \\
\hline $\begin{array}{l}1.13 \text { Patients with moderate or lower de- } \\
\text { gree of disability or dependence (accord- } \\
\text { ing to }<3 \text { scores in the modified Rankin } \\
\text { scale): sensitivity analysis: the Gam- } \\
\text { ble-Hollis analysis }\end{array}$ & 4 & & $\begin{array}{l}\text { Risk Ratio (IV, Fixed, 95\% } \\
\mathrm{CI} \text { ) }\end{array}$ & Subtotals only \\
\hline 1.13.1 Trial without missing data & 2 & & $\begin{array}{l}\text { Risk Ratio (IV, Fixed, 95\% } \\
\mathrm{CI} \text { ) }\end{array}$ & $1.23[1.00,1.50]$ \\
\hline 1.13.2 Trial with missing data & 2 & & $\begin{array}{l}\text { Risk Ratio (IV, Fixed, 95\% } \\
\mathrm{CI} \text { ) }\end{array}$ & $1.14[0.54,2.42]$ \\
\hline 1.14 Severe adverse events & 5 & & $\begin{array}{l}\text { Risk Ratio (M-H, Fixed, } \\
95 \% \mathrm{Cl})\end{array}$ & Subtotals only \\
\hline 1.14.1 Cardiovascular & 3 & 3591 & $\begin{array}{l}\text { Risk Ratio (M-H, Fixed, } \\
95 \% \mathrm{Cl})\end{array}$ & $1.04[0.84,1.29]$ \\
\hline $\begin{array}{l}\text { 1.14.2 Central nervous system (including } \\
\text { hemorrhagic or ischemic stroke) }\end{array}$ & 3 & 3591 & $\begin{array}{l}\text { Risk Ratio (M-H, Fixed, } \\
95 \% \mathrm{Cl})\end{array}$ & $1.30[1.07,1.59]$ \\
\hline 1.14.3 Respiratory (including pneumonia) & 3 & 3591 & $\begin{array}{l}\text { Risk Ratio (M-H, Fixed, } \\
95 \% \mathrm{Cl})\end{array}$ & $1.01[0.78,1.31]$ \\
\hline 1.14.4 Gastrointestinal & 3 & 1370 & $\begin{array}{l}\text { Risk Ratio (M-H, Fixed, } \\
95 \% \mathrm{Cl})\end{array}$ & $0.64[0.40,1.00]$ \\
\hline
\end{tabular}




\begin{tabular}{|c|c|c|c|c|}
\hline Outcome or subgroup title & No. of studies & $\begin{array}{l}\text { No. of partici- } \\
\text { pants }\end{array}$ & Statistical method & Effect size \\
\hline 1.14.5 Musculoskeletal & 2 & 1293 & $\begin{array}{l}\text { Risk Ratio (M-H, Fixed, } \\
95 \% \mathrm{Cl})\end{array}$ & $1.52[0.50,4.60]$ \\
\hline 1.14.6 Hepatic dysfunction & 1 & 267 & $\begin{array}{l}\text { Risk Ratio (M-H, Fixed, } \\
95 \% \mathrm{Cl})\end{array}$ & $0.78[0.18,3.41]$ \\
\hline 1.14.7 Renal and urologic disorders & 3 & 1560 & $\begin{array}{l}\text { Risk Ratio (M-H, Fixed, } \\
95 \% \mathrm{Cl})\end{array}$ & $2.04[0.99,4.22]$ \\
\hline 1.14.8 Hematological disorders & 3 & 1560 & $\begin{array}{l}\text { Risk Ratio (M-H, Fixed, } \\
95 \% \mathrm{Cl})\end{array}$ & $1.27[0.46,3.51]$ \\
\hline 1.15 Non-severe adverse events & 1 & & $\begin{array}{l}\text { Risk Ratio (M-H, Fixed, } \\
95 \% \mathrm{Cl})\end{array}$ & Subtotals only \\
\hline 1.15.1 Cardiac disorders & 1 & 2298 & $\begin{array}{l}\text { Risk Ratio (M-H, Fixed, } \\
95 \% \mathrm{Cl})\end{array}$ & $0.94[0.82,1.08]$ \\
\hline 1.15.2 Pyrexia & 1 & 2298 & $\begin{array}{l}\text { Risk Ratio (M-H, Fixed, } \\
95 \% \mathrm{Cl})\end{array}$ & $1.02[0.87,1.19]$ \\
\hline 1.15.3 Constipation & 1 & 2298 & $\begin{array}{l}\text { Risk Ratio (M-H, Fixed, } \\
95 \% \mathrm{Cl})\end{array}$ & $1.03[0.88,1.20]$ \\
\hline 1.15.4 Urinary tract infections & 1 & 2298 & $\begin{array}{l}\text { Risk Ratio (M-H, Fixed, } \\
95 \% \mathrm{Cl})\end{array}$ & $1.06[0.89,1.26]$ \\
\hline 1.15.5 Headache & 1 & 2298 & $\begin{array}{l}\text { Risk Ratio (M-H, Fixed, } \\
95 \% \mathrm{Cl})\end{array}$ & $0.96[0.79,1.18]$ \\
\hline 1.15.6 Nausea and vomiting symptoms & 1 & 2298 & $\begin{array}{l}\text { Risk Ratio (M-H, Fixed, } \\
95 \% \mathrm{Cl})\end{array}$ & $0.95[0.77,1.16]$ \\
\hline 1.15.7 Agitation & 1 & 2298 & $\begin{array}{l}\text { Risk Ratio (M-H, Fixed, } \\
95 \% \mathrm{Cl})\end{array}$ & $1.20[0.94,1.54]$ \\
\hline $\begin{array}{l}\text { 1.15.8 Hemorrhagic transformation } \\
\text { stroke }\end{array}$ & 1 & 2298 & $\begin{array}{l}\text { Risk Ratio (M-H, Fixed, } \\
95 \% \mathrm{Cl})\end{array}$ & $0.98[0.74,1.29]$ \\
\hline 1.15.9 Pneumonia & 1 & 2298 & $\begin{array}{l}\text { Risk Ratio (M-H, Fixed, } \\
95 \% \mathrm{Cl})\end{array}$ & $1.02[0.73,1.41]$ \\
\hline 1.15.10 Hypotension & 1 & 2298 & $\begin{array}{l}\text { Risk Ratio (M-H, Fixed, } \\
95 \% \mathrm{Cl})\end{array}$ & $0.92[0.63,1.36]$ \\
\hline $\begin{array}{l}\text { 1.16 Functional recovery: assessed with } \\
\text { the Barthel Index }\end{array}$ & 6 & & $\begin{array}{l}\text { Risk Ratio (M-H, Fixed, } \\
95 \% \mathrm{Cl})\end{array}$ & Subtotals only \\
\hline 1.16 .150 points & 1 & 77 & $\begin{array}{l}\text { Risk Ratio (M-H, Fixed, } \\
95 \% \mathrm{Cl})\end{array}$ & $1.26[0.71,2.26]$ \\
\hline 1.16.2 $\geq 95$ points & 4 & 3850 & $\begin{array}{l}\text { Risk Ratio (M-H, Fixed, } \\
95 \% \mathrm{Cl})\end{array}$ & $1.03[0.94,1.13]$ \\
\hline
\end{tabular}




\begin{tabular}{lllll}
\hline Outcome or subgroup title & No. of studies & $\begin{array}{l}\text { No. of partici- } \\
\text { pants }\end{array}$ & Statistical method & Effect size \\
\hline 1.16 .385 to 100 points & 1 & 63 & $\begin{array}{l}\text { Risk Ratio (M-H, Fixed, } \\
95 \% \mathrm{Cl})\end{array}$ & $3.12[1.10,8.91]$ \\
\hline $\begin{array}{l}1.17 \text { Patients with minor impairment (ac- } \\
\text { cording to } 1 \text { scores in the National Insti- } \\
\text { tutes of Health Stroke Scale) }\end{array}$ & 5 & 3950 & $\begin{array}{l}\text { Risk Ratio (M-H, Fixed, } \\
95 \% \mathrm{Cl})\end{array}$ & $1.08[0.96,1.21]$ \\
\hline
\end{tabular}

\section{Analysis 1.1. Comparison 1: Citicoline versus placebo or not intervention, Outcome 1: All-cause mortality}

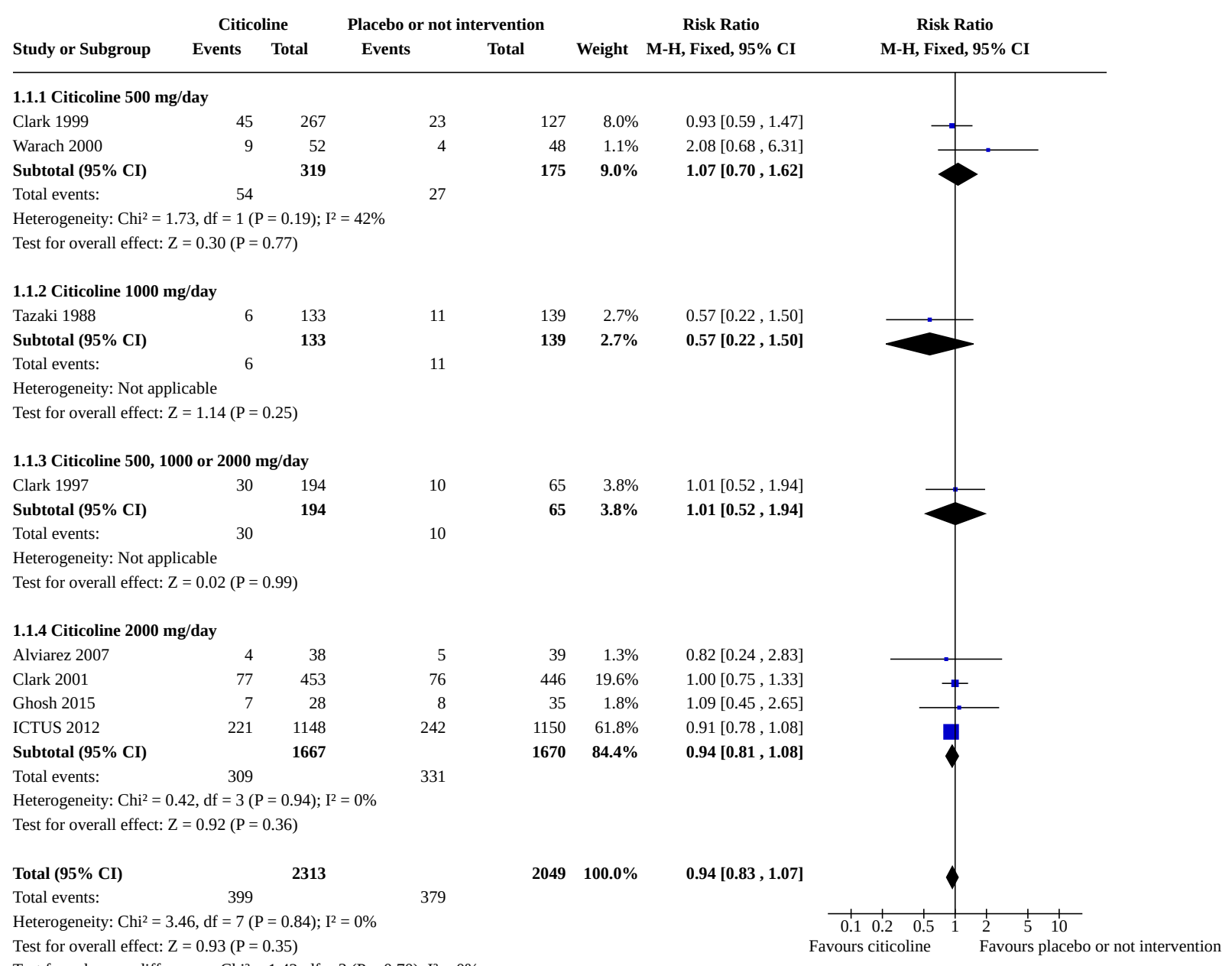




\section{Analysis 1.2. Comparison 1: Citicoline versus placebo or not intervention, Outcome 2: All-cause mortality: subgroup analysis}

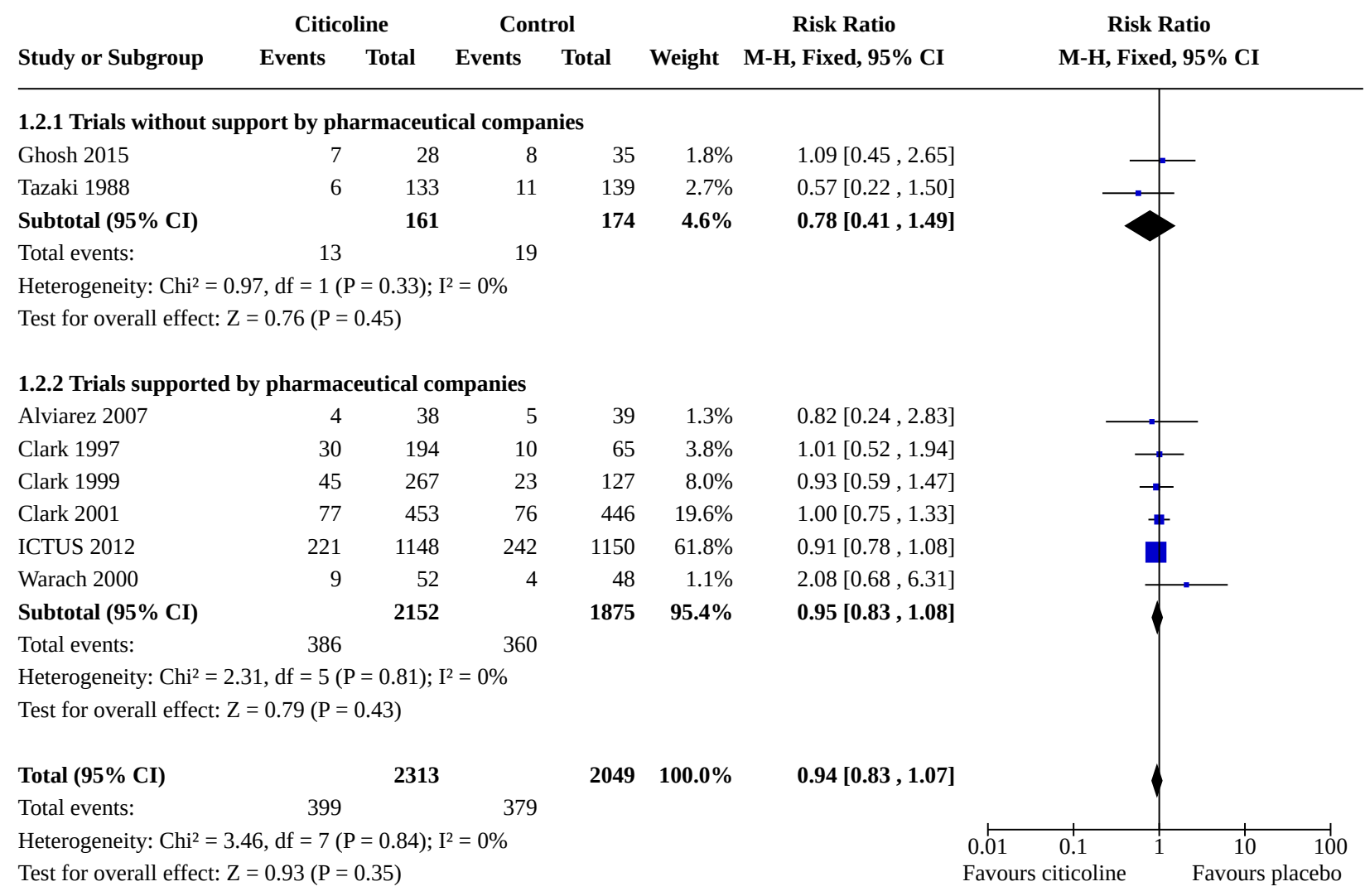


Analysis 1.3. Comparison 1: Citicoline versus placebo or not intervention, Outcome 3: All-cause mortality: subgroup analysis

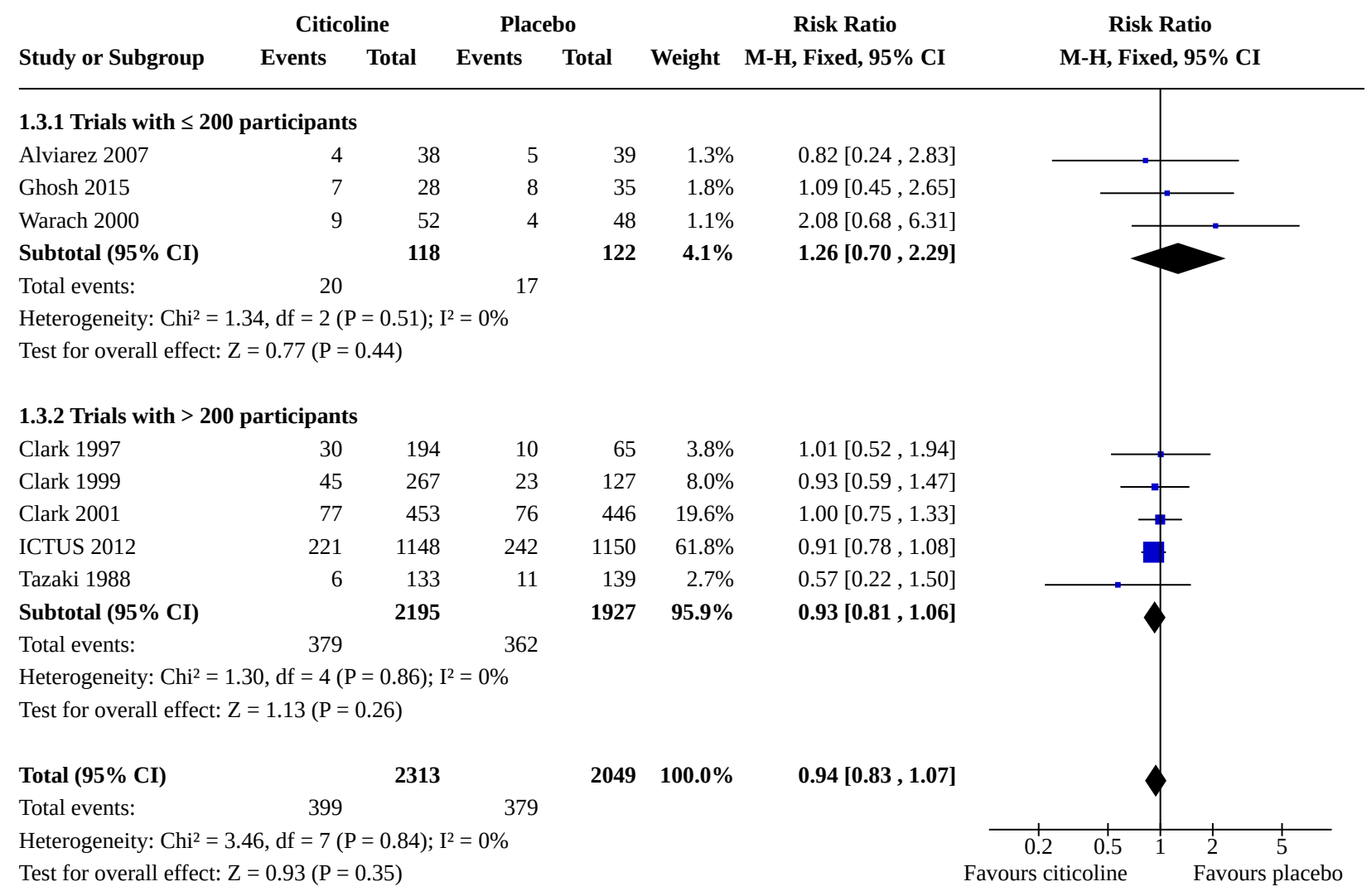


Analysis 1.4. Comparison 1: Citicoline versus placebo or not intervention, Outcome 4: All-cause mortality: sensitivity analysis: impact of missing outcome data

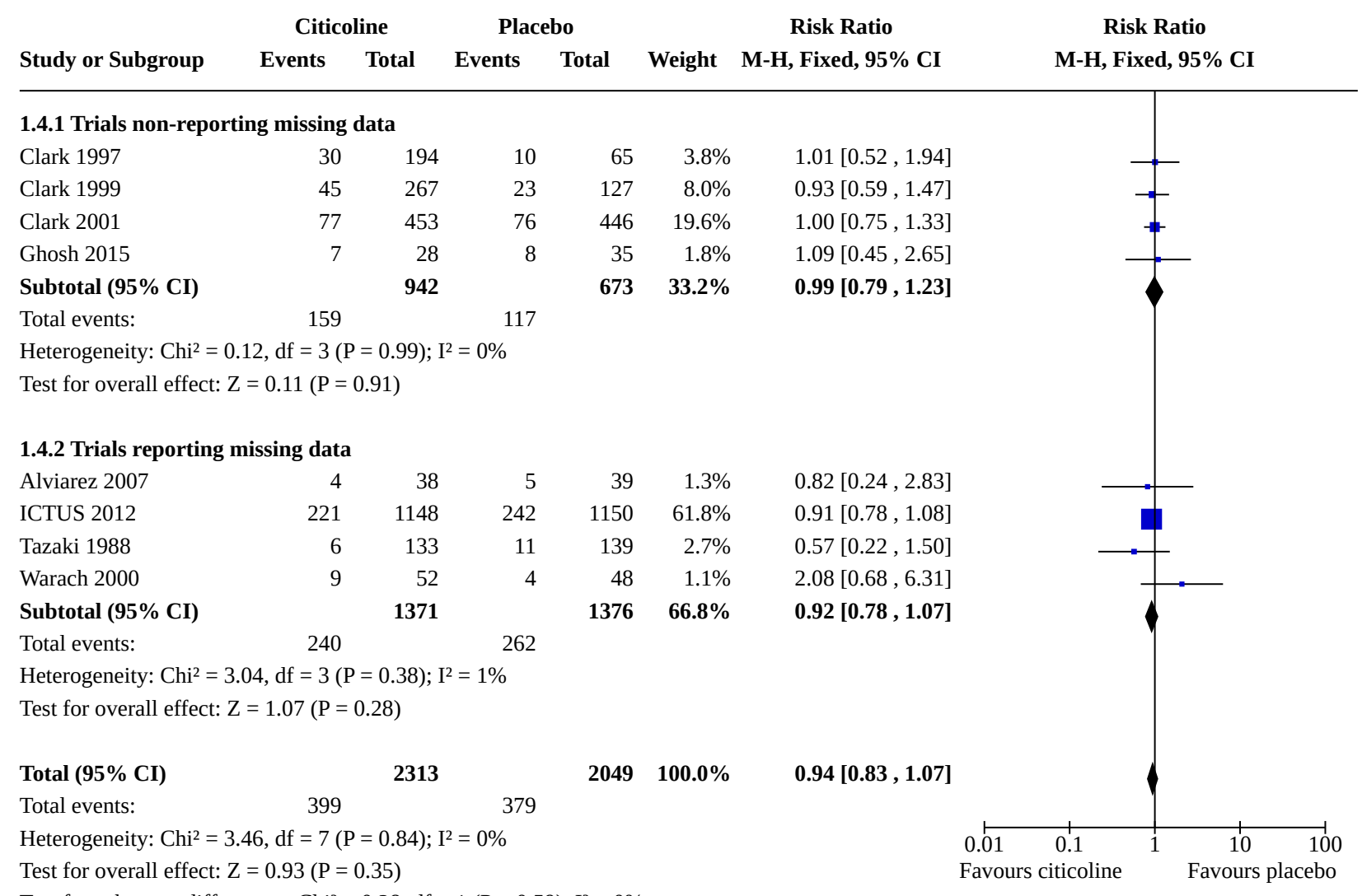


Analysis 1.5. Comparison 1: Citicoline versus placebo or not intervention, Outcome 5: All-cause mortality: sensitivity analysis: best-case scenario

\begin{tabular}{|c|c|c|c|c|}
\hline Study or Subgroup & $\log [R R]$ & SE & Weight & $\begin{array}{c}\text { Risk Ratio } \\
\text { IV, Fixed, 95\% CI }\end{array}$ \\
\hline \multicolumn{5}{|c|}{ 1.5.1 Trials without missing data } \\
\hline Clark 1997 & 0.05 & 0.336 & $11.3 \%$ & $1.05[0.54,2.03]$ \\
\hline Clark 1999 & -0.071 & 0.233 & $23.5 \%$ & $0.93[0.59,1.47]$ \\
\hline Clark 2001 & -0.002 & 0.147 & $59.0 \%$ & $1.00[0.75,1.33]$ \\
\hline Ghosh 2015 & 0.09 & 0.451 & $6.3 \%$ & $1.09[0.45,2.65]$ \\
\hline Subtotal (95\% CI) & & & $100.0 \%$ & $0.99[0.80,1.24]$ \\
\hline
\end{tabular}

Heterogeneity: $\mathrm{Chi}^{2}=0.15, \mathrm{df}=3(\mathrm{P}=0.98) ; \mathrm{I}^{2}=0 \%$

Test for overall effect: $\mathrm{Z}=0.06(\mathrm{P}=0.95)$

1.5.2 Trial with missing data

$\begin{array}{lrrrr}\text { Alviarez 2007 } & -1.187 & 0.528 & 1.7 \% & 0.31[0.11,0.86] \\ \text { ICTUS 2012 } & -0.865 & 0.071 & 93.1 \% & 0.42[0.37,0.48] \\ \text { Tazaki 1988 } & -0.796 & 0.474 & 2.1 \% & 0.45[0.18,1.14] \\ \text { Warach 2000 } & -0.493 & 0.386 & 3.1 \% & 0.61[0.29,1.30] \\ \text { Subtotal (95\% CI) } & & & \mathbf{1 0 0 . 0 \%} & \mathbf{0 . 4 2}[\mathbf{0 . 3 7}, \mathbf{0 . 4 9}]\end{array}$

Heterogeneity: $\mathrm{Chi}^{2}=1.31, \mathrm{df}=3(\mathrm{P}=0.73) ; \mathrm{I}^{2}=0 \%$

Test for overall effect: $\mathrm{Z}=12.51(\mathrm{P}<0.00001)$

Test for subgroup differences: $\mathrm{Chi}^{2}=41.51, \mathrm{df}=1(\mathrm{P}<0.00001), \mathrm{I}^{2}=97.6 \%$

Risk Ratio

IV, Fixed, 95\% CI 
Analysis 1.6. Comparison 1: Citicoline versus placebo or not intervention, Outcome 6: All-cause mortality: sensitivity analysis: worst-case scenario

\begin{tabular}{lrrrr} 
Study or Subgroup & $\log [\mathbf{R R}]$ & SE & Weight & $\begin{array}{c}\text { Risk Ratio } \\
\text { IV, Fixed, 95\% CI }\end{array}$ \\
\hline 1.6.1 Trials without missing data & & & \\
Clark 1999 & -0.071 & 0.233 & $23.5 \%$ & $0.93[0.59,1.47]$ \\
Clark 2001 & -0.002 & 0.147 & $59.0 \%$ & $1.00[0.75,1.33]$ \\
Clark 1997 & 0.005 & 0.336 & $11.3 \%$ & $1.01[0.52,1.94]$ \\
Ghosh 2015 & 0.09 & 0.451 & $6.3 \%$ & $1.09[0.45,2.65]$ \\
Subtotal (95\% CI) & & & $\mathbf{1 0 0 . 0 \%}$ & $\mathbf{0 . 9 9}[\mathbf{0 . 7 9}, \mathbf{1 . 2 3}$
\end{tabular}

Heterogeneity: $\mathrm{Chi}^{2}=0.12, \mathrm{df}=3(\mathrm{P}=0.99) ; \mathrm{I}^{2}=0 \%$

Test for overall effect: $\mathrm{Z}=0.10(\mathrm{P}=0.92)$

1.6.2 Trial with missing data

$\begin{array}{lrrrr}\text { Tazaki } 1988 & -0.268 & 0.449 & 2.2 \% & 0.76[0.32,1.84] \\ \text { ICTUS 2012 } & 0.722 & 0.069 & 94.3 \% & 2.06[1.80,2.36] \\ \text { Alviarez 2007 } & 0.853 & 0.498 & 1.8 \% & 2.35[0.88,6.23] \\ \text { Warach 2000 } & 1.454 & 0.521 & 1.7 \% & 4.28[1.54,11.88] \\ \text { Subtotal (95\% CI) } & & & \mathbf{1 0 0 . 0 \%} & \mathbf{2 . 0 4}[\mathbf{1 . 7 9}, \mathbf{2 . 3 3}]\end{array}$

Heterogeneity: $\mathrm{Chi}^{2}=6.89, \mathrm{df}=3(\mathrm{P}=0.08) ; \mathrm{I}^{2}=56 \%$

Test for overall effect: $\mathrm{Z}=10.66(\mathrm{P}<0.00001)$

Test for subgroup differences: $\mathrm{Chi}^{2}=30.59, \mathrm{df}=1(\mathrm{P}<0.00001), \mathrm{I}^{2}=96.7 \%$

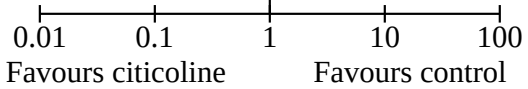


Analysis 1.7. Comparison 1: Citicoline versus placebo or not intervention, Outcome 7: All-cause mortality: sensitivity analysis: the Gamble-Hollis analysis

Risk Ratio

Study or Subgroup $\quad \log [R R] \quad$ SE $\quad$ Weight $\quad$ IV, Fixed, 95\% CI
Risk Ratio

IV, Fixed, 95\% CI

1.7.1 Trials without missing data

Clark 1997

Clark $1999 \quad-0.071$

$0.336 \quad 11.3 \%$

$1.01[0.52,1.94]$

Clark 1999

0.233

$23.5 \%$

$0.93[0.59,1.47]$

Clark 2001

$-0.002$

0.147

$59.0 \%$

1.00 [0.75, 1.33]

Ghosh 2015

0.09

0.451

$6.3 \%$

$1.09[0.45,2.65]$

Subtotal (95\% CI)

$100.0 \%$

0.99 [0.79, 1.23]

Heterogeneity: $\mathrm{Chi}^{2}=0.12, \mathrm{df}=3(\mathrm{P}=0.99) ; \mathrm{I}^{2}=0 \%$

Test for overall effect: $\mathrm{Z}=0.10(\mathrm{P}=0.92)$

1.7.2 Trial with missing data

$\begin{array}{lrrrr}\text { Alviarez 2007 } & -0.197 & 1.034 & 10.1 \% & 0.82[0.11,6.23] \\ \text { ICTUS 2012 } & -0.089 & 0.475 & 47.7 \% & 0.91[0.36,2.32] \\ \text { Tazaki 1988 } & -0.562 & 0.596 & 30.3 \% & 0.57[0.18,1.83] \\ \text { Warach 2000 } & 0.731 & 0.95 & 11.9 \% & 2.08[0.32,13.37] \\ \text { Subtotal (95\% CI) } & & & \mathbf{1 0 0 . 0 \%} & \mathbf{0 . 8 6}[\mathbf{0 . 4 5}, \mathbf{1 . 6 4}]\end{array}$

Heterogeneity: $\mathrm{Chi}^{2}=1.36, \mathrm{df}=3(\mathrm{P}=0.72) ; \mathrm{I}^{2}=0 \%$

Test for overall effect: $\mathrm{Z}=0.44(\mathrm{P}=0.66)$

Test for subgroup differences: Chi $^{2}=0.15, \mathrm{df}=1(\mathrm{P}=0.70), \mathrm{I}^{2}=0 \%$
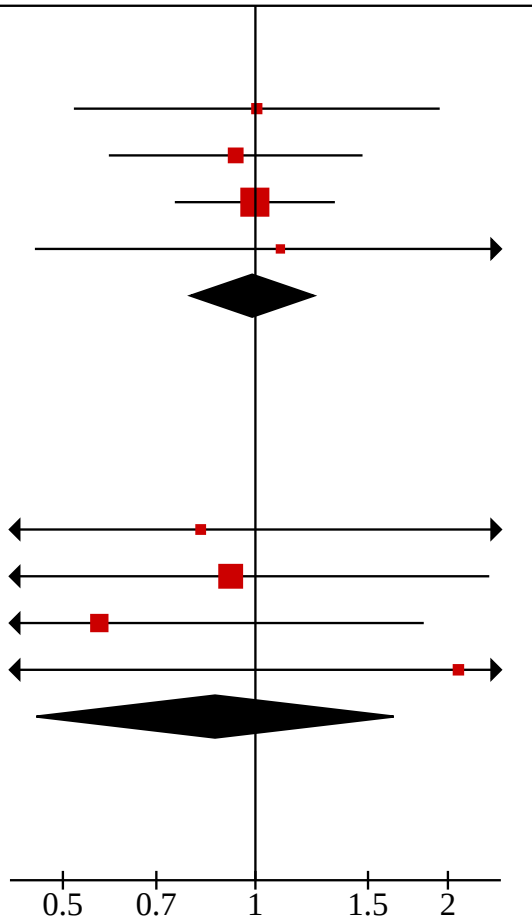

Favours citicoline Favours control

Analysis 1.8. Comparison 1: Citicoline versus placebo or not intervention, Outcome 8: Patients with moderate or lower degree of disability or dependence (according to $<3$ scores in the modified Rankin scale)

\begin{tabular}{lccccccc} 
& \multicolumn{2}{c}{ Citicoline } & \multicolumn{2}{c}{ Placebo } & \multicolumn{2}{c}{ Risk Ratio } & \multicolumn{2}{c}{ Risk Ratio } \\
Study or Subgroup & Events & Total & Events & Total & Weight & M-H, Fixed, 95\% CI & M-H, Fixed, 95\% CI
\end{tabular}

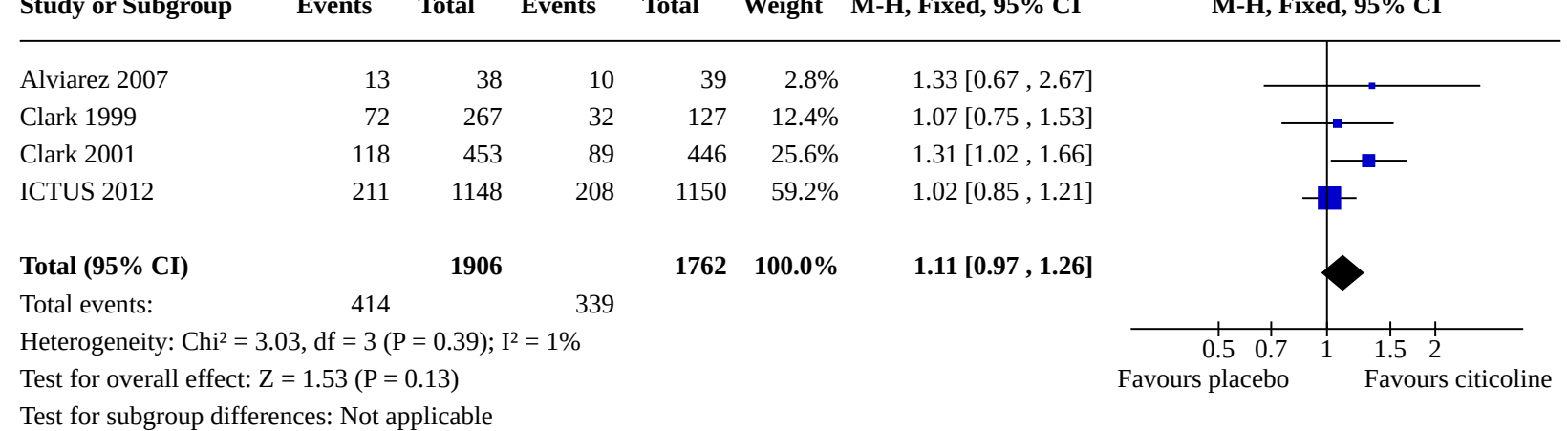


Analysis 1.9. Comparison 1: Citicoline versus placebo or not intervention, Outcome 9: Patients with moderate or lower degree of disability or dependence (according to $<3$ scores in the modified Rankin scale): subgroup analysis

\begin{tabular}{|c|c|c|c|c|c|c|c|}
\hline \multirow[b]{2}{*}{ Study or Subgroup } & \multicolumn{2}{|c|}{ Citicoline } & \multicolumn{2}{|c|}{ Placebo } & \multirow[b]{2}{*}{ Weight } & \multirow{2}{*}{$\begin{array}{c}\text { Risk Ratio } \\
\text { M-H,Fixed, 95\% CI }\end{array}$} & \multirow{2}{*}{$\begin{array}{c}\text { Risk Ratio } \\
\text { M-H, Fixed, 95\% CI }\end{array}$} \\
\hline & Events & Total & Events & Total & & & \\
\hline \multicolumn{8}{|c|}{ 1.9.1 Trials with $\leq 200$ participants } \\
\hline Alviarez 2007 & 13 & 38 & 10 & 39 & $2.8 \%$ & $1.33[0.67,2.67]$ & \\
\hline Subtotal (95\% CI) & & 38 & & 39 & $2.8 \%$ & $1.33[0.67,2.67]$ & \\
\hline Total events: & 13 & & 10 & & & & \\
\hline \multicolumn{8}{|c|}{ Heterogeneity: Not applicable } \\
\hline \multicolumn{8}{|c|}{ Test for overall effect: $\mathrm{Z}=0.82(\mathrm{P}=0.41)$} \\
\hline \multicolumn{8}{|c|}{ 1.9.2 Trials with $>200$ participants } \\
\hline Clark 1999 & 72 & 267 & 32 & 127 & $12.4 \%$ & $1.07[0.75,1.53]$ & $=$ \\
\hline Clark 2001 & 118 & 453 & 89 & 446 & $25.6 \%$ & $1.31[1.02,1.66]$ & - \\
\hline ICTUS 2012 & 211 & 1148 & 208 & 1150 & $59.2 \%$ & $1.02[0.85,1.21]$ & \\
\hline Subtotal (95\% CI) & & 1868 & & 1723 & $97.2 \%$ & $1.10[0.96,1.25]$ & \\
\hline Total events: & 401 & & 329 & & & & \\
\hline \multicolumn{8}{|c|}{ Heterogeneity: $\mathrm{Chi}^{2}=2.75, \mathrm{df}=2(\mathrm{P}=0.25) ; \mathrm{I}^{2}=27 \%$} \\
\hline \multicolumn{8}{|c|}{ Test for overall effect: $\mathrm{Z}=1.41(\mathrm{P}=0.16)$} \\
\hline Total (95\% CI) & & 1906 & & 1762 & $100.0 \%$ & $1.11[0.97,1.26]$ & \\
\hline Total events: & 414 & & 339 & & & & \\
\hline \multicolumn{7}{|c|}{ Heterogeneity: $\mathrm{Chi}^{2}=3.03, \mathrm{df}=3(\mathrm{P}=0.39) ; \mathrm{I}^{2}=1 \%$} & 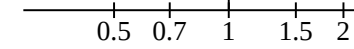 \\
\hline \multicolumn{7}{|c|}{ Test for overall effect: $\mathrm{Z}=1.53(\mathrm{P}=0.13)$} & Favours placebo \\
\hline
\end{tabular}

Analysis 1.10. Comparison 1: Citicoline versus placebo or not intervention, Outcome 10: Patients with moderate or lower degree of disability or dependence (according to $<3$ scores in the modified Rankin scale): sensitivity analysis: impact of missing outcome data

\begin{tabular}{|c|c|c|c|c|c|c|c|}
\hline & Citi & & & & & Risk Ratio & Risk Ratio \\
\hline Study or Subgroup & Events & Total & Events & Total & Weight & M-H, Fixed, 95\% CI & M-H, Fixed, 95\% CI \\
\hline
\end{tabular}

\begin{tabular}{lrrrrrr}
\hline 1.10.1 Trials without missing data & & & & & \\
Clark 1999 & 72 & 267 & 32 & 127 & $32.6 \%$ & $1.07[0.75,1.53]$ \\
Clark 2001 & 118 & 453 & 89 & 446 & $67.4 \%$ & $1.31[1.02,1.66]$ \\
Subtotal (95\% CI) & & $\mathbf{7 2 0}$ & & $\mathbf{5 7 3}$ & $\mathbf{1 0 0 . 0 \%}$ & $\mathbf{1 . 2 3}[\mathbf{1 . 0 1} \mathbf{1 . 5 0}$ \\
Total events: & 190 & & 121 & & &
\end{tabular}

Heterogeneity: $\mathrm{Chi}^{2}=0.81, \mathrm{df}=1(\mathrm{P}=0.37) ; \mathrm{I}^{2}=0 \%$

Test for overall effect: $\mathrm{Z}=2.01(\mathrm{P}=0.04)$

1.10.2 Trials with missing data

\begin{tabular}{|c|c|c|c|c|c|c|}
\hline Alviarez 2007 & 13 & 38 & 10 & 39 & $4.5 \%$ & $1.33[0.67,2.67]$ \\
\hline ICTUS 2012 & 211 & 1148 & 208 & 1150 & $95.5 \%$ & $1.02[0.85,1.21]$ \\
\hline Subtotal $(95 \%$ CI) & & 1186 & & 1189 & $100.0 \%$ & $1.03[0.87,1.22]$ \\
\hline Total events: & 224 & & 218 & & & \\
\hline
\end{tabular}

Heterogeneity: $\mathrm{Chi}^{2}=0.56, \mathrm{df}=1(\mathrm{P}=0.45) ; \mathrm{I}^{2}=0 \%$

Test for overall effect: $\mathrm{Z}=0.35(\mathrm{P}=0.73)$

Test for subgroup differences: $\mathrm{Chi}^{2}=1.74, \mathrm{df}=1(\mathrm{P}=0.19), \mathrm{I}^{2}=42.4 \%$

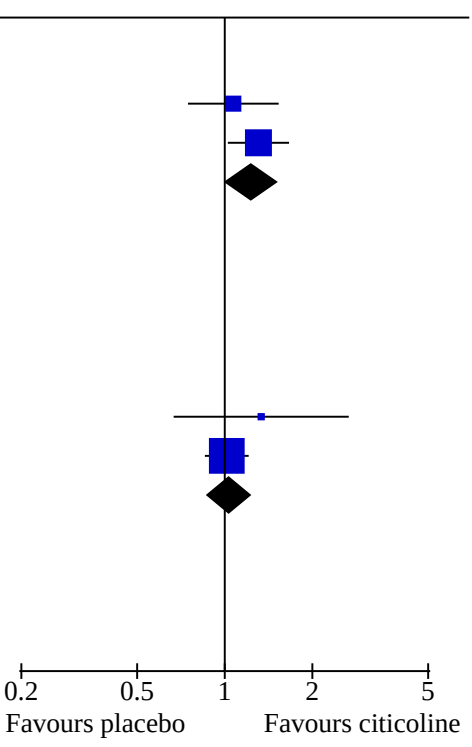


Analysis 1.11. Comparison 1: Citicoline versus placebo or not intervention, Outcome 11: Patients with moderate or lower degree of disability or dependence (according to $<3$ scores in the modified Rankin scale): sensitivity analysis: best-case scenario

Risk Ratio

Study or Subgroup $\quad \log [R R] \quad$ SE $\quad$ Weight $\quad$ IV, Fixed, 95\% C
Risk Ratio

IV, Fixed, 95\% CI

1.11.1 Trial without missing data

Clark 1999

0.068

0.183

$31.1 \%$

$1.07[0.75,1.53]$

Clark 2001

0.266

0.123

$68.9 \%$

$1.30[1.03,1.66]$

Subtotal (95\% CI)

$100.0 \%$

$1.23[1.00,1.50]$

Heterogeneity: $\mathrm{Chi}^{2}=0.81, \mathrm{df}=1(\mathrm{P}=0.37) ; \mathrm{I}^{2}=0 \%$

Test for overall effect: $\mathrm{Z}=2.00(\mathrm{P}=0.05)$

1.11.2 Trial with missing data

$\begin{array}{lrrrr}\text { Alviarez } 2007 & -0.315 & 0.294 & 5.8 \% & 0.73[0.41,1.30] \\ \text { ICTUS 2012 } & -0.846 & 0.073 & 94.2 \% & 0.43[0.37,0.50] \\ \text { Subtotal (95\% CI) } & & & \mathbf{1 0 0 . 0 \%} & \mathbf{0 . 4 4}[\mathbf{0 . 3 9}, \mathbf{0 . 5 1}]\end{array}$

Heterogeneity: $\mathrm{Chi}^{2}=3.07, \mathrm{df}=1(\mathrm{P}=0.08) ; \mathrm{I}^{2}=67 \%$

Test for overall effect: $\mathrm{Z}=11.51(\mathrm{P}<0.00001)$

Test for subgroup differences: $\mathrm{Chi}^{2}=67.32, \mathrm{df}=1(\mathrm{P}<0.00001), \mathrm{I}^{2}=98.5 \%$

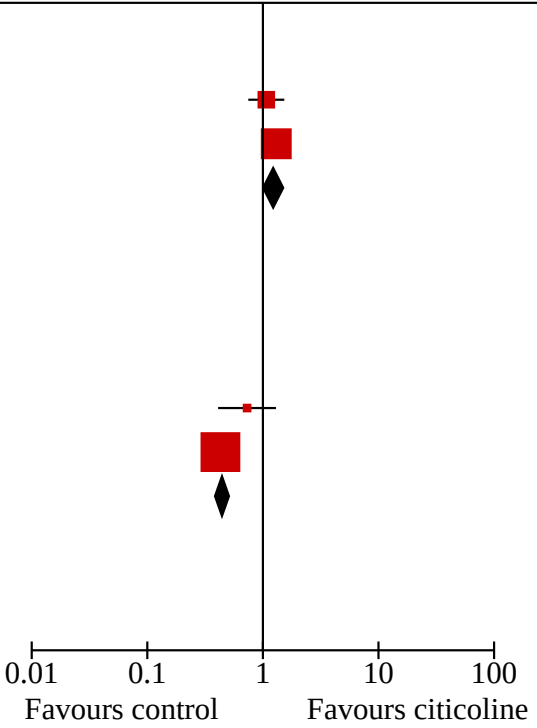

Analysis 1.12. Comparison 1: Citicoline versus placebo or not intervention, Outcome 12: Patients with moderate or lower degree of disability or dependence (according to $<3$ scores in the modified Rankin scale): sensitivity analysis: worst-case scenario

\begin{tabular}{lrrrr} 
Study or Subgroup & $\log [\mathrm{RR}]$ & SE & Weight & $\begin{array}{c}\text { Risk Ratio } \\
\text { IV, Fixed, 95\% CI }\end{array}$ \\
\hline 1.12.1 Trial without missing data & & & \\
Clark 1999 & 0.068 & 0.183 & $31.1 \%$ & $1.07[0.75,1.53]$ \\
Clark 2001 & 0.266 & 0.123 & $68.9 \%$ & $1.30[1.03,1.66]$ \\
Subtotal (95\% CI) & & & $\mathbf{1 0 0 . 0 \%}$ & $\mathbf{1 . 2 3}[\mathbf{1 . 0 0}, \mathbf{1 . 5 0}]$
\end{tabular}

Heterogeneity: $\mathrm{Chi}^{2}=0.81, \mathrm{df}=1(\mathrm{P}=0.37) ; \mathrm{I}^{2}=0 \%$

Test for overall effect: $\mathrm{Z}=2.00(\mathrm{P}=0.05)$

1.12.2 Trial with missing data

$\begin{array}{lrrrr}\text { Alviarez } 2007 & 0.758 & 0.327 & 4.9 \% & 2.13[1.12,4.05] \\ \text { ICTUS 2012 } & 0.852 & 0.074 & 95.1 \% & 2.34[2.03,2.71] \\ \text { Subtotal (95\% CI) } & & & \mathbf{1 0 0 . 0 \%} & \mathbf{2 . 3 3}[\mathbf{2 . 0 3}, \mathbf{2 . 6 9}]\end{array}$

Heterogeneity: $\mathrm{Chi}^{2}=0.08, \mathrm{df}=1(\mathrm{P}=0.78) ; \mathrm{I}^{2}=0 \%$

Test for overall effect: $\mathrm{Z}=11.74(\mathrm{P}<0.00001)$

Test for subgroup differences: $\mathrm{Chi}^{2}=26.45, \mathrm{df}=1(\mathrm{P}<0.00001), \mathrm{I}^{2}=96.2 \%$

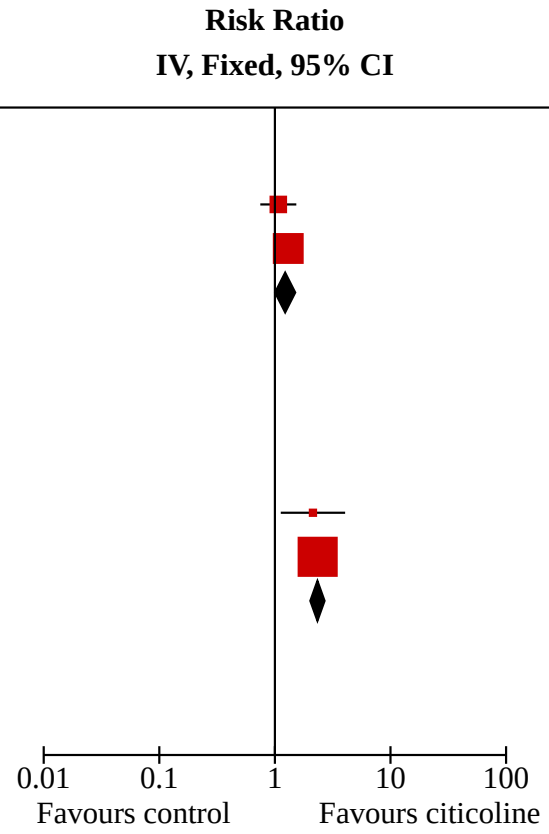


Analysis 1.13. Comparison 1: Citicoline versus placebo or not intervention, Outcome 13: Patients with moderate or lower degree of disability or dependence (according to < 3 scores in the modified Rankin scale): sensitivity analysis: the Gamble-Hollis analysis

Risk Ratio

Study or Subgroup $\log [R R]$
Weight
Risk Ratio

IV, Fixed, 95\% CI

1.13.1 Trial without missing data

Clark 1999

0.068

0.183

$31.1 \%$

$1.07[0.75,1.53]$

Clark 2001

0.266

0.123

$68.9 \%$

$1.30[1.03,1.66]$

$100.0 \%$

$1.23[1.00,1.50]$

Heterogeneity: $\mathrm{Chi}^{2}=0.81, \mathrm{df}=1(\mathrm{P}=0.37) ; \mathrm{I}^{2}=0 \%$

Test for overall effect: $\mathrm{Z}=2.00(\mathrm{P}=0.05)$

1.13.2 Trial with missing data

$\begin{array}{lrrrr}\text { Alviarez } 2007 & 0.293 & 0.584 & 43.0 \% & 1.34[0.43,4.21] \\ \text { ICTUS 2012 } & 0.016 & 0.507 & 57.0 \% & 1.02[0.38,2.74] \\ \text { Subtotal (95\% CI) } & & & \mathbf{1 0 0 . 0 \%} & \mathbf{1 . 1 4}[\mathbf{0 . 5 4}, \mathbf{2 . 4 2}]\end{array}$

Heterogeneity: $\mathrm{Chi}^{2}=0.13, \mathrm{df}=1(\mathrm{P}=0.72) ; \mathrm{I}^{2}=0 \%$

Test for overall effect: $\mathrm{Z}=0.35(\mathrm{P}=0.72)$

Test for subgroup differences: $\mathrm{Chi}^{2}=0.03, \mathrm{df}=1(\mathrm{P}=0.86), \mathrm{I}^{2}=0 \%$

\begin{tabular}{cccc}
\hline $\begin{array}{l}1 \\
01\end{array} 0.1$ & 1 & 10 & 100 \\
Favours control & & Favours citicoline
\end{tabular}


Analysis 1.14. Comparison 1: Citicoline versus placebo or not intervention, Outcome 14: Severe adverse events

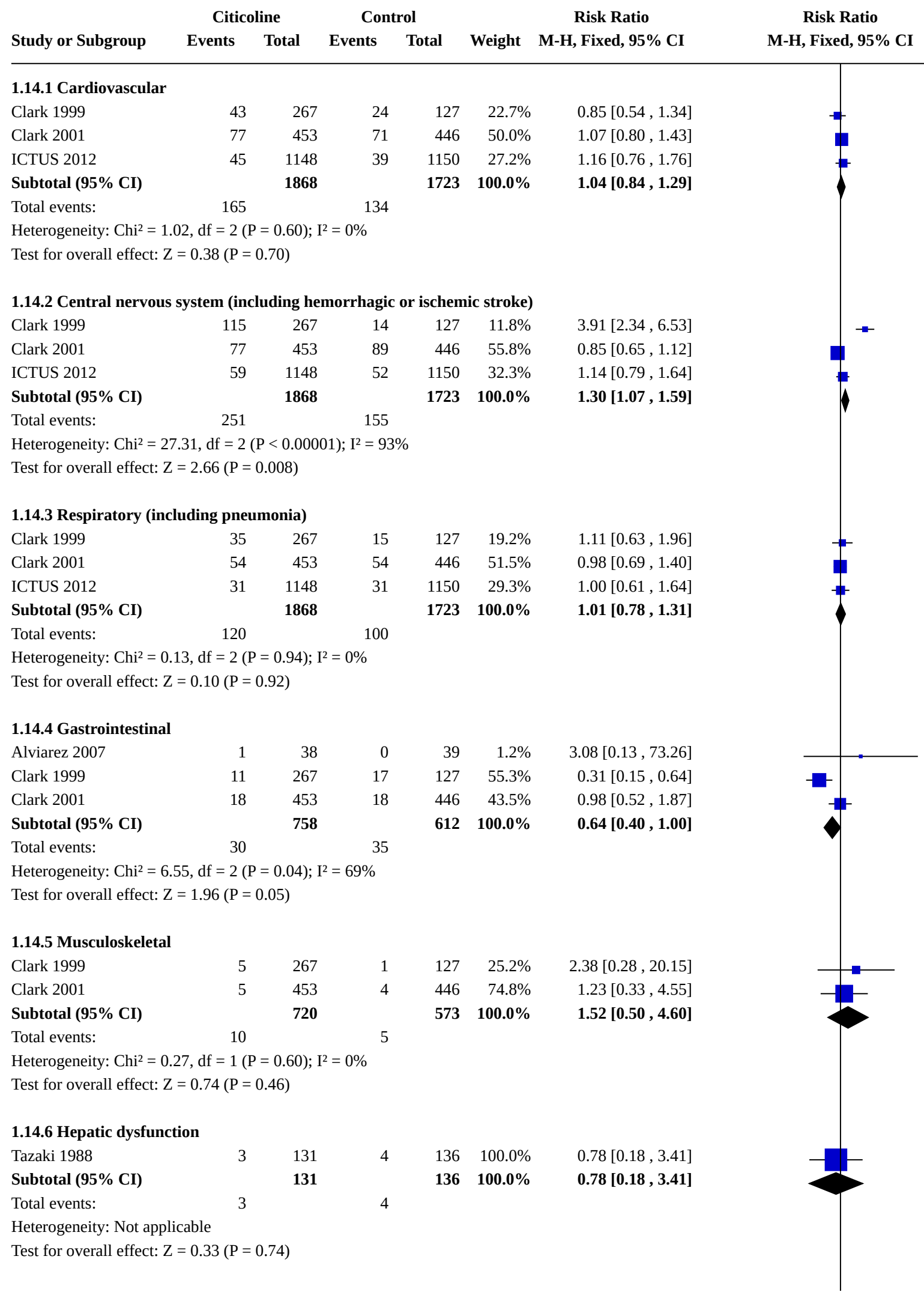


Analysis 1.14. (Continued)

iest ior uveran enect: $L-$ U.ss (r - U.14)

1.14.7 Renal and urologic disorders

$\begin{array}{lrrrrrr}\text { Clark 1999 } & 13 & 267 & 1 & 127 & 11.9 \% & 6.18[0.82,46.75] \\ \text { Clark 2001 } & 14 & 453 & 9 & 446 & 79.5 \% & 1.53[0.67,3.50] \\ \text { Tazaki } 1988 & 1 & 131 & 1 & 136 & 8.6 \% & 1.04[0.07,16.43] \\ \text { Subtotal (95\% CI) } & & \mathbf{8 5 1} & & \mathbf{7 0 9} & \mathbf{1 0 0 . 0 \%} & \mathbf{2 . 0 4}[\mathbf{0 . 9 9}, \mathbf{4 . 2 2}] \\ \text { Total events: } & 28 & & 11 & & & \end{array}$

Heterogeneity: $\mathrm{Chi}^{2}=1.85$, df $=2(\mathrm{P}=0.40) ; \mathrm{I}^{2}=0 \%$

Test for overall effect: $\mathrm{Z}=1.93(\mathrm{P}=0.05)$

1.14.8 Hematological disorders

\begin{tabular}{|c|c|c|c|c|c|c|}
\hline Clark 1999 & 5 & 267 & 1 & 127 & $19.8 \%$ & $2.38[0.28,20.15]$ \\
\hline Clark 2001 & 5 & 453 & 4 & 446 & $58.8 \%$ & $1.23[0.33,4.55]$ \\
\hline Tazaki 1988 & 0 & 131 & 1 & 136 & $21.5 \%$ & $0.35[0.01,8.42]$ \\
\hline Subtotal (95\% CI) & & 851 & & 709 & $100.0 \%$ & $1.27[0.46,3.51]$ \\
\hline
\end{tabular}

Total events:

10

Heterogeneity: $\mathrm{Chi}^{2}=0.97, \mathrm{df}=2(\mathrm{P}=0.62) ; \mathrm{I}^{2}=0 \%$

Test for overall effect: $\mathrm{Z}=0.46(\mathrm{P}=0.65)$

Test for subgroup differences: $\mathrm{Chi}^{2}=12.54$, $\mathrm{df}=7(\mathrm{P}=0.08), \mathrm{I}^{2}=44.2 \%$

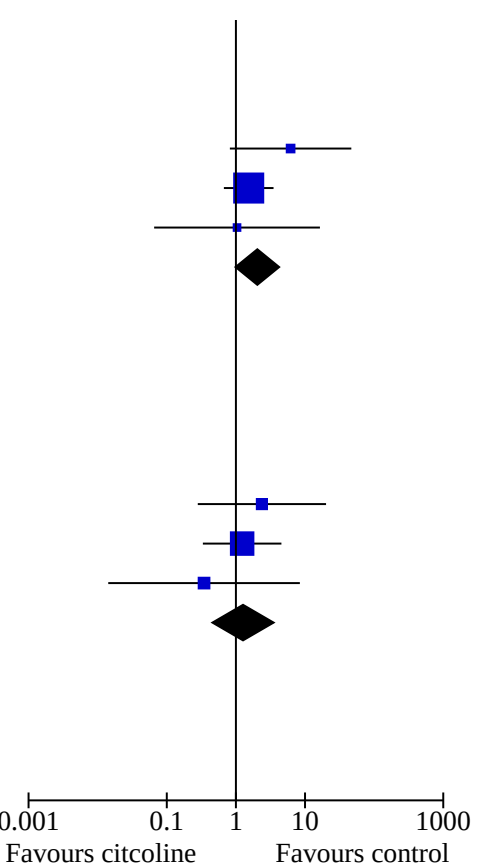


Analysis 1.15. Comparison 1: Citicoline versus placebo or not intervention, Outcome 15: Non-severe adverse events

\begin{tabular}{|c|c|c|c|c|c|c|c|}
\hline \multirow[b]{2}{*}{ Study or Subgroup } & \multicolumn{2}{|c|}{ Citicoline } & \multicolumn{2}{|c|}{ Control } & \multirow[b]{2}{*}{ Weight } & \multirow{2}{*}{$\begin{array}{c}\text { Risk Ratio } \\
\text { M-H, Fixed, 95\% CI }\end{array}$} & \multirow{2}{*}{$\begin{array}{c}\text { Risk Ratio } \\
\text { M-H, Fixed, 95\% CI }\end{array}$} \\
\hline & Events & Total & Events & Total & & & \\
\hline \multicolumn{8}{|c|}{ 1.15.1 Cardiac disorders } \\
\hline ICTUS 2012 & 277 & 1148 & 295 & 1150 & $100.0 \%$ & $0.94[0.82,1.08]$ & \\
\hline Subtotal $(95 \% \mathrm{CI})$ & & 1148 & & 1150 & $100.0 \%$ & $0.94[0.82,1.08]$ & \\
\hline Total events: & 277 & & 295 & & & & \\
\hline \multicolumn{8}{|c|}{ Heterogeneity: Not applicable } \\
\hline \multicolumn{8}{|c|}{ Test for overall effect: $\mathrm{Z}=0.84(\mathrm{P}=0.40)$} \\
\hline \multicolumn{8}{|l|}{ 1.15.2 Pyrexia } \\
\hline ICTUS 2012 & 258 & 1148 & 254 & 1150 & $100.0 \%$ & $1.02[0.87,1.19]$ & \\
\hline Subtotal $(95 \%$ CI) & & 1148 & & 1150 & $100.0 \%$ & $1.02[0.87,1.19]$ & \\
\hline Total events: & 258 & & 254 & & & & \\
\hline \multicolumn{8}{|c|}{ Heterogeneity: Not applicable } \\
\hline \multicolumn{8}{|c|}{ Test for overall effect: $\mathrm{Z}=0.22(\mathrm{P}=0.82)$} \\
\hline \multicolumn{8}{|l|}{ 1.15.3 Constipation } \\
\hline ICTUS 2012 & 245 & 1148 & 239 & 1150 & $100.0 \%$ & $1.03[0.88,1.20]$ & \\
\hline Subtotal $(95 \% \mathrm{CI})$ & & 1148 & & 1150 & $100.0 \%$ & $1.03[0.88,1.20]$ & \\
\hline Total events: & 245 & & 239 & & & & \\
\hline \multicolumn{8}{|c|}{ Heterogeneity: Not applicable } \\
\hline \multicolumn{8}{|c|}{ Test for overall effect: $\mathrm{Z}=0.33(\mathrm{P}=0.74)$} \\
\hline \multicolumn{8}{|c|}{ 1.15.4 Urinary tract infections } \\
\hline ICTUS 2012 & 219 & 1148 & 207 & 1150 & $100.0 \%$ & $1.06[0.89,1.26]$ & \\
\hline Subtotal $(95 \%$ CI) & & 1148 & & 1150 & $100.0 \%$ & $1.06[0.89,1.26]$ & \\
\hline Total events: & 219 & & 207 & & & & \\
\hline \multicolumn{8}{|c|}{ Heterogeneity: Not applicable } \\
\hline \multicolumn{8}{|c|}{ Test for overall effect: $\mathrm{Z}=0.66(\mathrm{P}=0.51)$} \\
\hline \multicolumn{8}{|l|}{ 1.15.5 Headache } \\
\hline ICTUS 2012 & 154 & 1148 & 160 & 1150 & $100.0 \%$ & $0.96[0.79,1.18]$ & \\
\hline Subtotal (95\% CI) & & 1148 & & 1150 & $100.0 \%$ & $0.96[0.79,1.18]$ & \\
\hline Total events: & 154 & & 160 & & & & \\
\hline \multicolumn{8}{|c|}{ Heterogeneity: Not applicable } \\
\hline \multicolumn{8}{|c|}{ Test for overall effect: $\mathrm{Z}=0.35(\mathrm{P}=0.73)$} \\
\hline \multicolumn{8}{|c|}{ 1.15.6 Nausea and vomiting symptoms } \\
\hline ICTUS 2012 & 153 & 1148 & 162 & 1150 & $100.0 \%$ & $0.95[0.77,1.16]$ & \\
\hline Subtotal $(95 \% \mathrm{CI})$ & & 1148 & & 1150 & $100.0 \%$ & $0.95[0.77,1.16]$ & \\
\hline Total events: & 153 & & 162 & & & & \\
\hline Heterogeneity: Not a & cable & & & & & & \\
\hline Test for overall effect & $=0.53(\mathrm{P}=$ & $0.60)$ & & & & & \\
\hline 1.15.7 Agitation & & & & & & & \\
\hline ICTUS 2012 & 125 & 1148 & 104 & 1150 & $100.0 \%$ & $1.20[0.94,1.54]$ & \\
\hline Subtotal (95\% CI) & & 1148 & & 1150 & $100.0 \%$ & $1.20[0.94,1.54]$ & \\
\hline Total events: & 125 & & 104 & & & & \\
\hline Heterogeneity: Not a & cable & & & & & & \\
\hline Test for overall effect & $=1.47(\mathrm{P}=$ & $0.14)$ & & & & & \\
\hline 1.15.8 Hemorrhagic & nsformatio & n stroke & & & & & \\
\hline ICTUS 2012 & 91 & 1148 & 93 & 1150 & $100.0 \%$ & $0.98[0.74,1.29]$ & \\
\hline
\end{tabular}


Analysis 1.15. (Continued)

1.13.0 nemorringic uransiormatuon stroke

$\begin{array}{lcccccc}\text { ICTUS 2012 } & 91 & 1148 & 93 & 1150 & 100.0 \% & 0.98[0.74,1.29] \\ \text { Subtotal (95\% CI) } & & \mathbf{1 1 4 8} & & \mathbf{1 1 5 0} & \mathbf{1 0 0 . 0 \%} & \mathbf{0 . 9 8}[\mathbf{0 . 7 4}, \mathbf{1 . 2 9}] \\ \text { Total events: } & 91 & & 93 & & & \end{array}$

Heterogeneity: Not applicable

Test for overall effect: $\mathrm{Z}=0.14(\mathrm{P}=0.89)$

\subsubsection{Pneumonia}

ICTUS 2012

Subtotal (95\% CI)

$68 \quad 1148$

67

$1150 \quad 100.0 \%$

$1.02[0.73,1.41]$

Total events:

Heterogeneity: Not applicable

Test for overall effect: $Z=0.10(P=0.92)$

\subsubsection{Hypotension}

ICTUS 2012

Subtotal (95\% CI)

Total events:

Heterogeneity: Not applicable

Test for overall effect: $\mathrm{Z}=0.40(\mathrm{P}=0.69)$

Test for subgroup differences: $\mathrm{Chi}^{2}=4.06, \mathrm{df}=9(\mathrm{P}=0.91), \mathrm{I}^{2}=0 \%$

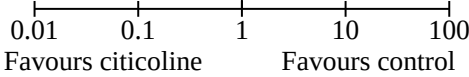


Analysis 1.16. Comparison 1: Citicoline versus placebo or not intervention, Outcome 16: Functional recovery: assessed with the Barthel Index

\begin{tabular}{|c|c|c|c|c|c|c|c|}
\hline \multirow[b]{2}{*}{ Study or Subgroup } & \multicolumn{2}{|c|}{ Citicoline } & \multicolumn{2}{|c|}{ Placebo } & \multirow[b]{2}{*}{ Weight } & \multirow{2}{*}{$\begin{array}{c}\text { Risk Ratio } \\
\text { M-H, Fixed, 95\% CI }\end{array}$} & \multirow{2}{*}{$\begin{array}{c}\text { Risk Ratio } \\
\text { M-H, Fixed, 95\% CI }\end{array}$} \\
\hline & Events & Total & Events & Total & & & \\
\hline \multicolumn{8}{|l|}{ 1.16.1 50 points } \\
\hline Alviarez 2007 & 16 & 38 & 13 & 39 & $100.0 \%$ & $1.26[0.71,2.26]$ & \\
\hline Subtotal (95\% CI) & & 38 & & 39 & $100.0 \%$ & $1.26[0.71,2.26]$ & \\
\hline Total events: & 16 & & 13 & & & & \\
\hline \multicolumn{8}{|c|}{ Heterogeneity: Not applicable } \\
\hline \multicolumn{8}{|c|}{ Test for overall effect: $\mathrm{Z}=0.79(\mathrm{P}=0.43)$} \\
\hline \multicolumn{8}{|l|}{ 1.16.2 $\geq 95$ points } \\
\hline Clark 1997 & 81 & 194 & 21 & 65 & $5.4 \%$ & $1.29[0.88,1.91]$ & \\
\hline Clark 1999 & 107 & 267 & 51 & 127 & $11.9 \%$ & $1.00[0.77,1.29]$ & \\
\hline Clark 2001 & 181 & 453 & 156 & 446 & $27.2 \%$ & $1.14[0.96,1.35]$ & 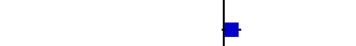 \\
\hline ICTUS 2012 & 307 & 1148 & 321 & 1150 & $55.4 \%$ & $0.96[0.84,1.09]$ & \\
\hline Subtotal (95\% CI) & & 2062 & & 1788 & $100.0 \%$ & $1.03[0.94,1.13]$ & \\
\hline Total events: & 676 & & 549 & & & & \\
\hline \multicolumn{8}{|c|}{ Heterogeneity: $\mathrm{Chi}^{2}=3.92, \mathrm{df}=3(\mathrm{P}=0.27) ; \mathrm{I}^{2}=24 \%$} \\
\hline \multicolumn{8}{|c|}{ Test for overall effect: $\mathrm{Z}=0.64(\mathrm{P}=0.53)$} \\
\hline \multicolumn{8}{|c|}{ 1.16.3 85 to 100 points } \\
\hline Ghosh 2015 & 10 & 28 & 4 & 35 & $100.0 \%$ & $3.13[1.10,8.91]$ & \\
\hline Subtotal (95\% CI) & & 28 & & 35 & $100.0 \%$ & $3.13[1.10,8.91]$ & \\
\hline Total events: & 10 & & 4 & & & & \\
\hline \multicolumn{8}{|c|}{ Heterogeneity: Not applicable } \\
\hline \multicolumn{8}{|c|}{ Test for overall effect: $\mathrm{Z}=2.13(\mathrm{P}=0.03)$} \\
\hline \multicolumn{7}{|c|}{ Test for subgroup differences: $\mathrm{Chi}^{2}=4.69, \mathrm{df}=2(\mathrm{P}=0.10), \mathrm{I}^{2}=57.3 \%$} & $\begin{array}{cc}1 & 1 \\
0.05 & 0.2 \\
\text { Favours } & \text { placebo }\end{array}$ \\
\hline
\end{tabular}

\section{Analysis 1.17. Comparison 1: Citicoline versus placebo or not intervention, Outcome 17: Patients} with minor impairment (according to $\leq 1$ scores in the National Institutes of Health Stroke Scale)

\begin{tabular}{lccccccc} 
& \multicolumn{2}{c}{ Citicoline } & \multicolumn{2}{c}{ Placebo } & \multicolumn{2}{c}{ Risk Ratio } & \multicolumn{2}{c}{ Risk Ratio } \\
Study or Subgroup & Events & Total & Events & Total & Weight & M-H, Fixed, 95\% CI & M-H, Fixed, 95\% CI
\end{tabular}

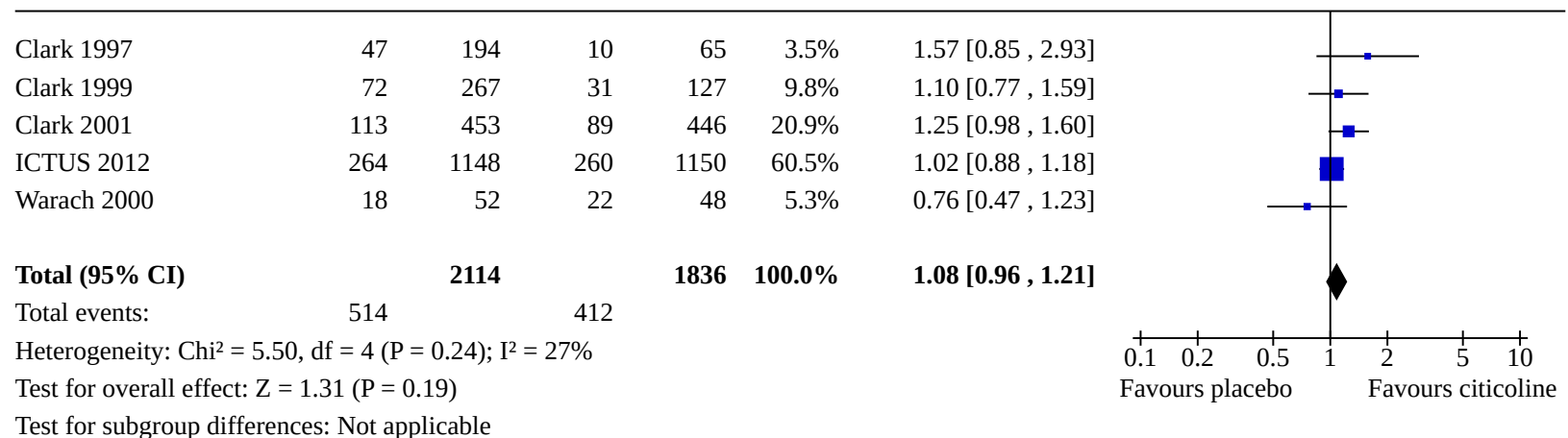

\section{ADDITIONAL TABLES}


Table 1. Meta-analyses with $95 \% \mathrm{Cl}$ using either a fixed-effect or random-effects model results

\begin{tabular}{|c|c|c|}
\hline Outcome & Fixed-effect & Random-effects \\
\hline All-cause mortality & $\begin{array}{l}\text { RR } 0.94,95 \% \mathrm{Cl} 0.83 \text { to } 1.07 ; \mathrm{I}^{2}= \\
0 \%\end{array}$ & $\begin{array}{l}\text { RR } 0.94,95 \% \mathrm{Cl} 0.83 \text { to } 1.07 ; 1^{2}= \\
0 \%\end{array}$ \\
\hline $\begin{array}{l}\text { Degree of disability or dependence in daily activities ac- } \\
\text { cording to the modified Rankin scale }\end{array}$ & $\begin{array}{l}\text { RR } 1.11,95 \% \mathrm{Cl} 0.97 \text { to } 1.26 ; I^{2}= \\
1 \%\end{array}$ & $\begin{array}{l}\mathrm{RR} 1.11,95 \% \mathrm{Cl} 0.97 \text { to } 1.26 ; I^{2}= \\
1 \%\end{array}$ \\
\hline $\begin{array}{l}\text { Severe adverse events (Reporting cardiovascular adverse } \\
\text { events) }\end{array}$ & $\begin{array}{l}\text { RR } 1.0495 \% \mathrm{Cl} 0.84 \text { to } 1.29 ;\left.\right|^{2}= \\
0 \%\end{array}$ & $\begin{array}{l}\text { RR } 1.0495 \% \text { Cl } 0.84 \text { to } 1.28 ; 1^{2}= \\
0 \%\end{array}$ \\
\hline $\begin{array}{l}\text { Functional recovery: assessed with the Barthel Index ( } \geq 95 \\
\text { points) }\end{array}$ & $\begin{array}{l}\text { RR } 1.03,95 \% \mathrm{Cl} 0.94 \text { to } 1.13 ; I^{2}= \\
24 \%\end{array}$ & $\begin{array}{l}\text { RR } 1.05,95 \% \mathrm{Cl} 0.93 \text { to } 1.17 ; 1^{2}= \\
24 \%\end{array}$ \\
\hline $\begin{array}{l}\text { Neurological function assessed with the National Institutes } \\
\text { of Health Stroke Scale (NIHSS): } \leq 1 \text { points) }\end{array}$ & $\begin{array}{l}\text { RR } 1.08,95 \% \mathrm{Cl} 0.96 \text { to } 1.21 ;\left.\right|^{2}= \\
27 \%\end{array}$ & $\begin{array}{l}\text { RR } 1.09,95 \% \mathrm{Cl} 0.93 \text { to } 1.27 ; 1^{2}= \\
27 \%\end{array}$ \\
\hline
\end{tabular}

Table 2. Included trials: description of the harms

\begin{tabular}{|c|c|}
\hline Trials & Harms \\
\hline Alviarez 2007 & $\begin{array}{l}\text { Quote: "A patient in the active group with a history of gastric ulcer presented a digestive bleeding } \\
\text { and the treatment was discontinued; no adverse effects were reported in the placebo group." }\end{array}$ \\
\hline Warach 2000 & $\begin{array}{l}\text { Quote: "Only two adverse events were seen seen in greater incidence in the citicoline group: edema } \\
\text { of the extremities }(p \leq 0.05) \text { and back pain }(p \leq 0.10) . "\end{array}$ \\
\hline Ghosh 2015 & Not reported \\
\hline Guillen 1995 & Quote: "In addition it was tolerated very well." \\
\hline ICTUS 2012 & Appropriate report (Analysis 1.14) \\
\hline Seifaddini 2017 & Not reported \\
\hline Tazaki 1988 & $\begin{array}{l}\text { See Analysis } 1.14 \text { for severe adverse events } \\
\text { Quote: "No serious adverse effects were related to treatment with CDP-choline in any patient with } \\
\text { cerebral infarction." }\end{array}$ \\
\hline Clark 1997 & $\begin{array}{l}\text { Quote: "There were no serious adverse events reasonably attributed to the study medication. The } \\
\text { only adverse events that were significantly different between the treatment groups and placebo } \\
\text { group were dizziness and accidental injury, primarily related to falling. Of the patients who fell, on- } \\
\text { ly one ( } 2000 \mathrm{mg} \text { group) was of clinical significance (associated with hip fracture), whereas the re- } \\
\text { mainder were minor in nature. It should be noted that the patients who were experiencing dizzi- } \\
\text { ness were not the same patients who experienced accidental injuries." }\end{array}$ \\
\hline Clark 1999 & Appropriate report (Analysis 1.14) \\
\hline Clark 2001 & Appropriate report (Analysis 1.14) \\
\hline
\end{tabular}




\begin{tabular}{|c|c|c|c|c|c|c|c|c|c|}
\hline Trial & $\begin{array}{l}\text { Sample } \\
\text { size es- } \\
\text { tima- } \\
\text { tion a pri- } \\
\text { ori/ran- } \\
\text { domized } \\
\text { partici- } \\
\text { pants }\end{array}$ & $\begin{array}{l}\text { Number } \\
\text { of report- } \\
\text { ed out- } \\
\text { comes/num- } \\
\text { ber of } \\
\text { com- } \\
\text { parison } \\
\text { groups }\end{array}$ & $\begin{array}{l}\text { Prefixed } \\
\text { primary } \\
\text { outcome }\end{array}$ & $\begin{array}{l}\text { Was clin- } \\
\text { ical pri- } \\
\text { maryout- } \\
\text { come? }\end{array}$ & $\begin{array}{l}\text { Statistical } \\
\text { power }\end{array}$ & Alpha & $\begin{array}{l}\text { Type of } \\
\text { statistical } \\
\text { test (1- } \\
\text { tailed or } \\
\text { 2-tailed) }\end{array}$ & Trial's conclusions & Notes \\
\hline $\begin{array}{l}\text { Alviarez } \\
2007\end{array}$ & $\mathrm{No} / 77$ & $4 / 2$ & Not stated & NA & NA & NA & NA & $\begin{array}{l}\text { Quote: "The Citicholine was superior to place- } \\
\text { bo to improve the percentage of patients that } \\
\text { can be assisted to if same after an episode of } \\
\text { ictus acute, taken place by the occlusion of } \\
\text { the cerebral media artery." }\end{array}$ & - \\
\hline $\begin{array}{l}\text { Warach } \\
2000\end{array}$ & Yes/100 & $\begin{array}{l}2 \text { (with } \\
\text { multiple } \\
\text { correla- } \\
\text { tions)/2 }\end{array}$ & Yes & No & $80 \%$ & $\begin{array}{l}\text { Not re- } \\
\text { ported }\end{array}$ & Not stated & $\begin{array}{l}\text { Quote: "We found a significant inverse rela- } \\
\text { tionship between lesion volume change over } \\
12 \text { weeks as measured by MRI and clinical } \\
\text { outcome for ischemic stroke. This relation- } \\
\text { ship supports the role of DWI as a surrogate } \\
\text { marker of clinically meaningful lesion pro- } \\
\text { gression in stroke clinical trials. The hypothe- } \\
\text { sis that citicoline reduces lesion growth and } \\
\text { improves clinical outcome will be tested fur- } \\
\text { ther." }\end{array}$ & $\begin{array}{l}\text { Quote: "It } \\
\text { was recog- } \\
\text { nized that } \\
\text { this study } \\
\text { would be } \\
\text { under- } \\
\text { powered } \\
\text { to } \\
\text { detect a } \\
\text { difference } \\
\text { in clinical } \\
\text { outcome." }\end{array}$ \\
\hline $\begin{array}{l}\text { Ghosh } \\
2015\end{array}$ & $\mathrm{No} / 100$ & $1 / 2$ & Yes & Yes & NA & NA & NA & $\begin{array}{l}\text { Quote: "Treatment with citicoline in patients } \\
\text { of stroke, presenting within } 48 \mathrm{~h} \text { of onset, in- } \\
\text { creases the probability of recovery and a fa- } \\
\text { vorable outcome at the end of the } 1^{\text {st }} \text { and the } \\
3^{\text {rd }} \text { month in all stroke groups. A large ran- } \\
\text { domized control trial is necessary in near fu- } \\
\text { ture to support the results of this study." }\end{array}$ & - \\
\hline $\begin{array}{l}\text { Guillen } \\
1995\end{array}$ & $\mathrm{No} / 40$ & $5 / 2$ & No stated & NA & NA & NA & NA & $\begin{array}{l}\text { Quote: "CDP-choline seemed better than the } \\
\text { placebo, leading to improvement as quan- } \\
\text { tified by the GCS }(p<.05) \text {, Mathew's Scale } \\
(p<: 01) \text {, Barthel's Scale }(p<.05) \text { and the Red } \\
\text { Cross Scales }(p<.05) . "\end{array}$ & - \\
\hline $\begin{array}{l}\text { ICTUS } \\
2012\end{array}$ & Yes/2298 & $7 / 2$ & Yes & Yes & Yes & Yes & Yes & $\begin{array}{l}\text { Quote: "Under the circumstances of the IC- } \\
\text { TUS trial, citicoline is not efficacious in the }\end{array}$ & - \\
\hline
\end{tabular}




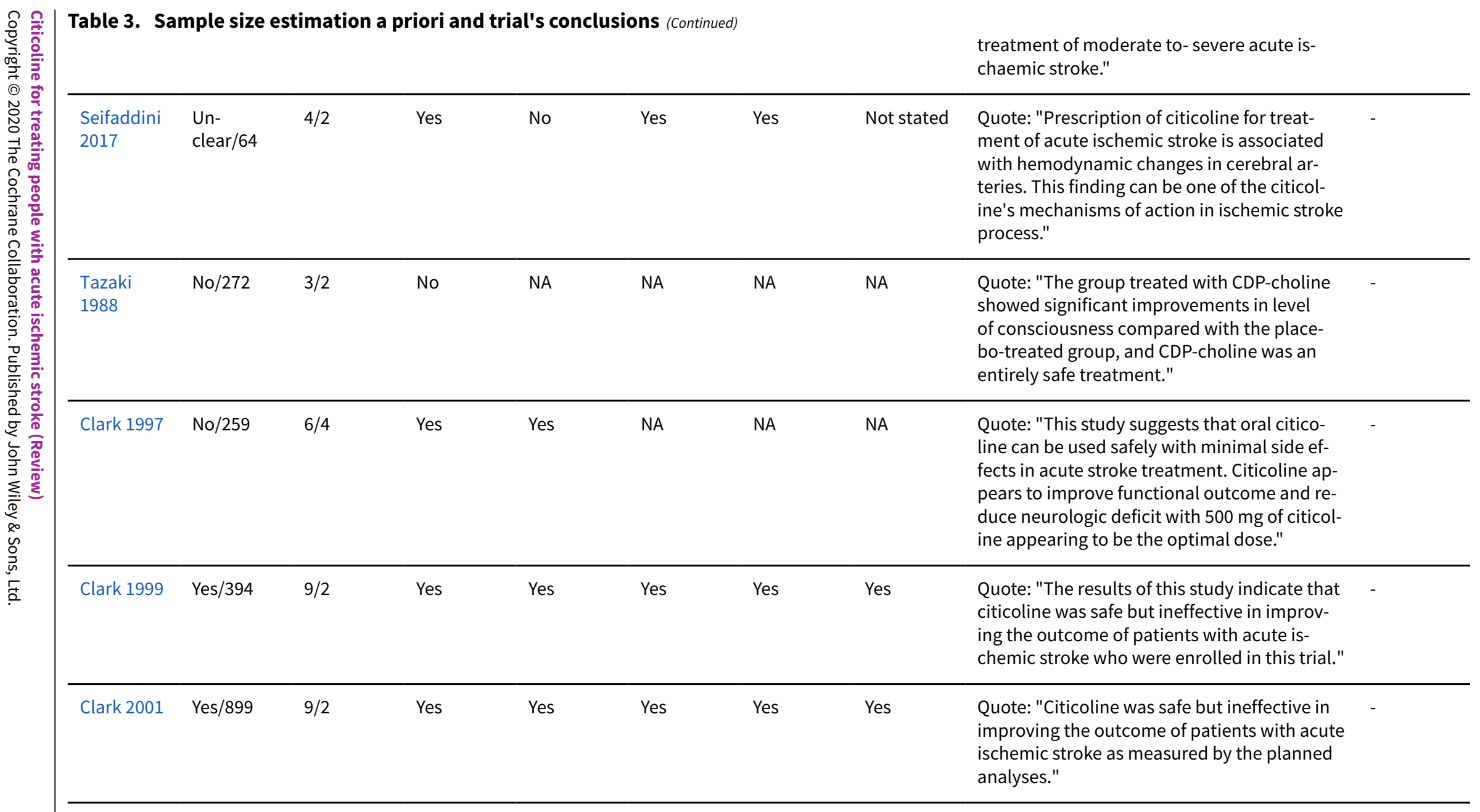

DWI: diffusion-weighted magnetic resonance imaging

GCS: Glasgow Coma scale.

MRI: magnetic resonance imaging

NA: not applicable 


\section{APPENDICES}

\section{Appendix 1. Modified Rankin scale for neurologic disability}

\begin{tabular}{lll}
\hline Domain & Grade \\
\hline No symptoms at all & 0 \\
\hline No significant disability despite symptoms: able to carry out all usual duties and activities & 1 & 2 \\
\hline $\begin{array}{l}\text { Slight disability: unable to carry out all previous activities but able to look after own affairs without } \\
\text { assistance }\end{array}$ & 3 \\
\hline Moderate disability: requiring some help, but able to walk without assistance & 4 \\
\hline $\begin{array}{l}\text { Moderately severe disability: unable to walk without assistance, and unable to attend to own bodi- } \\
\text { ly needs without assistance }\end{array}$ & 5 \\
\hline Severe disability: bedridden, incontinent, and requiring constant nursing care and attention & 6 \\
\hline Dead (this outcome was added for clinical trial purposes and was not part of the original scale) & \\
\hline Source: van Swieten 1988; Harrison 2013 & \\
\hline
\end{tabular}

\section{Appendix 2. The Barthel Index}

\section{The Barthel Index}

\begin{tabular}{lll}
\hline & With Help & Independent \\
\hline Feeding (if food needs to be cut up = help) & 5 & 10 \\
\hline Moving from wheelchair to bed and return (includes sitting up in bed) & $5-10$ & 15 \\
\hline Personal toilet (wash face, comb hair, shave, clean teeth) & 0 & 5 \\
\hline Getting on and off toilet (handling clothes, wipe, flush) & 5 & 10 \\
\hline Bathing self & 0 & 15 \\
\hline Walking on level surface (or if unable to walk, propel wheelchair) & 10 & 5 \\
\hline Propelling a wheelchair (*score only if unable to walk) & 0 & 10 \\
\hline Ascend and descend stairs & 5 & 10 \\
\hline Dressing (includes tying shoes, fastening fasteners) & 5 & 10 \\
\hline Controlling bowels & 5 & 10 \\
\hline Controlling bladder & 5 & 5 \\
\hline
\end{tabular}


(Continued)

A patient scoring $100 \mathrm{BI}$ is continent, feeds himself, dresses himself, gets up out of bed and chairs, bathes himself, walks at least a block, and can ascend and descend stairs. This does not mean that he is able to live alone: he may not be able to cook, keep house, and meet the public, but he is able to get along without attendant care

\section{Definition and discussion of scoring}

\section{- Feeding}

$10=$ Independent. The patient can feed himself a meal from a tray or table when someone puts the food within his reach. He must put on an assistive device if this is needed, cut up the food, use salt and pepper, spread butter, etc. He must accomplish this in a reasonable time.

5 = Some help is necessary (with cutting up food, etc., as listed above).

\section{- Moving from wheelchair to bed and return}

$15=$ Independent in all phases of this activity. Patient can safely approach the bed in his wheelchair, lock brakes, lift footrests, move safely to bed, lie down, come to a sitting position on the side of the bed, change the position of the wheelchair, if necessary, to transfer back into it safely, and return to the wheelchair.

$10=$ Either some minimal help is needed in some step of this activity or the patient needs to be reminded or supervised for safety of one or more parts of this activity.

5 = Patient can come to a sitting position without the help of a second person but needs to be lifted out of bed, or, if he transfers, requires a great deal of help.

\section{- Doing personal toilet}

$5=$ Patient can wash hands and face, comb hair, clean teeth, and shave. He may use any kind of razor but must put in blade or plug in razor without help, as well as get it from drawer or cabinet. Female patients must put on own makeup, if used, but need not braid or style hair.

\section{- Getting on and off toilet}

$10=$ Patient is able to get on and off toilet, fasten and unfasten clothes, prevent soiling of clothes, and use toilet paper without help. He may use a wall bar or other stable object for support if needed. If it is necessary to use a bed pan instead of a toilet, he must be able to place it on a chair, empty it, and clean it.

$5=$ Patient needs help because of imbalance or in handling clothes or in using toilet paper.

\section{- Bathing self}

$5=$ Patient may use a bath tub, a shower, or take a complete sponge bath. He must be able to do all the steps involved in whichever method is employed without another person being present.

\section{- Walking on a level surface}

15 = Patient can walk at least 50 yards without help or supervision. He may wear braces or prostheses and use crutches, canes, or a walkerette but not a rolling walker. He must be able to lock and unlock braces if used, assume the standing position and sit down, get the necessary mechanical aides into position for use, and dispose of them when he sits. (Putting on and taking off braces is scored under dressing.) 
(Continued)

$10=$ Patient needs help or supervision in any of the above but can walk at least 50 yards with a little help.

\section{- Propelling a wheelchair}

5 = If a patient cannot ambulate but can propel a wheelchair independently. He must be able to go around corners, turn around, maneuver the chair to a table, bed, toilet, etc. He must be able to push a chair at least 50 yards. Do not score this item if the patient gets score for walking.

\section{- Ascending and descending stairs}

$10=$ Patient is able to go up and down a flight of stairs safely without help or supervision. He may, and should, use handrails, canes, or crutches when needed. He must be able to carry canes or crutches as he ascends or descends stairs.

$5=$ Patient needs help with or supervision of any one of the above items.

\section{- Dressing and undressing}

$10=$ Patient is able to put on, remove and fasten all clothing, and tie shoe laces (unless it is necessary to use adaptations for this). The activity includes putting on and removing and fastening corset or braces when these are prescribed. Such special clothing as suspenders, loafer shoes, dresses that open down the front may be used when necessary.

$5=$ Patient needs help in putting on, removing or fastening any clothing. He must do at least half the work himself. He must accomplish this in a reasonable time. Women need not be scored on use of a brassiere or girdle unless these are prescribed garments.

\section{- Continence of bowels}

$10=$ Patient is able to control his bowels and have no accidents. He can use a suppository or take an enema when necessary (as for spinal cord injury patients who have had bowel training).

$5=$ Patient needs help in using a suppository or taking an enema or has occasional accidents.

\section{- Controlling bladder}

$10=$ Patient is able to control his bladder day and night. Spinal cord injury patients who wear an external device and leg bag must put them on independently, clean and empty bag, and stay dry day and night.

$5=$ Patient has occasional accidents or can not wait for the bed pan or get to the toilet in time or needs help with an external device.

Source: Carroll 2011

\section{Appendix 3. National Institutes of Health Stroke Scale (NIHSS)}

\begin{tabular}{lll}
\hline Domains & Items & Point \\
\hline $\begin{array}{ll}\text { AA: Level of conscious- } \\
\text { ness }\end{array}$ & - Alert; keenly responsive & 0 \\
& - Requires repeated stimulation to arouse & +1 \\
\hline
\end{tabular}


(Continued)

- Movements to pain $\quad+2$

- Postures or unresponsive +2

\begin{tabular}{|c|c|}
\hline 1B: Ask month and age & $\begin{array}{l}\text { - Both questions right } \\
\text { - } 1 \text { question right } \\
\text { - } 0 \text { questions right } \\
\text { - Dysarthric/intubated/trauma/language barrier } \\
\text { - Aphasic }\end{array}$ \\
\hline
\end{tabular}

\begin{tabular}{lll}
\hline 1C: 'Blink eyes' and & - Performs both tasks & 0 \\
'squeeze hands' & - Performs 1 task & +1 \\
& - Performs 0 tasks & +2
\end{tabular}

2: Horizontal extraocular movements
- Normal

- Partial gaze palsy: can be overcome

- Partial gaze palsy: corrects with oculocephalic reflex

- Forced gaze palsy: cannot be overcome
0

$+1$

$+2$

$+1$

$+2$

0

$+1$

$+2$

0

$+1$

$+1$

$+2$

3: Visual fields

- No visual loss

0

- Partial hemianopia

- Complete hemianopia

- Patient is bilaterally blind

$+1$

$+2$

$+3$

$+3$

4: Facial palsy

- Normal symmetry

0

- Minor paralysis (flat nasolabial fold, smile asymmetry)

- Partial paralysis (lower face)

- Unilateral complete paralysis (upper/lower face)

- Bilateral complete paralysis (upper/lower face)

- Drift, but doesn't hit bed

- Drift, hits bed

- Some effort against gravity

- No effort against gravity

- No movement

- Amputation/joint fusion 
(Continued)

5B: Right arm motor drift
- No drift for 10 seconds

- Drift, but doesn't hit bed

- Drift, hits bed

- Some effort against gravity

- No effort against gravity

- No movement

- Amputation/joint fusion
0

$+1$

$+2$

$+2$

$+3$

$+4$

0

6A: Left leg motor drift

- No drift for 5 seconds

0

- Drift, but doesn't hit bed

- Drift, hits bed

$+1$

- Some effort against gravity

$+2$

- No effort against gravity

- No movement

- Amputation/joint fusion

0

6B: Right leg motor drift

- No drift for 5 seconds

0

- Drift, but doesn't hit bed

- Drift, hits bed

- Some effort against gravity

- No effort against gravity

- No movement

- Amputation/joint fusion

0

\section{7: Limb ataxia}

- No ataxia

- Ataxia in 1 limb

- Ataxia in 2 limbs

- Does not understand

- Paralyzed

- Amputation/joint fusion

- Mild-moderate loss: less sharp/more dull

- Mild-moderate loss: can sense being touched

- Complete loss: cannot sense being touched at all

- No response and quadriplegic

- Coma/unresponsive 
(Continued)

\section{9: Language/aphasia}

- Normal; no aphasia

0

- Mild-moderate aphasia: some obvious changes, without significant limitation

- Severe aphasia: fragmentary expression, inference needed, cannot identify materials

- Mute/global aphasia: no usable speech/auditory comprehension

- Coma/unresponsive

\section{$+1$}

$+2$

$+3$

$+3$

\section{0: Dysarthria}

- Normal

- Mild-moderate dysarthria: slurring but can be understood

- Severe dysarthria: unintelligible slurring or out of proportion to dysphasia

- Mute/anarthric

- Intubated/unable to test

0

$+1$

$+2$

$+2$

0

0

$+1$

$+1$

$+2$

$+2$

Source: NIHSS

\section{Appendix 4. Cochrane Central Register of Controlled Trials (Central) search strategy}

IDSearchHits

\#1MeSH descriptor: [Cerebrovascular Disorders] this term only 1540

\#2MeSH descriptor: [Basal Ganglia Cerebrovascular Disease] this term only 11

\#3MeSH descriptor: [Brain Ischemia] explode all trees 3346

\#4MeSH descriptor: [Carotid Artery Diseases] this term only 493

\#5MeSH descriptor: [Carotid Artery Thrombosis] explode all trees 19

\#6MeSH descriptor: [Intracranial Arterial Diseases] this term only 11

\#7MeSH descriptor: [Cerebral Arterial Diseases] this term only 26

\#8MeSH descriptor: [Intracranial Embolism and Thrombosis] this term only 88

\#9MeSH descriptor: [Stroke] explode all trees 8879

\#10(isch?emi ${ }^{\star}$ near/6 (stroke* or apoplex* or cerebral vasc* or cerebrovasc* or cva or attack*)):ti,ab,kw (Word variations have been searched) 1931

\#11((brain or cerebr* or cerebell* or vertebrobasil* or hemispher ${ }^{\star}$ or intracran* or intracerebral or infratentorial or supratentorial or middle cerebr ${ }^{\star}$ or mca* or anterior circulation) near/5 (isch?emi ${ }^{\star}$ or infarct ${ }^{\star}$ or thrombo* or emboli* or occlus ${ }^{\star}$ or hypoxi $\left.{ }^{\star}\right)$ ):ti,ab,kw $\left(\right.$ Word $^{*}$ variations have been searched) 7468

\#12\{or \#1-\#11\} 18155

\#13MeSH descriptor: [Choline] explode all trees 1343

\#14MeSH descriptor: [Acetylcholine] this term only 461

\#15MeSH descriptor: [Phosphatidylcholines] this term only 279

\#16MeSH descriptor: [Dimyristoylphosphatidylcholine] explode all trees 1

\#17MeSH descriptor: [1,2-Dipalmitoylphosphatidylcholine] this term only 16

\#18MeSH descriptor: [Lecithins] explode all trees 47

\#19MeSH descriptor: [Choline Dehydrogenase] this term only 1

\#20MeSH descriptor: [Choline Kinase] this term only 1

\#21(bursine or vidine or fagine or cholin ${ }^{\star}$ ):ti,ab,kw (Word variations have been searched) 5445 
\#22(benzoylcholine or chloroacetylcholine or bromoacetylcholine or carbachol or citicoline or diphosphocholine or phosphorylcholine or propylbenzilylcholine or succinylcholine or thiocholine or acetylthiocholine or butyrylthiocholine):ti,ab,kw (Word variations have been searched) 1781

\#23(atsefen or centrophenoxine or cerutil or cetrexin or helfergin or meclofenoxate):ti,ab,kw (Word variations have been searched)41

\#24MeSH descriptor: [Receptors, Cholinergic] explode all trees 281

\#25((acetylcholin* or cholin*) near/5 (receptor ${ }^{\star}$ or site*)):ti,ab,kw (Word variations have been searched) 1439

\#26cholinocep ${ }^{\star}$.tw.:ti,ab,kw (Word variations have been searched) 0

\#27\{0r\#13-\#26\} 8203

$\# 28 \# 12$ and \#27 138

\section{Appendix 5. MEDLINE Ovid search strategy}

1. cerebrovascular disorders/ or basal ganglia cerebrovascular disease/ or exp brain ischemia/ or carotid artery diseases/ or carotid artery thrombosis/ or intracranial arterial diseases/or cerebral arterial diseases/or exp "intracranial embolism and thrombosis"/ or exp stroke/

2. (isch?emi\$ adj6 (stroke\$ or apoplex\$ or cerebral vasc\$ or cerebrovasc\$ or cva or attack\$)).tw.

3. ( (brain or cerebr\$ or cerebell\$ or vertebrobasil\$ or hemispher\$ or intracran\$ or intracerebral or infratentorial or supratentorial or middle cerebral artery or MCA\$ or anterior circulation or posterior circulation or basilar artery or vertebral artery or space-occupying) adj5 (isch? emi\$ or infarct\$ or thrombo $\$$ or emboli\$ or occlus\$ or hypoxi\$)).tw.

4. 1 or 2 or 3

5. exp Choline/

6. acetylcholine/

7. phosphatidylcholines/ or dimyristoylphosphatidylcholine/ or 1,2-dipalmitoylphosphatidylcholine/ or lecithin/ or choline dehydrogenase/ or choline kinase/

8. (bursine or vidine or fagine or cholin\$).tw.

9. (benzoylcholine or chloroacetylcholine or bromoacetylcholine or carbachol or citicoline or diphosphocholine or phosphorylcholine or propylbenzilylcholine or succinylcholine or thiocholine or acetylthiocholine or butyrylthiocholine).tw.

10. (atsefen or centrophenoxine or cerutil or cetrexin or helfergin or meclofenoxate).tw.

11. exp Receptors, Cholinergic/

12. exp Cholinergic Neurons/

13. ((acetylcholin\$ or cholin\$) adj5 (receptor\$ or site\$)).tw.

14. cholinocep\$.tw.

15. or/5-14

16. randomized controlled trial.pt.

17. controlled clinical trial.pt.

18. randomized.ab.

19. placebo.ab.

20. randomly.ab.

21. trial.ab.

22. groups.ab.

23. or/16-22

24. 4 and 15 and 23

\section{Appendix 6. Embase Ovid search strategy}

1. cerebrovascular disease/ or cerebral artery disease/ or cerebrovascular accident/ or stroke/ or vertebrobasilar insufficiency/ or carotid artery disease/ or exp carotid artery obstruction/ or exp brain infarction/ or exp brain ischemia/ or exp occlusive cerebrovascular disease/

2. (isch?emi\$ adj6 (stroke\$ or apoplex\$ or cerebral vasc\$ or cerebrovasc\$ or cva or attack\$)).tw.

3. ((brain or cerebr\$ or cerebell\$ or vertebrobasil\$ or hemispher\$ or intracran\$ or intracerebral or infratentorial or supratentorial or middle cerebr\$ or mca\$ or anterior circulation) adj5 (isch?emi\$ or infarct\$ or thrombo $\$$ or emboli\$ or occlus\$ or hypoxi\$)).tw.

4. 1 or 2 or 3

5. choline derivative/ or choline/

6. citicoline/

7. acetylcholine/

8. exp glycerophospholipid/ or choline kinase/ or choline dehydrogenase/

9. (bursine or vidine or fagine or cholin\$).tw.

10. (benzoylcholine or chloroacetylcholine or bromoacetylcholine or carbachol or citicoline or diphosphocholine or phosphorylcholine or propylbenzilylcholine or succinylcholine or thiocholine or acetylthiocholine or butyrylthiocholine).tw.

11. (atsefen or centrophenoxine or cerutil or cetrexin or helfergin or meclofenoxate).tw.

12. cholinergic receptor/

13. exp cholinergic receptor stimulating agent/ or cholinergic receptor affecting agent/

14. ((acetylcholin\$ or cholin\$) adj5 (receptor\$ or site\$)).tw.

15. cholinocep\$.tw.

16. or/5-15 
17. Randomized Controlled Trial/ or "randomized controlled trial (topic)"/

18. Randomization/

19. Controlled clinical trial/ or "controlled clinical trial (topic)"/

20. control group/ or controlled study/

21. clinical trial/ or "clinical trial (topic)"/ or phase 1 clinical trial/ or phase 2 clinical trial/ or phase $3 \mathrm{clinical}$ trial/ or phase $4 \mathrm{clinical}$ trial/

22. Crossover Procedure/

23. Double Blind Procedure/

24. Single Blind Procedure/ or triple blind procedure/

25. placebo/ or placebo effect/

26. (random\$ or RCT or RCTs).tw.

27. (controlled adj5 (trial\$ or stud\$)).tw.

28. (clinical\$ adj5 trial\$).tw.

29. ((control or treatment or experiment\$ or intervention) adj5 (group\$ or subject\$ or patient\$)).tw.

30. (quasi-random $\$$ or quasi random\$ or pseudo-random $\$$ or pseudo random\$).tw.

31. ((control or experiment\$ or conservative) adj5 (treatment or therapy or procedure or manage\$)).tw.

32. ((singl\$ or doubl\$ or tripl\$ or trebl\$) adj5 (blind\$ or mask\$)).tw.

33. (cross-over or cross over or crossover).tw.

34. (placebo\$ or sham).tw.

35. trial.ti.

36. (assign\$ or allocat\$).tw.

37. controls.tw.

38. or/17-37

39. 4 and 16 and 38

\section{Appendix 7. LILACS (Latin American and Caribbean Health Science Information database) search strategy}

(tw:(citicoline)) AND (tw:(ictus))

\section{Appendix 8. US National Institutes of Health Ongoing Trials Register ClinicalTrials.gov (www.clinicaltrials.gov)}

citicoline OR choline | ischaemic stroke OR brain ischaemia OR cerebral infarction OR acute stroke

\section{Appendix 9. World Health Organization (WHO) International Clinical Trials Registry Platform (ICTRP) (www.who.int/ ictrp/en);}

stroke AND citicoline OR stroke AND choline

cerebrovascular AND citicoline OR cerebrovascular AND choline

\section{Appendix 10. Food and Drug Administration}

Citicoline or cytidine 5'-diphosphocholine

\section{Appendix 11. European Medicines Agency}

Citicoline or cytidine $5^{\prime}$-diphosphocholine

\section{Appendix 12. Domains for assessing of risk of bias in included studies}

\section{Generation of the allocation sequence}

- Low risk of bias, if the allocation sequence was generated by a computer or random number table, drawing of lots, tossing of a coin, shuffling of cards or throwing dice.

- Unclear, if the trial was described as randomized but the method used for the allocation sequence generation was not described.

- High risk of bias, if a system involving dates, names or admittance numbers was used for the allocation of patients. These studies are known as quasi-randomized and we excluded them from the review.

\section{Allocation concealment}

- Low risk of bias, if the allocation of patients involved a central independent unit, on-site locked computer, identical-appearing numbered drug bottles or containers prepared by an independent pharmacist or investigator, or sealed envelopes.

- Unclear, if the trial was described as randomized but the method used to conceal the allocation was not described.

- High risk of bias, if the allocation sequence was known to the investigators who assigned participants or if the study was quasirandomized. We excluded the latter from the review. 


\section{Blinding (or masking)}

We assessed each trial (as low, unclear or high risk) with regard to the following levels of blinding.

- Blinding of clinician (person delivering treatment) to treatment allocation.

- Blinding of participant to treatment allocation.

- Blinding of outcome assessor to treatment allocation.

\section{Incomplete outcome data}

- Low risk of bias, if the numbers and reasons for dropouts and withdrawals in all intervention groups were described or it was specified that there were no dropouts or withdrawals.

- Unclear, if the report gave the impression that there had been no dropouts or withdrawals but this was not specifically stated.

- High risk of bias, if the number or reasons for dropouts and withdrawals were not described.

We further examined the percentage of dropouts overall in each trial and per randomization arm and we evaluated whether intention-totreat analysis was performed or could be performed from the published information.

\section{Selective outcome reporting}

- Low risk of bias, if predefined or clinically relevant and reasonably expected outcomes were reported on.

- Unclear, if not all predefined or clinically relevant and reasonably expected outcomes were reported on or were not reported on fully, or it was unclear whether data on these outcomes were recorded or not.

- High risk of bias, if one or more clinically relevant and reasonably expected outcomes were not reported on when data on these outcomes were likely to have been recorded.

\section{Other bias}

- Low risk of bias, the trial appeared to be free of other components that could put it at risk of bias.

- Unclear, the trial may or may not be free of other components that could put it at risk of bias.

- High risk of bias, there were other factors in the trial that could put it at risk of bias.

We will consider trials at low risk of bias to be those that used an adequate system to generate their allocation sequence, had adequate allocation concealment, adequate blinding, adequate handling of incomplete outcome data, were free of selective outcome reporting and were free of other bias.

We will consider trials in which we could assess one of the domains as having a high risk of bias or an unclear risk of bias as trials with an overall high risk of bias.

\section{Appendix 13. Method for grading levels of impaired consciousness, according to Japanese Coma Scale}

\begin{tabular}{ll}
\hline Grade & Description \\
\hline 0 & Patient fully alert \\
\hline I & Patient spontaneously awake but \\
I-1 & Obtunded or confused \\
I-2 & Disoriented to time, place, and person \\
I-3 & Unable to state name and date of birth \\
\hline
\end{tabular}

\begin{tabular}{ll}
\hline II & Patient may be aroused, but falls into drowsy state after cessation of stimulation \\
II-1 & Easily aroused by spoken words \\
II-2 & Aroused by loud voice or shaking the shoulders \\
II-3 & Aroused only by repeated stimuli \\
\hline
\end{tabular}

III Patient cannot be aroused by painful stimuli


(Continued)

III-1

III-2

III-3
Responds by movement to avoid stimulus

Responds with minimal movement such as decerebrate and decorticate posturing

Does not respond except for respiratory changes

Source: Tazaki 1988

\section{FEE D B A C K}

\section{New Feedback, October 2020}

\section{Summary}

There are some mistakes in the publication, specifically on the labelling of the results for citicoline and placebo in the Forest Plots of the analysis 1.8 to 1.13 related to the modified Rankin scale (pages 60 to 63), the analysis 1.16 of the Barthel Index and the analysis 1.17 of the NIHSS (page 68). A modified Rankin scale ( $<3$ points), a Barthel Index ( $\geq 95$ points) and a NIHSS ( $\leq 1$ point) are positive outcomes and the results of the clinical trials included in this meta-analysis at least tend to favor citicoline, not placebo. In the current publication, results of this scales indicate to favor placebo, which is just the contrary. Most probably the legend on the base of the plot's is in a wrong position. There is a relevant difference between favours placebo rather than favours citicoline, that at the end distorts reality and compromises the content of the article, despite this could involve also a mistake in the interpretation of the results We consider that these errors are serious and should be corrected and/or commented immediately.

\section{Reply}

We thank Dr Emilio Gil for the interest in our review and the feedback provided. We appreciate his detailed comment, which contributed to identify a formal error (namely, a mistake in the legend of a set of forest plots) and also highlighted some issues about the interpretation of the results.

We have addressed the comments provided by Dr Gil and have provided an amended version of the review to ensure that the errors were fixed. We additionally revised the text of the review to ensure that its findings and conclusions were framed to avoid ambiguous or equivocal messages.

The conclusions for the review in the current version are consistent with its findings, taking into account the quality of evidence and the clinical magnitude of the results obtained, and has not changed in relation to the version originally published.

The consistent low certainty of evidence across all outcomes and the clinically irrelevant effects of citicoline support our conclusion that citicoline may make little to no difference in any of the patient important outcomes assessed.

We provide here a detailed account of the amendments done in the review that should serve as a response to Dr Gil.

\section{Revision of graphs labels from analysis 1.8 to $1.13,1.16$ and 1.17}

As Dr Gil pointed out the labels for the plots from the outcomes related to disability, functional recovery and neurological function are incorrect. As these outcomes are positive the right panel of the plots shows a result favouring citicoline, whereas the left panel shows a result favouring placebo.

Action: we switched the graph labels of the plots in these analyses (in the current version graph labels are 'Favours citicoline' for the forest plot right panel, and 'Favours placebo' for the left panel).

\section{Clarification of the outcomes}

To avoid an equivocal definition of outcomes and to better reflect what was measured in the review we decided to reword the outcomes related to disability, functional recovery and neurological function. We defined these outcomes as dichotomous, as in consequence they should be described in terms of the proportion of patients that attained the outcome during the trial. This change entails strictly a change in the name of the outcome, but it does not have an impact on the data extracted, statistical analyses, and interpretation of results or the review conclusions.

Action: we changed the outcomes wording both in the review text and in the included figures. We reworded the outcomes for analysis 1.8 to $1.13,1.16$ and 1.17 (e.g., the new wording for analysis 1.8. in the current version is "Patients with moderate or lower degree of disability or dependence (according to $<3$ scores in the modified Rankin scale)" 


\section{Changes in the wording of review findings}

As a consequence of the changes related to the issues stated above, we also revised the wording of review findings and conclusions to better reflect the measurement approach for the outcomes related to disability, functional recovery and neurological function in our review. We followed a novel approach to communicate the findings of systematic reviews through informative statements combining effect size and certainty of an outcome (Santesso J, Clinical Epidemiology, 2020, https://doi.org/10.1016/j.jclinepi.2019.10.014). By implementing this approach we are convinced that the statements should not leave room for doubt about the magnitude of the effects found in the review.

Action: we worded the findings of the review according to this new approach and amended accordingly the abstract and plain language summary (e.g.; the original text "Four trials found no difference in the proportion of patients with disability or dependence in daily activities according to the Rankin scale comparing citicoline with placebo" changed to "Four trials showed that citicoline may not increase the proportion of patients with a moderate or lower degree of disability or dependence compared with placebo".

\section{Revision of trial sequential analysis}

We reviewed the wording of findings related to the TSA for disability to ensure that were accurate.

\section{Minor amendments in the 'Results' section and additional typos}

We did some editing through the review results, mainly those related to the reporting of subgroup analyses related to disability, to ensure that interpretation of results is consistent with the outcome definition. For example:

- we changed the original "meta-analysis of two trials reporting missing data showed a reduction of $56 \%$ of risk of disability or dependence in people receiving citicoline versus control ( $\mathrm{RR} 0.44,95 \% \mathrm{Cl} 0.39$ to $0.51 ; \mathrm{IP}=67 \%$ )" to "meta-analysis of two trials reporting missing data showed that citicoline may result in a slight reduction in the proportion of patients with a moderate or lower degree of disability or dependence compared with placebo (RR $0.44,95 \% \mathrm{Cl} 0.39$ to 0.51 ; IP $=67 \%$ )";

- in the subgroup analysis according the trials sample size for disability, we changed the original "A meta-analysis including three trials showed no difference comparing citicoline with placebo as regards degree of disability or dependence in daily activities" to "A metaanalysis including the three trials which included more than 200 participants showed that citicoline may result in little or no difference in the proportion of patients with a moderate or lower degree of disability or dependence compared with placebo";

- in the sensitivity analysis assessing the impact of missing data there was a copy edit error in the Cl95\% boundaries (lower limit 1.01 instead of 1.00)

\section{Contributors}

Feedback: Emilio Gil, Ferrer International

Authors' response: Review author team

WHAT'S NEW

\begin{tabular}{lll}
\hline Date & Event & Description \\
\hline 7 December 2020 & Feedback has been incorporated & Feedback and authors' responses added \\
\hline
\end{tabular}

\section{H I S T O RY}

Protocol first published: Issue 7, 2018

Review first published: Issue 8, 2020

\section{CONTRIBUTIONS OF AUTHORS}

Drafting the Cochrane Review: all authors

Developing the search strategy: Ivan Solà, Arturo Martí-Carvajal

\section{DECLARATIONS OF INTEREST}

Arturo Martí-Carvajal: none known.

Claudia Valli: none known.

Cristina Martí-Amarista: none known.

Ivan Solà: none known.

Joan Martí-Fàbregas: none known. 
Xavier Bonfill Cosp: none known.

\section{SOURCES OF SUPPORT}

\section{Internal sources}

- Facultad de Ciencias de la Salud Eugenio Espejo, Universidad UTE (Cochrane Ecuador), Quito, Ecuador

- Facultad de Medicina, Universidad Francisco de Vitoria (Cochrane Madrid), Madrid, Spain

\section{External sources}

- Cochrane Stroke Group, UK

- Iberoamerican Cochrane Network, Spain, Spain

\section{DIFFERENCES BETWEEN PROTOCOLANDREVIEW}

- Disability or dependence in daily activities (<3 points) according to the modified Rankin scale. Usually, RCTs use 1 or less than 1 . However, we used less than 3 to avoid ruling out one trial that used this cut-off point. This threshold was discussed with our team's neurologist who agreed with our approach.

- We did not conduct estimation of the fragility index (FI) due to lack of data. For future updates, we will conduct it as was planned.

- Transparency is the goal. If we had strictly assumed the 90th day to carry out the meta-analyses, we would have lost a lot of information. Therefore, this Cochrane Review would have a high risk of publication bias.

\section{N DEX TERMS}

\section{Medical Subject Headings (MeSH)}

Activities of Daily Living; Acute Disease; Bias; Brain Ischemia [complications]; Cause of Death; Cytidine Diphosphate Choline [adverse effects] [*therapeutic use]; Nootropic Agents [adverse effects] [*therapeutic use]; Randomized Controlled Trials as Topic; Recovery of Function; Stroke [*drug therapy] [etiology] [mortality]

\section{MeSH check words}

Aged; Aged, 80 and over; Humans; Middle Aged 